\title{
THE IMPACT OF A CONTROLLED 10-WEEK PISTACHIO FEEDING CROSSOVER TRIAL ON BLOOD LIPIDS AND MEASURES OF ADIPOSITY
}

\author{
A Thesis \\ presented to \\ the Faculty of California Polytechnic State University, \\ San Luis Obispo \\ In Partial Fulfillment \\ of the Requirements for the Degree \\ Master of Science in Agriculture \\ with a Specialization in Food Science and Nutrition
}

by

Alison Helen Bushnell

June 2015 
(C) 2015

Alison Helen Bushnell

ALL RIGHTS RESERVED 


\section{COMMITTEE MEMBERSHIP}

TITLE:

AUTHOR:

DATE SUBMITTED:

COMMITTEE CHAIR:

COMMITTEE MEMBER:

COMMITTEE MEMBER:
The impact of a controlled 10-week pistachio feeding crossover trial on blood lipids and measures of adiposity

Alison Helen Bushnell

June 2015

Aydin Nazmi, Ph.D., Associate Professor, Food Science and Nutrition Department and Director of STRIDE, California Polytechnic State University, San Luis Obispo

Laura Hall, Ph.D., RD

Soma Roy, Ph.D., Associate Professor, Statistics Department, California Polytechnic State University, San Luis Obispo 


\begin{abstract}
The impact of a controlled 10-week pistachio feeding crossover trial on blood lipids and measures of adiposity
\end{abstract}

\title{
Alison Helen Bushnell
}

Cardiovascular disease (CVD) is the leading cause of death in the United States and has negative impacts at both the individual- and population-level through reduced quality of life, economic burden, and strain on the healthcare system. Dietary modifications, such as pistachio consumption, may help prevent CVD and two of its leading risk factors: dyslipidemia and overweight/obesity. The objective of this study was to determine the effects of pistachio consumption (20\% daily energy need) on measures of adiposity and blood lipids in healthy young adult females. This study utilized 10 -week crossover feeding trials at California Polytechnic State University, San Luis Obispo (CP-SLO) and California State Polytechnic University, Pomona (CP-P). Participants ( $\mathrm{n}=48$, mean age $21 \pm 0.51$ years) served as their own controls. Mean body mass index (BMI) was 21.9 \pm 2.32 $\mathrm{kg} / \mathrm{m}^{2}$ and mean total cholesterol (TC) was $155.0 \pm 27.7 \mathrm{mg} / \mathrm{dL}$. Pistachio diet participants consumed $20 \%$ of their daily energy needs of pistachios each day, whereas control diet participants maintained their usual diet without consuming nuts. The two diet treatments were separated by a 15 -week washout period during which all participants resumed their usual diets. No significant differences were found between diet treatments for triacylglycerols (TAG) $(p=0.6), \mathrm{TC}(\mathrm{p}=0.5)$, low-density lipoprotein cholesterol (LDL-C) $(\mathrm{p}=0.4)$, high-density lipoprotein cholesterol (HDLC) $(p=0.9), T C / H D L-C(p=0.7)$, body weight $(p=0.8), B M I(p=0.9)$, waist circumference $(\mathrm{WC})(\mathrm{p}=0.4)$, or total body fat percentage $(\mathrm{p}=0.9)$. Likewise, no significant differences were found during the pistachio treatment or during the control treatment for any measured variable. Strengths of this study were the crossover design, utilization of dual-energy x-ray absorptiometry (DXA) for precise body composition measurements, and the use of individually measured bags of pistachios to help with compliance. Limitations of the study included the relatively small sample size and short intervention period. Pistachio supplementation was not associated with significant changes in measures of adiposity or the lipid profile. Longer interventions with more participants are needed to test the long-term effects of pistachio consumption with greater power to detect differences. 


\section{ACKNOWLEDGMENTS}

Over the past three years I have been privileged to work with an outstanding group of advisors. I would like to thank Dr. Laura Hall, who was my first introduction to Cal Poly, and for the past three years, has provided invaluable guidance and support. Thank you to Dr. Aydin Nazmi for offering honest and direct feedback and for improving my knowledge and skills as a writer, and thank you to Dr. Soma Roy for adding valuable insight and expertise to this study.

In addition, I would like to thank the California State University Agricultural Research Institute for their generous grant, and the American Pistachio Growers for their substantial grant as well as donating all of the pistachios used during this study. 


\section{TABLE OF CONTENTS}

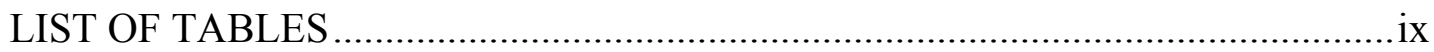

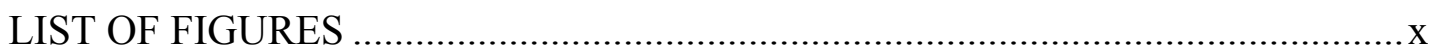

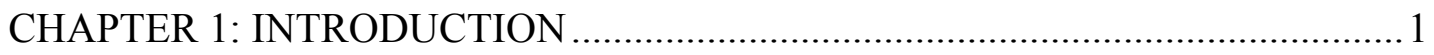

CHAPTER 2: LITERATURE REVIEW …………………...............................

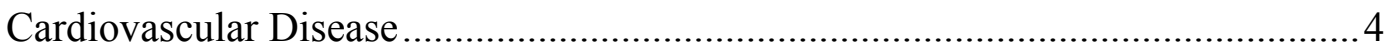

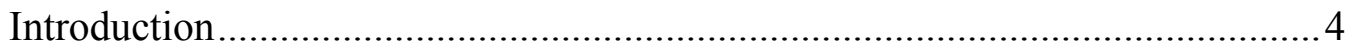

Impacts of Cardiovascular Disease .................................................................

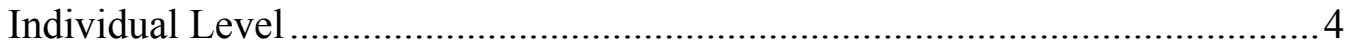

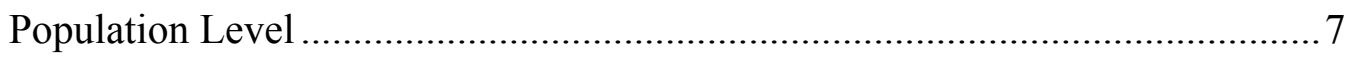

Risk Factors for Cardiovascular Disease .......................................................... 11

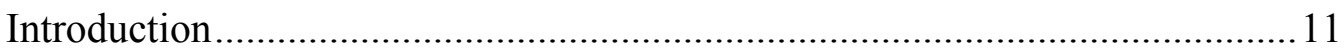

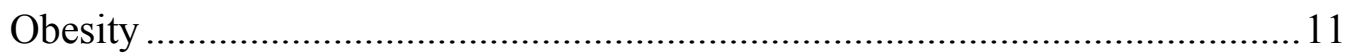

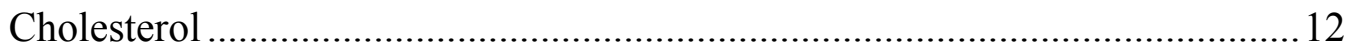

Low-Density Lipoprotein Cholesterol (LDL-C)................................................ 13

High-Density Lipoprotein Cholesterol (HDL-C)................................................. 15

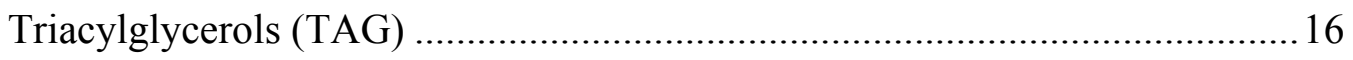

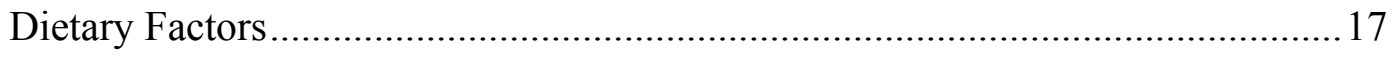

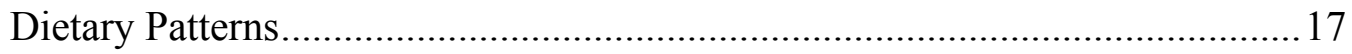

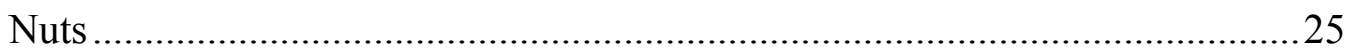

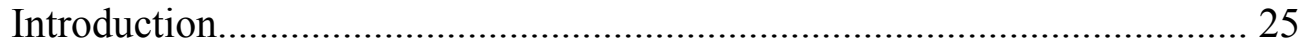

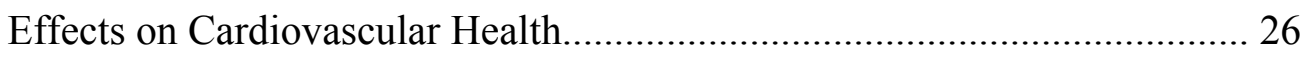

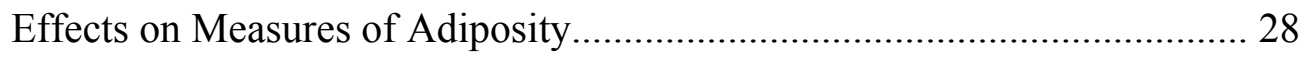




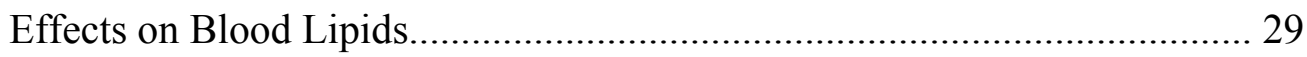

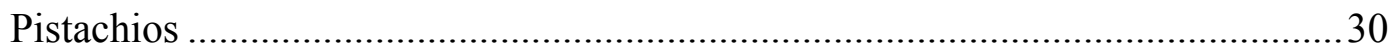

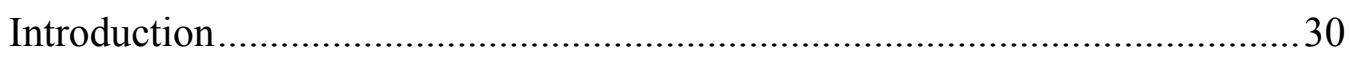

Effects on Measures of Adiposity ........................................................ 34

Effects on Blood Lipids ..................................................................... 46

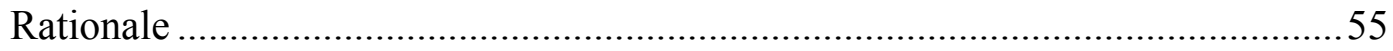

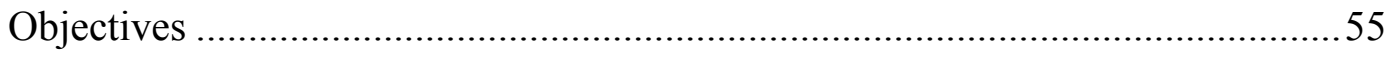

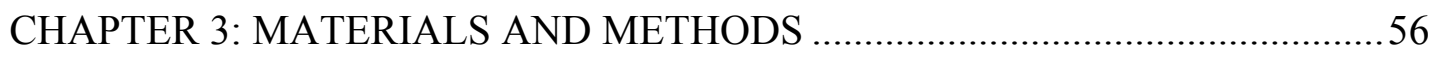

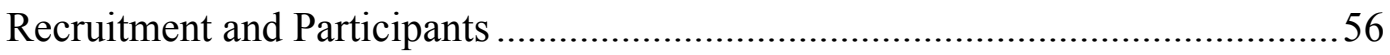

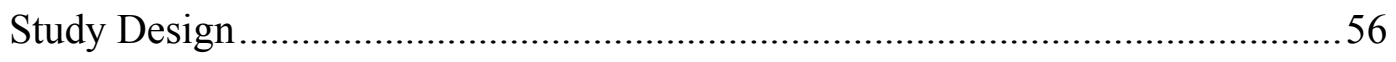

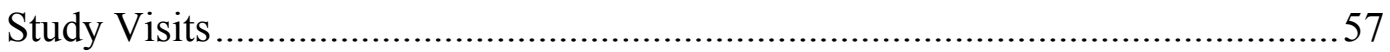

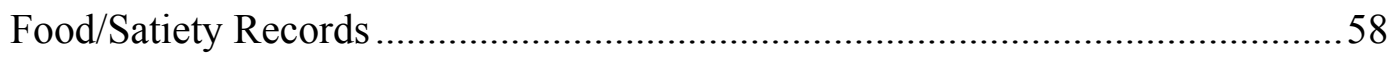

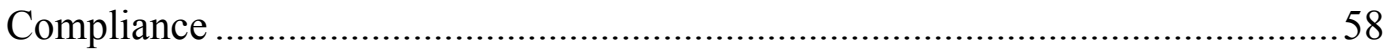

Anthropometric Measurements...............................................................59

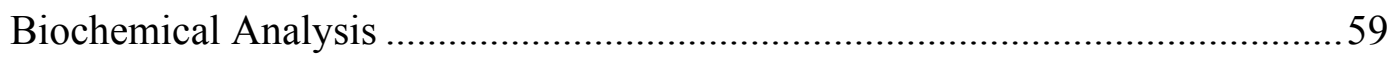

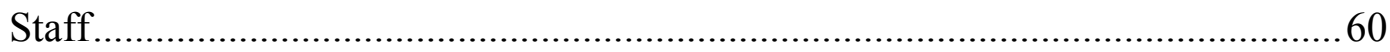

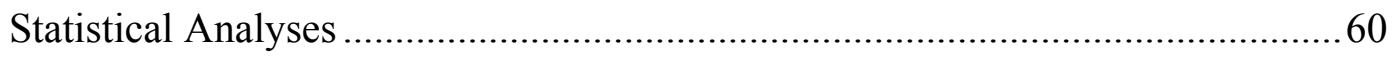

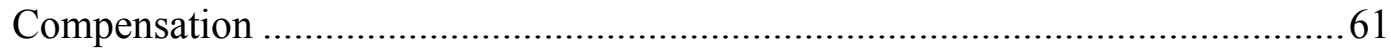

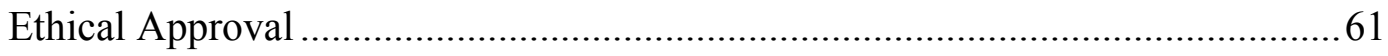

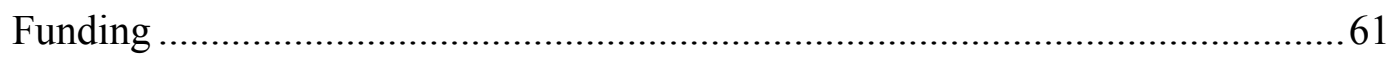

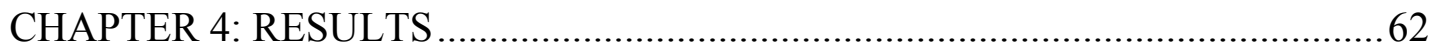

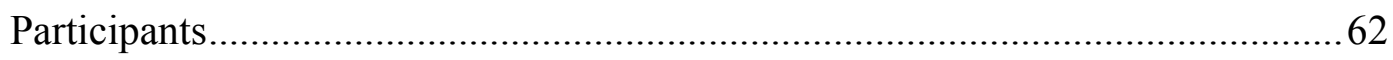

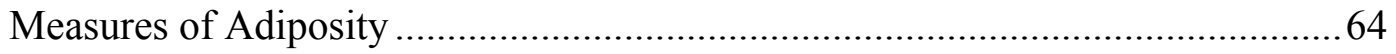


Blood Lipids

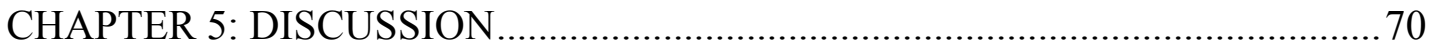

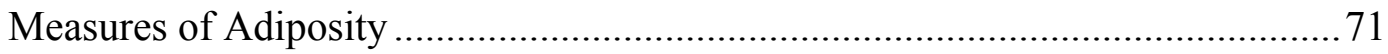

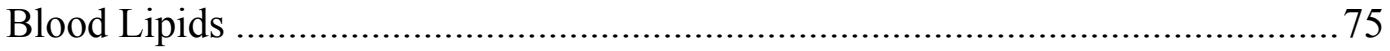

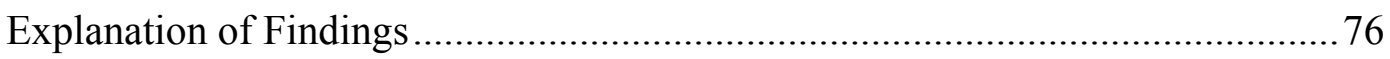

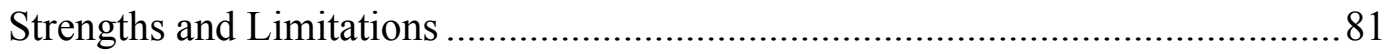

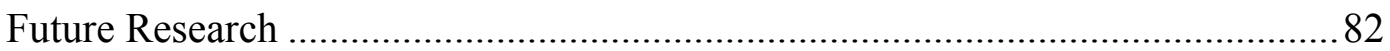

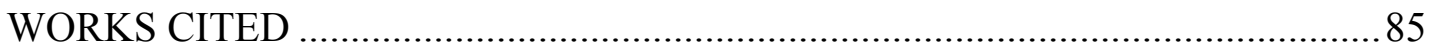

APPENDICES

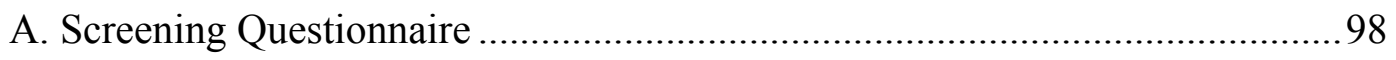

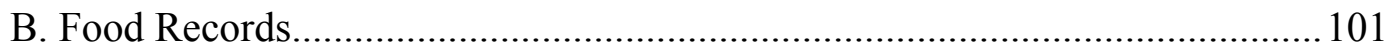

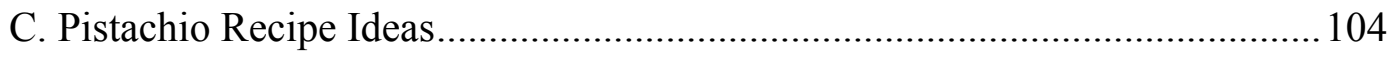

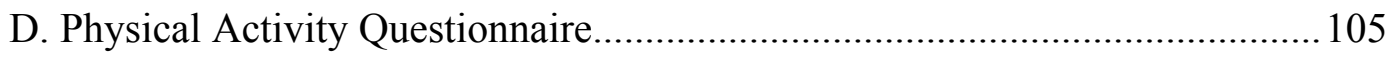

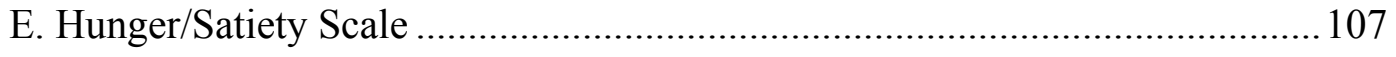

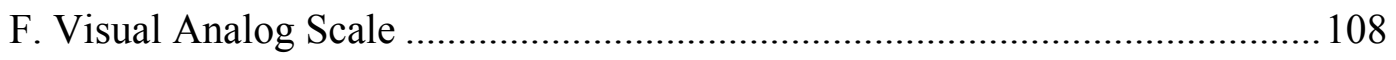

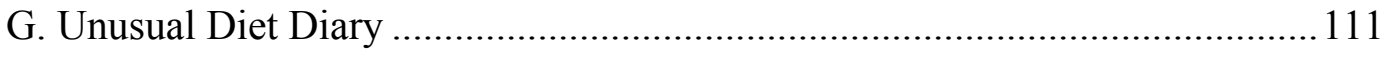

H. Informed Consent Form ....................................................................... 113 


\section{LIST OF TABLES}

Table 1. Weight classification and BMI range for adults adapted from (WHO, 2000).

Table 2. Total cholesterol (TC) levels and classifications adapted from (AHA, 2010).

Table 3. Low-density lipoprotein cholesterol (LDL-C) levels and classifications adapted from (AHA, 2010).

Table 4. High-density lipoprotein cholesterol (HDL-C) levels and classifications adapted from (AHA, 2010)

Table 5. Triacylglycerol (TAG) levels and classifications adapted from (AHA, 2010).

Table 6. Average nutrient composition of selected nuts per $100 \mathrm{~g}^{1}$ adapted from (USDA, 2015).

Table 7. Published clinical trials on effects of pistachio consumption on measures of adiposity and blood lipids 35

Table 8. Participant baseline characteristics, mean \pm SD. .64

Table 9. Measures of adiposity at baseline and end of diet treatments, $(n=48)$. .65

Table 10. Blood lipids at baseline and end of diet treatments, $(n=48)$. .67 


\section{LIST OF FIGURES}

Page

Figure 1. Projected number of adults $\geq 65$ years and $\geq 85$ years living in the United States between 2011 and 2040, adapted from (Odden et al., 2011). 8

Figure 2. Projected mortality from coronary heart disease in adults 35-64 years and adults 65-84 years in 2010, 2020, 2030, and 2040, adapted from (Odden et al., 2011).

Figure 3. Projected direct and indirect medical costs associated with CVD from 2010 to 2030, adapted from (Heidenreich et al., 2011).

Figure 4. Prevalence estimates for poor, intermediate, and ideal cardiovascular health in US Adults $\geq 20$ years based on four metrics of cardiovascular health from the American Heart Association 2020 goals, adapted from (Go et al., 2014).

Figure 5. Average daily energy intake of adult females and males in the United States from 1971-1974 and 2005-2006 NHANES data, adapted from (Nielsen \& Popkin, 2003)

Figure 6. Participant flow-charts from CP-SLO (top) and CP-P (bottom)..................63

Figure 7. Measures of adiposity at baseline and end of diet treatments. .....................66

Figure 8 . Blood lipids at baseline and end of diet treatments ${ }^{1}$. .69 


\section{CHAPTER 1: INTRODUCTION}

Cardiovascular disease (CVD) is the number one cause of death in the United States, responsible for approximately 1 in every 4 deaths (Kochanek, Xu, Murphy, Miniño, \& Kung, 2009). More than 83 million Americans live with at least one form of CVD and far more are at risk due to pre-existing risk factors. One of the most powerful risk factors, dyslipidemia, affects 71 million adults, two thirds of whom do not have their condition under control (Centers for Disease Control and Prevention, 2010). Another risk factor, obesity, affects one third of adults and 17\% of children (Ogden, Carroll, Kit, \& Flegal, 2014). The individual- and population-level consequences of CVD include diminished quality of life, increased risk of death, and economic burden.

Patients with CVD may have debilitating physical problems, psychological problems, or difficulty with social interaction in addition to an increased risk of death. Mortality and morbidity are increased in all age categories of CVD patients leading to elevated health care costs. Annually, CVD costs the United States $\$ 306.12$ billion in health care and lost productivity, which equates to 1 out of every 6 dollars spent on health care (Heidenreich et al., 2011). As the population ages, even greater stress will be placed on the healthcare system (Odden et al., 2011). Thus, it is critical to address the causes of CVD through prevention strategies at the individual and population levels.

Diet affects a multitude of variables related to cardiovascular health. The Centers for Disease Control and Prevention (2013) recently found that more than 200,000 CVD deaths each year may be prevented by modifying dietary and physical activity behavior. Dietary behavior strongly influences measures of adiposity and lipid status, which are both strong risk factors for CVD. Excess weight is associated with CVD, hypertension, hypercholesterolemia, diabetes, and cancer (Bray, 2004). Similarly, dyslipidemia is 
linked closely with hypertension and is a powerful indicator of atherosclerosis (Hsu et al., 2013).

Plant-based diets, which emphasize fruits, vegetables, nuts, and other minimally processed foods, may help lower body mass index (BMI), blood pressure, and cholesterol levels (Tuso, Ismail, Ha, \& Bartolotto, 2013). Nuts are naturally high in healthy fats, protein, and other beneficial nutrients (Alexiadou \& Katsilambros, 2011). Pistachios in particular have many unique nutritional properties and contain fewer calories per serving than any other nut (Dreher, 2012). Consequently, they have been the topic of many recent studies.

Previous research has found that pistachio consumption improves lipid profile and decreases CVD risk (Aldemir, Okulu, Neselioglu, Erel, \& Kayigil, 2011; Baer, Gebauer, \& Novotny, 2012; Edwards, Kwaw, Matud, \& Kurtz, 1999; Gebauer, West, Kay, Alaupovic, Bagshaw, \& Kris-Etherton, 2008; Gulati, Misra, Randey, Bhatt, \& Saluja, 2014; Kocygit, Koylu, \& Keles, 2006; Li et al., 2010; Sari et al., 2010; Sheridan, Cooper, Erario, \& Cheifetz, 2007; Wang, Li, Liu, Ly, \& Yang, 2012), but research evaluating pistachios' effects on lipid status has largely focused on unhealthy populations. None of the studies that have investigated the effects of pistachio consumption on measures of adiposity (Aldemir et al., 2011; Edwards et al., 1999; Gebauer et al., 2008; Gulati et al., 2014; Kocygit et al., 2006; Li et al., 2010; Sari et al., 2010; Sheridan et al., 2007; Wang et al., 2012) have utilized dual-energy x-ray absorptiometry (DXA), the current gold standard to analyze body composition and fat distribution (Fowke \& Matthews, 2010). There is a conspicuous gap in the scientific literature regarding the effects of pistachio consumption on lipid status and measures of adiposity in healthy populations. 
The objective of this study is to determine the impact of pistachio consumption on lipid status and measures of adiposity among healthy young adult females using a crossover design with two 10 -week treatment periods: a pistachio diet ( $20 \%$ of kcals) and a no-pistachio control diet. It is hypothesized that daily pistachio consumption will help improve lipid status and have little or no effect on measures of adiposity. 


\section{CHAPTER 2: LITERATURE REVIEW}

\section{Cardiovascular Disease}

\section{Introduction}

Thirty-five percent of all deaths in the United States are a result of CVD, which is equal to 2,300 lives lost every day or one life every 39 seconds (Lloyd-Jones et al., 2009). Currently, 1 in every 3 Americans has one or more forms of CVD for a total of nearly 81 million people (Lloyd-Jones et al., 2009). Unless improvements are made in prevention and treatment, it is projected that the percentage of people with CVD in the United States will increase from $36.9 \%$ in 2011 to $40.5 \%$ by 2030 (Heidenreich et al., 2011). Atherosclerosis, which causes CVD, occurs when the walls of vessels thicken and lose elasticity, resulting in narrowing of the lumen of the vessel due to plaque build up. The American Heart Association (AHA) estimates that more than 12 million individuals are affected by atherosclerosis, which results in more than a half a million deaths every year (Go et al., 2014). Thus, prevention strategies must focus on reducing the number of people affected by CVD.

\section{Impacts of Cardiovascular Disease}

CVD has negative impacts both at the individual and population levels.

Individuals are physically, psychologically, and economically affected. Meanwhile, disease at the population level leads to a massive economic burden and unsustainable stress on the healthcare system.

Individual Level

According to the World Health Organization (WHO) (1997), quality of life is defined as "The individual's perceptions of their position in life in the context of the 
culture and value systems in which they live and in relation to their goals, expectations, standards, and concerns." Quality of life is a multi-factorial concept that includes physical and psychological health as well as the ability to have independence and functioning social relationships. Individual economic status can also contribute to overall quality of life indicators.

One of the most common physical symptoms of coronary heart disease (CHD), one of the main manifestations of CVD, is angina, which occurs when blood flow to one area of the heart is blocked, resulting in a lack of oxygenated blood traveling to that area. Angina may occur either at rest or during physical stress and manifests as chest pain that may radiate to the arms or neck; however, angina may also lead to indigestion, nausea, vomiting, sweating, shortness of breath, weakness, or fatigue (U.S. Department of Health and Human Services, 2011). Intermittent claudication, which results in cramping in the calf, thigh, buttocks, or feet during physical activity, is also common with some forms of CVD. Because physical activity increases such symptoms, individuals may unintentionally or intentionally alter their pattern of physical activity (Jude \& Gibbons, 2005). A number of other symptoms, including pulmonary congestion, fatigue, loss of appetite, heart palpitations, dyspnea, edema, headache, orthopnea, and flushed face are evident with some forms of CVD. Any one of these symptoms has the potential to greatly reduce an individual's ability to conduct their activities of daily life and as such may lead to a decrease in quality of life (Vader \& Drazner, 2009).

One of the most common psychological problems associated with CVD, and CHD in particular, is depression (Stapelberg, Neumann, Shum, McConnell, \& HalmiltonCraig, 2011). The prevalence of major depression in CHD patients is between $15 \%$ and 
$23 \%$ in comparison to $4.6 \%$ in the general population (Brotman, Golden, \& Wittstein, 2007). Among people with CHD, depression and/or anxiety may lead to decreased quality of life. Coronary heart disease can be difficult for patients as well as their family members and often causes anxiety and depression in both groups due to physical and psychological barriers (Reid, Ski, \& Thompson, 2013).

Coronary heart disease outcomes such as myocardial infarction (MI) impose greater restrictions on patients and further reduce quality of life. Patients who have suffered from a MI show greater psychological distress, lower self-esteem, and difficulty functioning in social or occupational capacities (Brown, Munford, \& Munford, 1993). Rates of major depression have been found to be as high as $20 \%$ in patients suffering a MI and rates of anxiety as high as $30 \%$ to $40 \%$. Likewise, depression increases the risk of death or new cardiovascular events by 1.5 to 2 times in CHD patients (Nicholson, Kuper, \& Hemingway, 2006), and by $36 \%$ in CHD patients with anxiety (Roest, Martens, Denollet, \& De Jonge, 2010).

Depression associated with CHD may be attributed to a lack of physical function, limited social support, or feelings of inadequacy in patients not able to provide for their families. Among post-MI patients with a lack of emotional support, cardiac events are nearly three times as likely (Stapelberg et al., 2011). Additionally, half of participants in a cohort study of patients with CHD admitted being unhappy in their lives in part due to their physical limitations. The consequences of a decreased perception of quality of life can be substantial. Among those who have experienced a cardiac event, depression can increase the risk of a subsequent cardiac event or death by $300 \%$ to $400 \%$ (Simmonds et al., 2013). 
Cardiovascular disease affects individuals financially in the short term and the long term. Short-term costs are those associated with hospitalizations including ambulance rides, diagnostic testing, inpatient care, and immediate procedures like surgery. Long-term costs include the price of prescription medications; doctor appointments and medical tests; and lost productivity and income (indirect costs) related to an inability to work (DeVol \& Bedroussian, 2007). Among individuals with CVD, $74.8 \%$ reported having expenses related to prescription medications, $65 \%$ reported expenses associated with outpatient care, and $13 \%$ reported expenses related to emergency or inpatient services (Uberoi \& Cohen, 2012). Individuals with CVD have an average total medical expenditure of $\$ 7,026$ per year compared to only $\$ 1,884$ in individuals with no chronic conditions (Uberoi \& Cohen, 2012). Additionally, in adults with CVD plus other chronic conditions, average total medical expenditure more than doubles to $\$ 14,627$ per year (Uberoi \& Cohen, 2012).

In sum, the individual-level physical, psychological, and economic burdens associated with CVD are wide ranging and negatively impact quality of life indicators for patients and their families.

\section{Population Level}

The aging population in the United States is predicted to put great stress on the healthcare system in the coming decades. Because medical costs continue to rise, the effects of the aging population on an already overburdened healthcare system is worrisome. As a result of greater life expectancy and the "Baby Boom" following World War II the number of adults entering into older age is set to increase in coming years. From 2011 to 2040 the number of adults aged 65 years and older living in the United States will increase nearly $200 \%$ from 41.4 million to 79.7 million (Centers for Disease 
Control and Prevention, 2003). During the same timeframe the population ages 85 years and older is expected to rise from 5.7 million to 14.1 million (Figure 1) (U.S. Department of Health and Human Services, 2012). Because chronic diseases disproportionately affect the elderly, the population increase in older adults will significantly impact the prevalence, incidence, and overall cost of CVD (Odden et al., 2011)

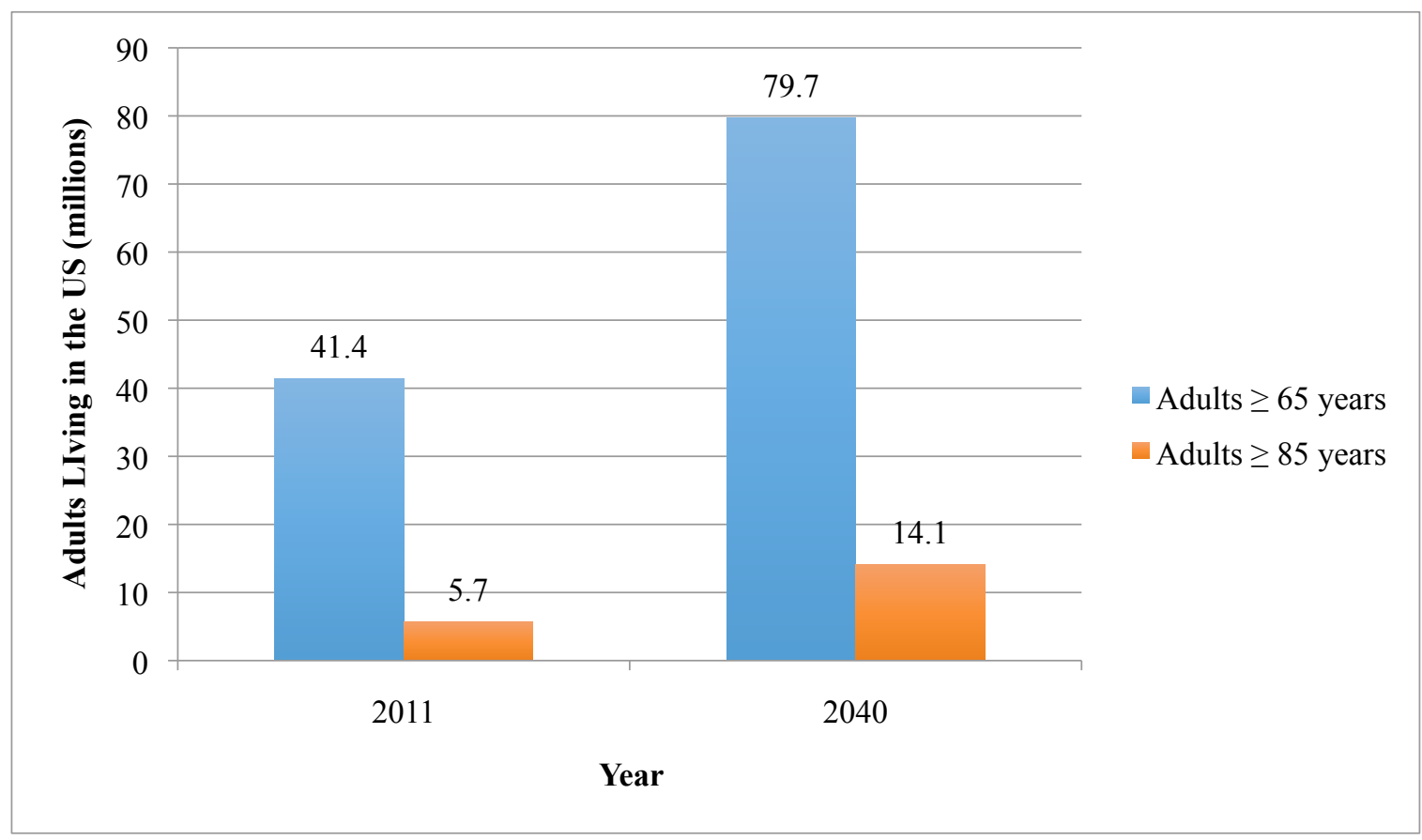

Figure 1. Projected number of adults $\geq 65$ years and $\geq 85$ years living in the United States between 2011 and 2040, adapted from (Odden et al., 2011).

Coronary heart disease, in particular, is most prevalent in the elderly and will increase the need for both preventative efforts and treatments in the future. This need is associated with an increased burden on hospitals and medical personnel as well as public health departments and training institutions. Not only is the number of new cases of CHD estimated to increase by $25 \%$ from 2010 to 2040 , but the number of deaths from CHD is 
also projected to increase by more than 50\% during the same timeframe (Figure 2)

(Odden et al., 2011).

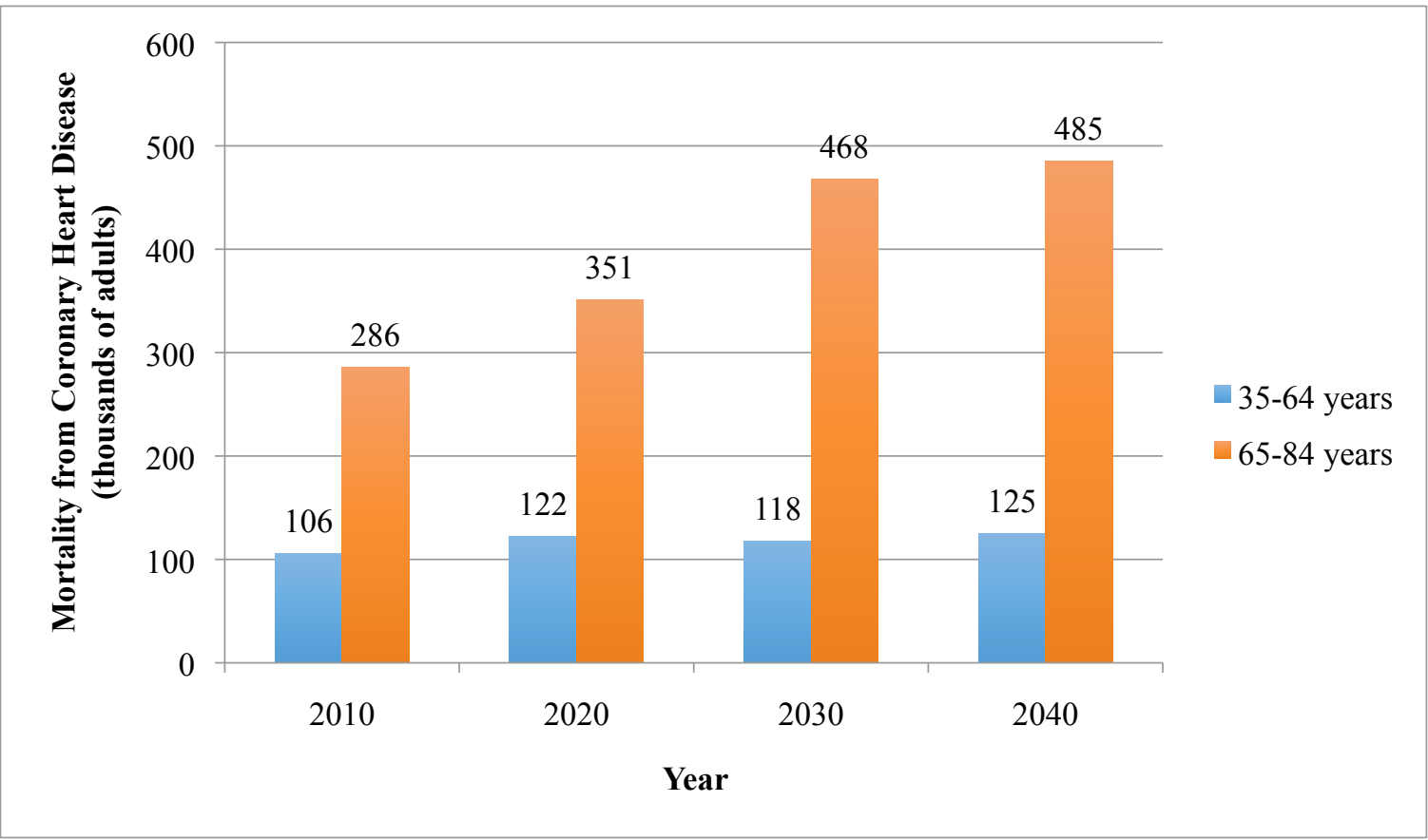

Figure 2. Projected mortality from coronary heart disease in adults 35-64 years and adults 65-84 years in 2010, 2020, 2030, and 2040, adapted from (Odden et al., 2011).

The costs associated with CVD on the national-level are both direct and indirect.

Between 2010 and 2030, direct medical costs alone are expected to rise from $\$ 273$ billion to $\$ 818$ billion, while indirect costs associated with lost productivity are projected to rise from $\$ 172$ billion to $\$ 276$ billion, placing great strain on the nation's healthcare system (Figure 3) (Heidenreich et al., 2011). 


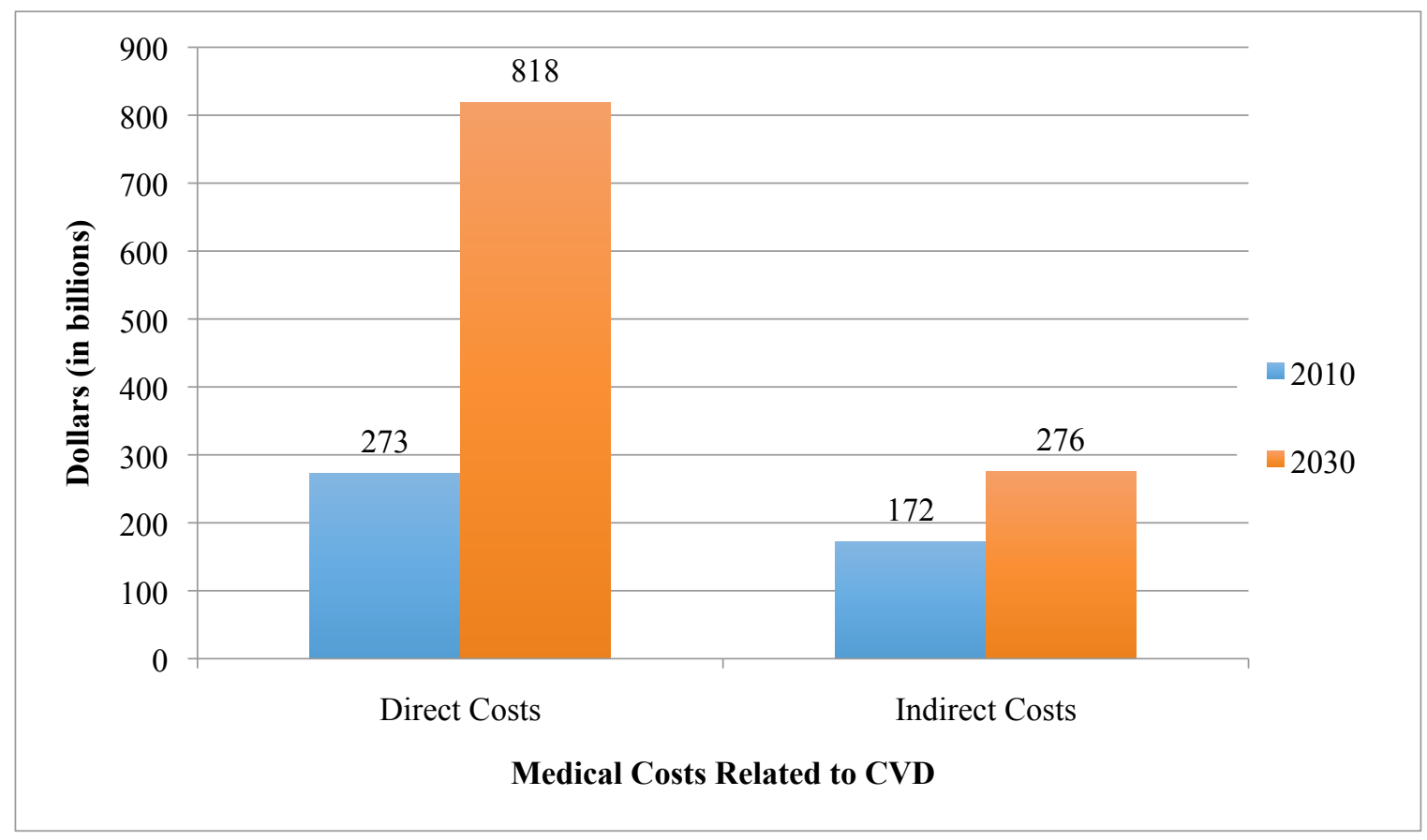

Figure 3. Projected direct and indirect medical costs associated with CVD from 2010 to 2030, adapted from (Heidenreich et al., 2011).

Prevention is key in lessening the financial impact of the aging population. Population-based prevention interventions, as opposed to drug therapy or clinical interventions, are the most cost-effective way to prevent CHD. Simple changes such as diet modification, physical activity, avoiding smoking, and controlling weight are all inexpensive ways to improve cardiovascular health and begin to minimize the consequences of heart disease on the nation's healthcare system (Prosser et al., 2000). While the effects of CVD can be damaging on the individual and national levels, many of the risk factors associated with CHD are preventable through lifestyle changes, in particular diet modification. 


\section{Risk Factors for Cardiovascular Disease}

Introduction

Risk factors for CVD may be non-modifiable (including genetics, age, and sex) or modifiable (including diet, physical activity level, lipid status, BMI, blood pressure, and smoking/alcohol use) (Hsu et al., 2013). Coronary heart disease kills nearly 380,000 people in the US annually and even more are at risk of developing CHD as a result of modifiable lifestyle factors (Center for Disease Control and Prevention, 2014). Modifiable factors are related to more than $90 \%$ of the risk for a first heart attack (Hsu et al., 2013). Two of the most common CVD risk factors, obesity and abnormal lipid status, are described below.

Obesity

A BMI of $30 \mathrm{~kg} / \mathrm{m}^{2}$ or greater indicates obesity and a BMI of $25-29.9 \mathrm{~kg} / \mathrm{m}^{2}$ indicates overweight (Table 1) (World Health Organization, 2000).

Table 1. Weight classification and BMI range for adults adapted from (WHO, 2000).

\begin{tabular}{|l|l|}
\hline \multicolumn{1}{|c|}{ Weight Classification } & \multicolumn{1}{c|}{ BMI $\left(\mathbf{k g} / \mathbf{m}^{\mathbf{2}}\right)$} \\
\hline Underweight & $<18.50$ \\
\hline Normal & $18.50-24.99$ \\
\hline Overweight & $\geq 25$ \\
\hline Obese & $\geq 30$ \\
\hline
\end{tabular}

Obesity has reached epidemic proportions in the United States. In 2011-2012, 16.9\% of youth and $34.9 \%$ of adults were obese (Ogden et al., 2014). Additionally, $68.5 \%$ of all adults aged 20 or older and $31.8 \%$ of youth ages 2 to 19 years old were overweight or obese (Ogden et al., 2014). Overweight and obesity have significant consequences on health including positive associations with CHD and stroke as well as other CVD risk factors such as dyslipidemia, physical inactivity, type two diabetes mellitus (T2DM), and 
hypertension, all of which are associated with atherosclerosis (U.S. Department of Health and Human Services, 2002). While obesity impacts multiple risk factors for CVD, it has been increasingly recognized as an independent risk factor for $\mathrm{CHD}$ in the past decade (Nelms, Sucher, Lacey \& Roth, 2011). Additionally, although it is difficult to obtain the exact number of deaths due to obesity alone, it is estimated that obesity causes 300,000 deaths per year in the United States (Flegal, Williamson, Pamuk, Rosenberg, 2004).

It is important that obesity in the population is reduced to help lessen its impact on CHD incidence. One study found that a $10 \%$ reduction in BMI over the next 30 years could help counteract the estimated increase in CHD incidence in the aging population by $80 \%$ through blood pressure, cholesterol, and diabetes control (Odden et al., 2011).

However, if the average BMI of adults increases by $10 \%$, the incident cases of CHD are projected to more than double by 2040 (Odden et al., 2011).

\section{Cholesterol}

Cholesterol is a precursor for many major hormones in the body, and is an important constituent of cell membranes and structures. In the blood, cholesterol travels via lipoproteins, the major classes of which are low-density lipoprotein cholesterol (LDLC), high-density lipoprotein cholesterol (HDL-C), and very-low-density lipoprotein cholesterol (VLDL-C) (USDHHS, 2002).

Desirable total cholesterol (TC) levels are less than $200 \mathrm{mg} / \mathrm{dL}$, whereas cholesterol levels of 200 to $239 \mathrm{mg} / \mathrm{dL}$ convey borderline-high risk for CVD, and levels of $240 \mathrm{mg} / \mathrm{dL}$ and above convey very high risk for CVD (Table 2) (American Heart Association, 2010). 
Table 2. Total cholesterol (TC) levels and classifications adapted from (AHA, 2010).

\begin{tabular}{|l|l|}
\hline \multicolumn{1}{|c|}{ Classification } & \multicolumn{1}{c|}{ TC Level (mg/dL) } \\
\hline Desirable & Less than 200 \\
\hline Borderline High & $200-239$ \\
\hline High & 240 and above \\
\hline
\end{tabular}

Among adults in the United States, the average TC level is around $200 \mathrm{mg} / \mathrm{dL}$, which is classified as borderline high risk for CVD (Roger et al., 2012). Currently, $13.8 \%$ of American adults have TC levels greater than or equal to $240 \mathrm{mg} / \mathrm{dL}$ and approximately $5.6 \%$ of adults have undiagnosed hypercholesterolemia (Fryar, Kirsch, Eberhardt, Yoon, \& Wright, 2010).

The effect of serum cholesterol on CVD risk is well documented. Individuals with high TC are at double the risk of developing CVD compared to those with optimal levels (CDCP, 2014), and research shows that adults with higher cholesterol levels suffer more effects from atherosclerosis and CHD than those with lower levels (USDHHS, 2002). Early prevention is the key to reducing CVD risk associated with serum cholesterol levels. One study found that when 42-year-old adults decrease their serum cholesterol by $10 \%$ they have a reduction in relative CHD risk of $50 \%$, but if the same $10 \%$ reduction in serum cholesterol is completed at age 70 , the reduction in relative CHD risk is only $20 \%$ (Stamler et al., 2000). Thus, early interventions to reduce TC levels may help decrease CVD risk later in life.

\section{Low-Density Lipoprotein Cholesterol (LDL-C)}

The main function of LDL-C, which transports around $60 \%$ of total serum cholesterol, is to deliver cholesterol and other lipids to peripheral tissues (including the vascular epithelium) to be utilized for membrane construction or hormone synthesis 
(Gropper, Smith, \& Groff, 2009). If LDL-C in the vascular epithelium becomes oxidized it can initiate the development of or add to existing atherosclerotic plaque, which is why LDL-C level is considered one of the best indicators of CVD risk and the main focus of cholesterol lowering therapy (USDHHS, 2002). The largest component of LDL-C is cholesterol, while protein, triacylglycerols (TAG), and phospholipids compose the remaining sections. Desirable levels of LDL-C are less than $100 \mathrm{mg} / \mathrm{dL}$ (or less than 70 $\mathrm{mg} / \mathrm{dL}$ for those already at risk for CVD) (Marieb \& Hoehn, 2013); near/above optimal levels are 100 to $129 \mathrm{mg} / \mathrm{dL}$; borderline high levels are 130 to $159 \mathrm{mg} / \mathrm{dL}$; levels of 160 to $189 \mathrm{mg} / \mathrm{dL}$ convey high risk of CVD; and levels of $190 \mathrm{mg} / \mathrm{dL}$ and above convey very high risk of CVD (Table 3) (AHA, 2010).

Table 3. Low-density lipoprotein cholesterol (LDL-C) levels and classifications adapted from (AHA, 2010).

\begin{tabular}{|l|l|}
\hline \multicolumn{1}{|c|}{ Classification } & \multicolumn{1}{c|}{ LDL-C Level (mg/dL) } \\
\hline Desirable & Less than 100 \\
\hline Near optimal/above optimal & $100-129$ \\
\hline Borderline high & $130-159$ \\
\hline High & $160-189$ \\
\hline Very high & 190 and above \\
\hline
\end{tabular}

In 2007 to 2010 the average value of LDL-C among adults in the United States was $115.8 \mathrm{mg} / \mathrm{dL}$, and in 1999 to 2004 the age-adjusted prevalence of high LDL-C among adults was $25.3 \%$ (Hyre, Muntner, Menke, Raggi, \& He, 2007). This rate is particularly troubling since LDL-C levels above $100 \mathrm{mg} / \mathrm{dL}$ seem to be atherogenic (Lloyd-Jones, Larson, Beiser, \& Levy, 1999). According to the Third Report of the National Cholesterol Education Program Expert Panel on Detection, Evaluation, and Treatment of High Blood Cholesterol in Adults, atherogenesis is significant in those with borderline high levels of LDL-C and is "markedly accelerated" among those with high 
and very high LDL-C levels (USDHHS, 2002). Thus, maintaining optimal LDL-C levels is essential to prevent atherosclerosis and maintain cardiovascular health.

\section{High-Density Lipoprotein Cholesterol (HDL-C)}

The role of HDL-C in the blood stream is to scavenge unesterified cholesterol from areas where it has accumulated, including peripheral tissues, cells, and other lipoproteins, and deliver it to the liver for excretion. High-density lipoprotein cholesterol can also compete with LDL-C for receptor sites in areas such as the vascular epithelium thereby reducing the risk of atherosclerosis (Gropper et al., 2009). Unlike LDL-C, HDL$\mathrm{C}$ is composed primarily of protein with smaller amounts of cholesterol, phospholipids, and TAG, and comprises approximately $20 \%$ to $30 \%$ of serum cholesterol (Marieb \& Hoehn, 2013).

High-density lipoprotein cholesterol values of $60 \mathrm{mg} / \mathrm{dL}$ or higher provide protection against heart disease, while values of less than $40 \mathrm{mg} / \mathrm{dL}$ for men and less than $50 \mathrm{mg} / \mathrm{dL}$ for women put the individual at greater risk of CVD (Table 4) (AHA, 2010).

Table 4. High-density lipoprotein cholesterol (HDL-C) levels and classifications adapted from (AHA, 2010).

\begin{tabular}{|l|l|}
\hline \multicolumn{1}{|c|}{ Classification } & \multicolumn{1}{c|}{ HDL-C Level (mg/dL) } \\
\hline Heart disease risk factor & $\begin{array}{l}\text { Less than } 40 \text { for men } \\
\text { Less than } 50 \text { for women }\end{array}$ \\
\hline Protection against heart disease & 60 or higher \\
\hline
\end{tabular}

As of 2010, 21.8\% of adults aged 20 years and older had HDL-C levels below $40 \mathrm{mg} / \mathrm{dL}$ (Go et al., 2014). There is strong evidence to suggest that low levels of HDL-C are associated with CHD morbidity and mortality. Studies have shown that HDL-C is an independent risk factor for $\mathrm{CHD}$ and that $\mathrm{CHD}$ risk increases between $2 \%$ and $3 \%$ for every $1 \%$ decrease in HDL-C (Gordon et al., 1989). 
Triacylglycerols (TAG)

Triacylglycerols are composed of a glycerol backbone and three fatty acids, which may be saturated, unsaturated, polyunsaturated, or a combination (Gropper et al., 2009). They represent the most abundant and efficient storage form of fat in the body, producing large quantities of energy when oxidized (Marieb \& Hoehn, 2013). In addition, 95\% of dietary fat comes from TAG, which varies in form depending on the composition of fatty acids (Gropper et al., 2009).

A desirable blood TAG value is less than $150 \mathrm{mg} / \mathrm{dL} ; 150$ to $199 \mathrm{mg} / \mathrm{dL}$ is considered borderline-high risk; 200 to $499 \mathrm{mg} / \mathrm{dL}$ is considered high risk; and 500 $\mathrm{mg} / \mathrm{dL}$ or above is considered very high risk (Table 5) (AHA, 2010).

Table 5. Triacylglycerol (TAG) levels and classifications adapted from (AHA, 2010).

\begin{tabular}{|l|l|}
\hline \multicolumn{1}{|c|}{ Classification } & \multicolumn{1}{c|}{ TAG Level (mg/dL) } \\
\hline Desirable & Less than 150 \\
\hline Borderline-high & $150-199$ \\
\hline High & $200-499$ \\
\hline Very high & 500 or higher \\
\hline
\end{tabular}

Presently, $31 \%$ of adults in the United States have TAG levels greater than or equal to $150 \mathrm{mg} / \mathrm{dL}$. While TAG values have not been clearly identified as an independent risk factor for CVD, many studies have shown positive relationships between serum TAG levels and CHD incidence, and strong associations between high TAG values and CVD risk when combined with high LDL-C and low HDL-C as part of the atherogenic dyslipidemic triad (Miller et al., 2011). Additionally, TAG values are associated with other known risk factors for CVD including obesity, hypertension, diabetes, and cigarette smoking (Grundy, 1998). 
Obesity, TC, HDL-C, LDL-C, and TAG are all modifiable risk factors for CVD and are all strongly impacted by diet.

\section{Dietary Factors}

Dietary Patterns

Presently, neither children nor adults in the United States are consuming ideal diets. Data from the National Health and Nutrition Examination Survey (NHANES) from 2009-2010 show that among children and teenagers, consumption of whole grain, fruits, and vegetables are far below national guidelines. Fewer than $3 \%$ of children consume adequate amounts of vegetables per day and only between $5 \%$ and $10 \%$ of children consume enough fruit per day with consumption decreasing consistently with age (Go et al., 2014). Similarly, fewer than 7\% of all children meet guidelines for servings of whole grain per day, with an average of less than one serving per day in all age and sex groups (Go et al., 2014). Children also consume high amounts of sugarsweetened beverages, sweets and bakery desserts, and processed meats. For example, consumption of sugar-sweetened beverages increased with age from 7 to 8 servings per week in 5 to 9 year-olds to 13 to 16 servings per week in 15 to 19 year-olds (Go et al., 2014). Results are similar for adults (Krebs-Smith, Guenther, Subar, Kirkpatrick, \& Dodd, 2010).

Among adults aged 19 and older, $85.1 \%$ have usual fruit intakes below recommended amounts according to MyPyramid food groups, $86.8 \%$ do not consume adequate vegetables, and $98.8 \%$ do not consume enough whole grains (Krebs-Smith et al., 2010). When compared to maximum discretionary calorie allowances, intakes of energy from solid fats, added sugars, and alcoholic beverages were over-consumed in 
more than $90 \%$ of adults less than 72 years of age (Krebs-Smith et al., 2010). While between only $31-47 \%$ of Americans are categorized as "ideal" by the American Heart Association's Goals for 2020 in metrics of cardiovascular health such as physical activity, cholesterol levels, and BMI, a smaller fraction (0.5\%) of Americans are categorized as "ideal" with regard to their healthy diet score (Figure 4) (Go et al., 2014). Part of this problem stems from the obesogenic environment in the United States today (Chaput, Klingenberg, Astrup, \& Sjodin, 2011).

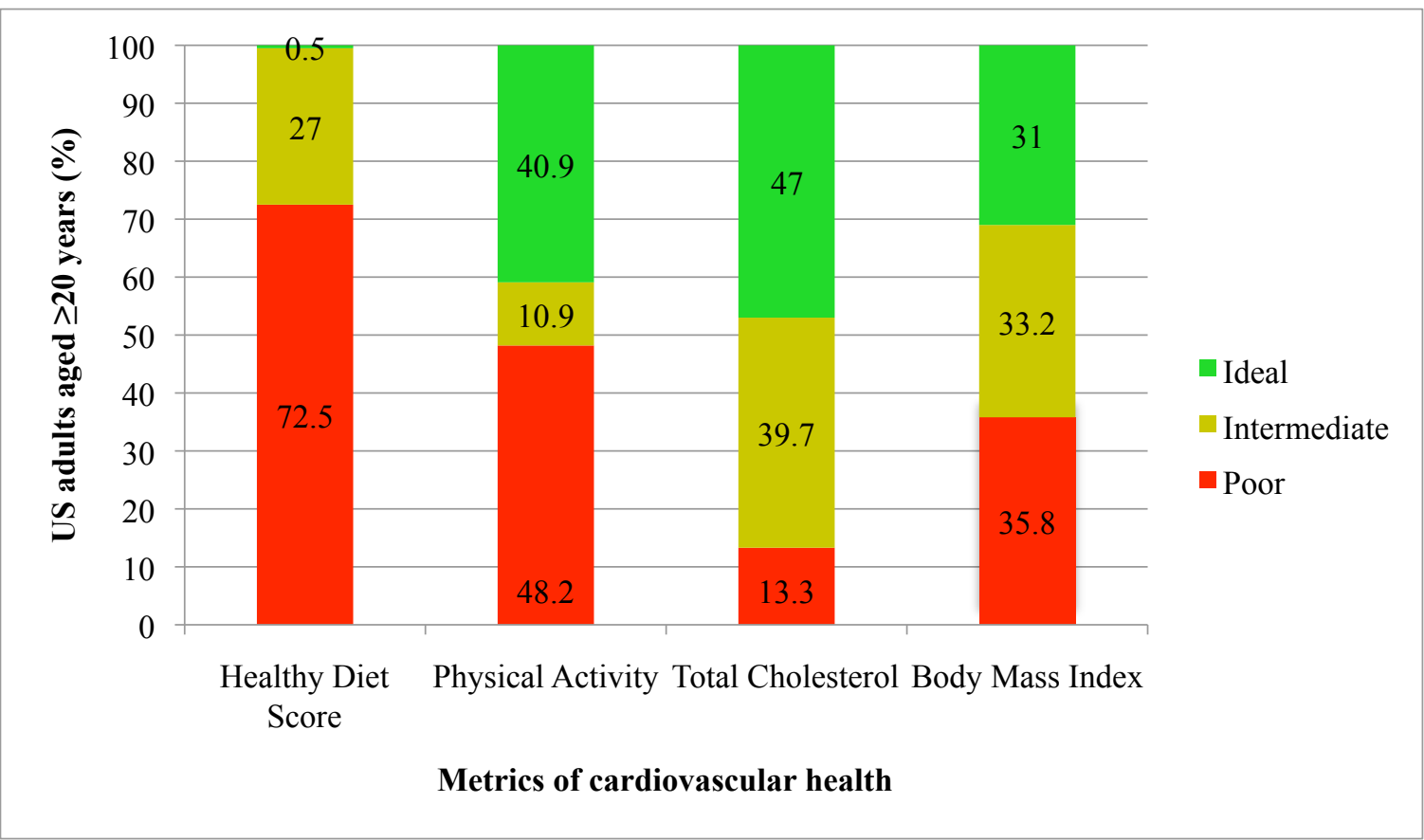

Figure 4. Prevalence estimates for poor, intermediate, and ideal cardiovascular health in US Adults $\geq \mathbf{2 0}$ years based on four metrics of cardiovascular health from the American Heart Association 2020 goals, adapted from (Go et al., 2014).

In contrast to much of human history, where people spent extensive amounts of time and energy in search of food, food is now abundant, reasonably priced, and energydense. Fast-food options are increasingly available, meaning that more food is eaten outside of the home and often in large portions (Chaput et al., 2011). These factors 
contribute to the choices of many Americans to consume diets that are high in saturated fat, sodium, and added sugar in addition to being low in fiber (Hill, Wyatt, Reed, \& Peters, 2003).

This Western diet pattern is high in red meat, processed meat, refined grains, fried foods, sweets, and desserts (Heidemann et al., 2008), and has led to an overall increase in energy intake over time. Data from NHANES comparing surveys from 1971 to 1974 and 2005 to 2006 found that energy intake of females in the United States has increased by $22 \%$ (from 1,542 to $1,886 \mathrm{kcal} /$ day) and energy intake of males has increased $10 \%$ (from 2,450 to 2,693 kcal/day) (Figure 5) (Nielsen \& Popkin, 2003). Additionally, between 1970 and 2008 the net average daily per capita caloric intake increased by around 600 kcals (U.S. Department of Agriculture and U.S. Department of Health and Human Services, 2010). 


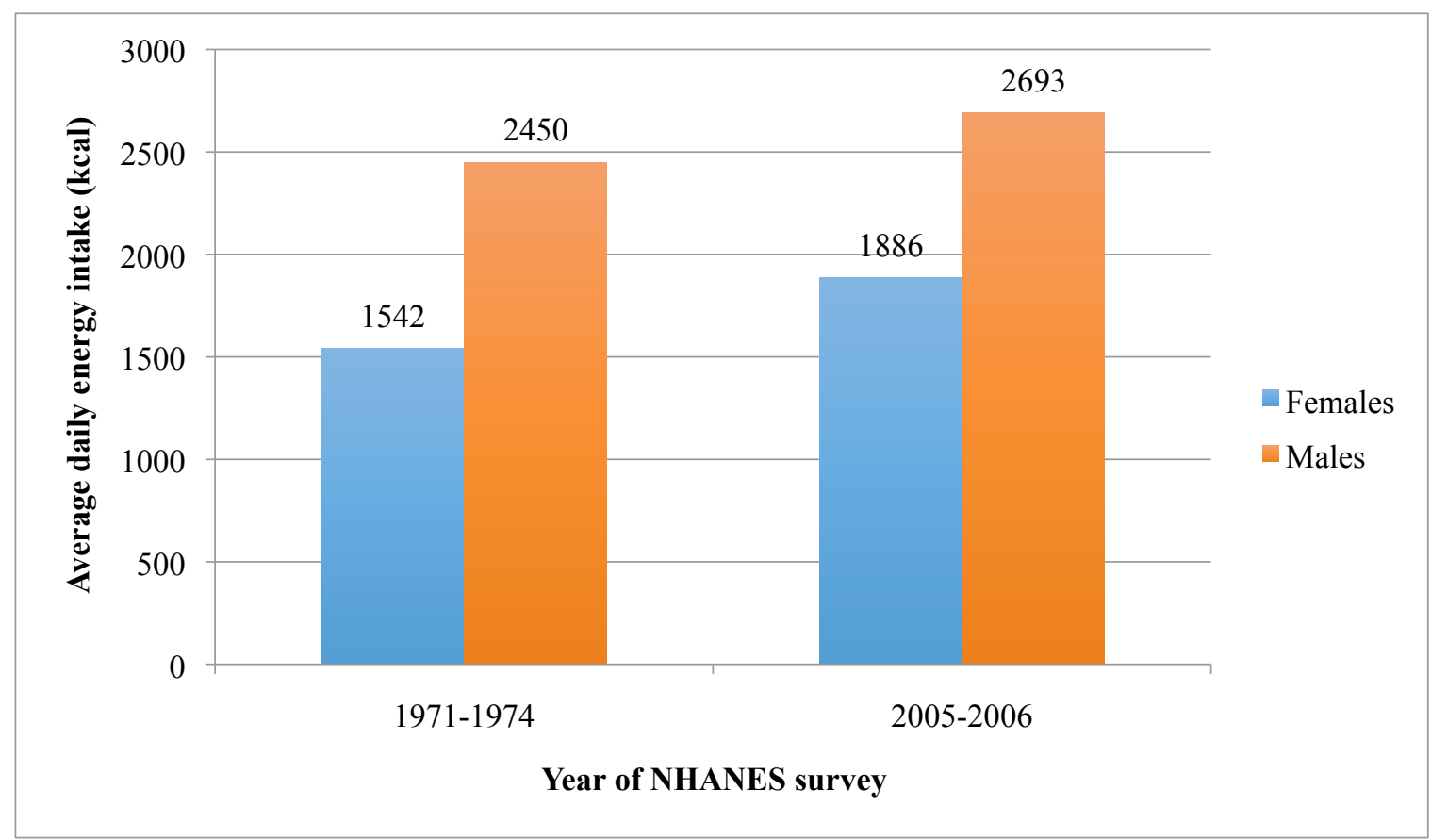

Figure 5. Average daily energy intake of adult females and males in the United States from 1971-1974 and 2005-2006 NHANES data, adapted from (Nielsen \& Popkin, 2003).

The Western diet pattern negatively impacts CVD risk. The INTERHEART study of 52 countries and more than 16,000 participants between 1999 and 2003 found that the risk of $\mathrm{MI}$ is $30 \%$ higher among those who consume a Western diet compared to those who consume a prudent diet (Iqbal et al., 2008). A prudent diet is characterized by a high intake of fruit, vegetables, and legumes as well as lean protein sources such as fish and poultry (Iqbal et al., 2008). Additionally, an 8-year prospective study of 44,875 men aged 40 to 75 years without diagnosed CVD showed that the Western diet pattern was associated with a $43 \%$ greater chance of CHD incidence in participants with the highest quintile of Western diet score compared to the lowest quintile of Western diet score $(p=0.004)$. The same study found that the prudent diet pattern was inversely associated with total CHD regardless of smoking status, body weight, or parental history of MI, with a $25 \%$ reduced risk of $\mathrm{CHD}$ among participants with the highest quintile of prudent diet 
score compared to the lowest quintile of prudent diet score $(\mathrm{p}=0.02)$ (Hu et al., 2000). These studies show that long-term dietary patterns can greatly impact CVD risk.

The Western and prudent diet patterns may also affect measures of adiposity. A review of the Nurses' Health Study II by Schulze et al. (2006), which followed 51,670 women from 1991 to 1999, found that women who maintained a low Western diet score gained significantly less weight compared to women who maintained a high Western diet score over time (4.90 kg versus $5.62 \mathrm{~kg}$, respectively, $\mathrm{p}<0.001$ ). Additionally, compared to women who decreased their prudent diet score, those who increased their prudent diet score over time experienced less overall weight gain $(7.98 \mathrm{~kg}$ versus $3.75 \mathrm{~kg}$, respectively, $\mathrm{p}<0.001$ ) (Schulze et al., 2006). These results indicate that the prudent diet pattern may decrease the risk of weight gain over time whereas the Western diet pattern may increase the risk of weight gain over time.

Similarly, a cross-sectional study by Denova-Gutierrez et al. (2011) of 6,070 men and women aged 20 to 70 years from the Health Workers Cohort Study found that the percentage of participants who were overweight or obese in the highest quintile of Western diet score was nearly $11 \%$ higher compared to the lowest quintile Western diet score $(66.0 \%$ versus $55.8 \%$, respectively). Body fat percentage was also significantly higher among participants with the highest quintile Western diet score compared to the lowest quintile Western diet score $(32.4 \%$ versus $29.8 \%$, respectively; $\mathrm{p}<0.001)$, whereas body fat percentage was significantly lower in the highest quintile of the prudent diet score compared to the lowest quintile prudent diet score (30.4\% versus $31.8 \%$, respectively; $\mathrm{p}=0.002$ ) (Denova-Gutierrez et al., 2011). These studies indicate that the 
Western diet pattern may be associated with a higher risk of overweight/obesity and a high body fat percentage compared to the prudent diet pattern.

The Western and prudent diet patterns may also impact the risk of developing metabolic syndrome (MetS), defined as any of three of the following risk factors: waist circumference $(\mathrm{WC})>102 \mathrm{~cm}$ in men and $>88 \mathrm{~cm}$ in women; TAG $\geq 150 \mathrm{mg} / \mathrm{dL}$; HDL-C $<40 \mathrm{mg} / \mathrm{dL}$ in men and $<50 \mathrm{mg} / \mathrm{dL}$ in women; systolic blood pressure $\geq 130 \mathrm{~mm} \mathrm{Hg}$, diastolic blood pressure $\geq 85 \mathrm{~mm} \mathrm{Hg}$, or current use of antihypertensive medication; and fasting glucose $\geq 100 \mathrm{mg} / \mathrm{dL}$ or current drug treatment for elevated glucose (Grundy et al., 2005). The 9-year Atherosclerosis Risk in Communities Study, which followed 15,972 men and women ages 45 to 64 years, found that the Western diet pattern was associated with an 18\% greater risk of MetS incidence for participants in the highest quintile of Western diet scores compared to those in the lowest quintile of Western diet scores (Lutsey, Steffen, \& Stevens, 2008). As such, in comparison to the prudent diet pattern, the Western diet pattern may negatively impact multiple risk factors for CVD including measures of adiposity and blood lipids.

Similar to the prudent diet pattern, the Mediterranean diet (which includes a high intake of olive oil, fruit, nuts, vegetables, and cereals; modest fish and poultry intake; and only small amounts of dairy products, red and processed meats, and sweets) has been associated with beneficial effects on cardiovascular health. A dietary intervention study comparing the Mediterranean diet to a control diet in 7,447 subjects at high cardiovascular risk found that the Mediterranean diet reduced the incidence of major cardiovascular events by nearly 30\% (Estruch et al., 2013). Additionally, Fung et al. (2009) reviewed data from 74,886 women ages 38 to 63 in the Nurses' Health Study and 
found that those with the highest quintile Alternate Mediterranean Diet (aMed) Score (which encompassed high consumption of plant foods, plant protein, monounsaturated fat, and fish; and low consumption of animal products and saturated fat) had a $29 \%$ lower risk of developing CHD compared to the lowest quintile aMed score. Therefore, the Mediterranean diet pattern may be associated with a lower risk of CHD as well as cardiovascular events.

The Mediterranean diet has also been associated with changes in measures of adiposity. A cross-sectional study of 1,547 men and 1,615 women aged 25 to 74 in northeast Spain found that increased adherence to the Mediterranean diet was associated with reductions in $\mathrm{WC}$ of 0.43 inches men $(\mathrm{p}=0.030)$ and 0.68 inches women $(\mathrm{p}=0.007)$, as well as a $39 \%$ reduced risk of obesity among both sexes when comparing the highest to lowest tertile Mediterranean diet scores (Schroder, Marrugat, Vila, Covas, \& Elosua, 2004). Additionally, a 3-year prospective study following 17,238 non-obese women and 10,589 non-obese men from the Spanish cohort of the European Prospective Investigation into Cancer and Nutrition found that high adherence to the Mediterranean diet was associated with a $31 \%$ reduction in obesity incidence in both women and men (Mendez et al., 2006). This suggests that the Mediterranean diet pattern may be beneficial in helping to reduce the risk of obesity in both men and women.

The Mediterranean diet may also affect the lipid profile. In a 3-month dietary intervention among 212 male and female volunteers, participants in the Mediterranean diet group showed a significant decrease in TC $(6.6 \pm 1.0$ to $6.2 \pm 1.0 \mathrm{mmol} / \mathrm{L}, \mathrm{p}<0.001)$ and TAG (1.6 \pm 1.0 to $1.4 \pm 0.9 \mathrm{mmol} / \mathrm{L}, \mathrm{p}<0.001)$ (Vincent-Baudry et al., 2005). In addition, a 4-week randomized crossover study (where 22 healthy subjects were fed a 
Mediterranean diet or an ordinary Swedish diet) found that compared to the Swedish diet, the Mediterranean diet decreased TC, LDL-C, and TAG by $17 \%, 22 \%$, and $17 \%$, respectively (Ambring et al., 2004). Similar to the prudent diet pattern (and in contrast to the Western diet pattern), the Mediterranean diet pattern is associated with a reduced risk of CVD, overweight/obesity, and abnormal blood lipids.

Plant-based diets have also been associated with favorable impacts on CVD risk. This dietary pattern emphasizes consumption of a variety of plant foods including fruits, vegetables, nuts, seeds, legumes, and cereal grains (Pilis, Stec, Zych, \& Pilis, 2014), and limits animal products and highly processed foods (Tuso et al., 2013). It has been shown to be high in phytochemicals, fiber, antioxidants, magnesium, vitamins $\mathrm{C}$ and $\mathrm{E}$, and folic acid while low in cholesterol, total fat, saturated fatty acids (SFA), and sodium (Li, 2013). This nutrient profile is associated with reduced risk of atherosclerosis, CHD, T2DM, obesity, cancer, and MetS (Pilis et al., 2014) due to beneficial effects on BMI, cholesterol levels, and blood pressure (McEvoy, Temple, \& Woodside, 2012).

A meta-analysis by $\mathrm{Li}$ (2013) of 124,706 participants from seven prospective cohort studies determined that compared with omnivores, vegetarians had 29\% lower mortality from CHD, $16 \%$ lower mortality from circulatory diseases, and $12 \%$ lower mortality from cerebrovascular diseases. Lower mortality rates among vegetarians were associated with improvements in TC, TAG, and LDL-C; improvements in ratios of TC/HDL-C, LDL-C/HDL-C, and TAG/HDL-C; decreased blood pressure; and lower BMI and waist-to-hip ratio (Li, 2013). According to Sabaté and Wien (2010), a metaanalysis of studies on adult vegetarians showed that vegetarians had $2 \mathrm{~kg} / \mathrm{m}^{2}$ lower BMI values than non-vegetarians. The same study found that male and female vegetarians 
weighed $7.6 \mathrm{~kg}$ and $3.3 \mathrm{~kg}$ less, respectively, than non-vegetarians of the same sex. These studies indicate that plant-based diets may help reduce the risk of mortality due to CVD by improving blood lipid status and measures of adiposity such as BMI.

Plant-based diets may even be associated with reversing certain aspects of CVD progression. The Lifestyle Heart Trial found that when patients with heart disease consumed a plant-based diet, $82 \%$ had some level of regression of atherosclerosis (Ornish et al., 1990). Among the treatment group given a plant-based diet, participants showed a $40 \%$ decrease in LDL-C at year one, which was maintained at $20 \%$ below baseline at year five. Reductions of this magnitude are similar to those seen with lipid-lowering medications, indicating that lifestyle changes alone can impact cardiovascular health (Ornish et al., 1990; Ornish et al., 1998).

Plant-based diets that include nuts have reported similar beneficial effects as a plant-based diet without nuts, but with a greater magnitude. A review of small, randomized trials suggests that while vegetarian and lacto-ovo-vegetarian diets reduced TC and LDL-C by $10-15 \%$, a vegetarian diet with added fiber, soya, and nuts reduced TC and LDL-C by 20-35\% (Ferdowsian \& Barnard, 2009). While the prudent, Mediterranean, and plant-based diets are all associated with positive effects on CVD risk, lipid profile, and measures of adiposity, those that include nuts may be more beneficial compared to plant-based diets without nuts. Therefore, the study of nuts in the diet is important to better understand their effects on cardiovascular health.

Nuts

\section{Introduction}

The term "nut" refers to tree nuts and peanuts (peanuts botanically are considered groundnuts or legumes but are widely accepted as nuts by the consumer definition), with 
the most popular nuts being almonds, peanuts, walnuts, pecans, and pistachios (Ros, 2010). Nuts are recognized as a healthy dietary component in many countries (Vadivel, Kunyanga, \& Biesalki, 2012) including the United States, Canada, and Spain, which have all included nuts into their recommended dietary guidelines (Chen \& Blumberg, 2008). Since the year 2000 the AHA has recommended nuts as part of a healthy diet, and a recent report by the AHA stipulating goals for 2020 to reduce disease and promote health included nuts as an important component in the ideal diet for cardiovascular health (Lloyd-Jones et al., 2009). Additionally, in the summer of 2003 the United States Food and Drug Administration (USFDA) issued a qualified health claim for the association of nut consumption and reduced risk of CHD reporting that, "Scientific evidence suggests but does not prove that eating $1.5 \mathrm{oz}$ per day of most nuts, such as pistachios, as part of a diet low in saturated fat and cholesterol may reduce the risk of heart disease" (O’Neil, Keast, Fulgoni, \& Nichlas, 2010). This claim was supported by the 2010 Dietary Guidelines Advisory Committee, which stated that research most strongly supported this claim for almonds, pistachios, and walnuts (USDA and USDHHS, 2010). Consequently, nuts have gained recognition as a healthy food option (Nash \& Nash, 2008).

\section{Effects on Cardiovascular Health}

Nuts have been shown to have beneficial health effects due to their cardioprotective, antidiabetic, antioxidant, anti-inflammatory, and hypocholesterolemic properties (Vadivel et al., 2012). Results from epidemiologic studies have been consistent in establishing the protective effects of nuts on cardiovascular health. A review of four large cohort studies (the Adventist Health Study, the Iowa Women's Health Study, the Nurses' Health Study, and the Physician's Health Study) has shown 
that nut consumption reduces the risk of CHD in a dose-dependent manner. Results from these four studies indicated that the average reduction in risk of death from CHD was $8.3 \%$ for each weekly serving of nuts, which equated to a $37 \%$ reduced risk of CHD death overall (Kelly Jr. \& Sabaté, 2006).

Furthermore, nuts have been associated with improved glycemic control and reduced fasting insulin levels (Josse, Kendall, Augustin, Ellis, \& Jenkins, 2007) and have been found to help reduce the risk of developing T2DM (Jenkins, Hu, Tapsell, Josse, \& Kendall, 2008). The beneficial effects on treatment and prevention of T2DM may be due to the anti-inflammatory and antioxidant potential of nuts (Casas-Agustench et al., 2009).

Nuts have antioxidant properties due to their distinct nutrient profile. Nuts contain phenolic compounds and antioxidant vitamins, which have been shown to inhibit LDL-C oxidation (Blomhoff, Carlsen, Andersen, \& Jacobs, 2006). Additionally, nuts contain a relatively high amount of monounsaturated fatty acids (MUFA), which are not vulnerable to oxidation. While nuts also contain polyunsaturated fatty acids (PUFA), which may be more easily oxidized, the other antioxidant components present in nuts help to counteract any oxidation that may occur (Alexiadou \& Katsilambros, 2011).

Nut consumption may also have beneficial impacts on inflammation. The MultiEthnic Study of Atherosclerosis composed of 6,000 men and women aged 45 to 84 years examined the relationship between nut consumption and inflammatory markers, and their relation to atherosclerosis. Researchers found a significant inverse association between nut consumption and markers of inflammation including C-reactive protein, interleukin6, and fibrinogen (Sabaté \& Ang, 2009). 
Nut consumption has also been shown to beneficially impact flow-mediated dilation (a standard method to assess endothelial function) (Ros, 2010) and reduce endothelial dysfunction due to hypercholesterolemia. Because endothelial dysfunction is associated with the progression of atherosclerosis, nut consumption may help prevent atherosclerosis and thus CVD (Ros et al., 2004).

\section{Effects on Measures of Adiposity}

While nuts have a high energy density and fat content, evidence suggests that when consumed in moderation as part of a healthy diet their consumption does not increase the risk of becoming overweight or obese (Flores-Mateo, Rojas-Rueda, Basora, Ros, \& Salas-Salvadó, 2013). For example, Mediterranean populations consume nearly double the amount of nuts per capita than Americans but have much lower rates of obesity (Sabaté, 1993). Additionally, multiple large prospective cohort studies and controlled feeding trials have found an inverse relationship between frequency of nut consumption and BMI (Flores-Mateo et al., 2013). The Seguimiento Universidad de Navarra study (composed of 8,865 adults in a Mediterranean population) showed that even after adjusting for baseline BMI, participants who consumed nuts more than twice per week had a $40 \%$ lower risk of weight gain and a $43 \%$ reduced risk of becoming overweight/obese compared to those who never or rarely consumed nuts (Bes-Rastrollo et al., 2007). Frequent nut consumers may weigh less and have less chance of gaining weight than their counterparts who consume nuts infrequently (Fraser, Sabaté, Beeson, \& Strahan, 1992).

A review of nut-feeding studies by Sabaté (2003) found that nuts consistently were not associated with weight gain when consumed during short-term trials in 
moderate to large quantities. Well-controlled feeding studies, controlled crossover feeding studies, and other intervention studies have shown no significant association between nut consumption and weight change. This evidence suggests that when nuts are substituted into the diet they are not associated with significant changes in weight.

\section{Effects on Blood Lipids}

Clinical trials have consistently shown the hypocholesterolemic effects of nut consumption. A review by Sabaté, Oda, and Ros (2010) of 25 clinical trials evaluating the effects of nut consumption on the lipid profile consisted of 1,284 observations from 583 participants in 7 different countries. While the type of nuts consumed and the range of dietary control varied greatly among the studies, results showed consistent cholesterollowering effects among all age groups and genders, independent of the type of nut consumed. The average estimated reduction of TC was $11 \mathrm{mg} / \mathrm{dL}$ (5\%) and of LDL-C was $10 \mathrm{mg} / \mathrm{dL}(7 \%)$ in response to an average daily intake of $67 \mathrm{~g}$ of nuts or approximately $20 \%$ of energy. Reductions in both TC and LDL-C occurred in a dosedependent manner. Among patients with high serum TAG values (greater than 150 $\mathrm{mg} / \mathrm{dL}$ ) a significant reduction of $10.2 \mathrm{mg} / \mathrm{dL}$ was also observed (Sabaté et al., 2010).

This review also found that the decrease in LDL-C was greater than predicted based on the differences in fatty acid and cholesterol composition between nut and control diets. The authors suggest that the enhanced cholesterol-reducing effects of nuts can be attributed to other nutritional components such as fiber and phytosterols (Sabaté et al., 2010). Previous research has indicated that the lipids from nuts may not be efficiently absorbed (Baer et al., 2012). Because plant cell walls control the degree and speed with which lipids are released during digestion, whole nuts have been shown to cause smaller 
increases in postprandial lipemia when compared to their respective oils or flours. Berry et al. (2008) found that following the consumption of almond seeds, increases in TAG among participants were lower compared to increases in TAG following consumption of almond oil or flour. Additionally, an intervention trial of 63 healthy men and women found that consumption of whole peanuts equated to greater fecal fat and energy loss when compared to peanut butter, oil, or flour. The fact that the energy in nuts is not fully absorbed during digestion is one reason why nuts may be considered as part of a healthy diet without excessive concern for weight gain or negative impacts on the lipid profile (Traoret et al., 2008).

Compared to the top three most highly consumed nuts in the US, as reviewed in the studies above, pistachios have fewer calories and less total fat per serving, giving them the potential to induce similar cardiovascular benefits with reduced energy and fat intake. The following section will highlight the nutrient composition of pistachios and the subsequent impacts of pistachio consumption on measures of adiposity and the lipid profile.

\section{Pistachios}

\section{Introduction}

The pistachio (Pistacia vera L.) is a tree nut in the family Anacardiaceae (Herber \& Bowerman, 2008). While researchers have only recently begun studying the various health benefits of pistachios, different populations have been taking advantage of their healthful properties for centuries. For millennia pistachios have been utilized for their nutritional properties and have been used to treat diseases. Pistachios were even used in ancient Greek and Assyrian civilizations to remedy bites from poisonous animals and as 
folk remedies for numerous conditions. They were a valuable food for early explorers and traders due to their high nutritional value and relatively light weight (Salas-Salvadó, Casas-Agustench, \& Salas-Huetos, 2011). The largest producers of pistachios worldwide are California and Iran, each producing hundreds of millions of pounds annually (Dreher, 2012).

\section{Biochemical Composition}

The unique biochemical composition of pistachios yields beneficial effects on cardiovascular health by impacting lipid status, glycemic control, blood pressure, and measures of adiposity (Kris-Etherton et al., 2008). Pistachios are rich in unsaturated fatty acids, phytosterols, lutein, dietary fiber, protein, magnesium, carotenoids, gammatocopherol, phenolic compounds, and potassium (U.S. Department of Agriculture, 2015). In comparison to other tree nuts, pistachios contain higher levels of phytosterols, potassium, carotenoids, and tocopherols (Phillips, Ruggio, \& Ashraf-Khorassani, 2005). Compared to almonds, peanuts, pecans, and walnuts, pistachios have fewer calories and less fat per serving (USDA, 2015) (Table 6). 
Table 6. Average nutrient composition of selected nuts per $100 \mathrm{~g}^{1}$ adapted from (USDA, 2015).

\begin{tabular}{|c|c|c|c|c|c|c|c|c|c|c|c|c|c|c|}
\hline Nuts & $\begin{array}{l}\text { Energy } \\
\text { (kcal) }\end{array}$ & $\begin{array}{l}\text { Total } \\
\text { Fat } \\
\text { (g) }\end{array}$ & $\begin{array}{l}\text { SFA } \\
(\mathrm{g})\end{array}$ & $\begin{array}{l}\text { MUFA } \\
\text { (g) }\end{array}$ & $\begin{array}{l}\text { PUFA } \\
\text { (g) }\end{array}$ & $\begin{array}{l}\text { Total } \\
\text { Protein } \\
\text { (g) }\end{array}$ & $\begin{array}{l}\text { Plant } \\
\text { Sterols } \\
\text { (mg) }\end{array}$ & $\begin{array}{l}\text { Fiber } \\
\text { (g) }\end{array}$ & $\begin{array}{l}\text { Ca } \\
(\mathrm{mg})\end{array}$ & $\begin{array}{l}\text { Mg } \\
(\mathrm{mg})\end{array}$ & $\begin{array}{l}\text { K } \\
(\mathrm{mg})\end{array}$ & $\begin{array}{l}\text { Lutein and } \\
\text { zeaxanthin } \\
(\mu g)\end{array}$ & $\begin{array}{l}\text { Beta- } \\
\text { carotene } \\
(\mu \mathrm{g})\end{array}$ & $\begin{array}{l}\text { Gamma- } \\
\text { tocopherol } \\
\text { (mg) }\end{array}$ \\
\hline Pistachios & 562 & 45.39 & 5.556 & 23.82 & 13.74 & 20.27 & 214 & 10.3 & 105 & 121 & 1025 & 1405 & 249 & 22.6 \\
\hline Almonds & 579 & 49.93 & 3.802 & 31.55 & 12.33 & 21.15 & 120 & 12.5 & 269 & 270 & 733 & 1 & 1 & 0.64 \\
\hline Peanuts & 567 & 49.24 & 6.279 & 24.43 & 15.56 & 25.8 & NR & 8.5 & 92 & 168 & 705 & 0 & 0 & NR \\
\hline Pecans & 691 & 71.97 & 6.180 & 40.80 & 21.61 & 9.17 & 102 & 9.6 & 70 & 121 & 410 & NR & NR & NR \\
\hline Walnuts & 654 & 65.21 & 6.126 & 8.933 & 47.17 & 15.23 & 72 & 6.7 & 98 & 158 & 441 & 9 & 12 & 20.83 \\
\hline
\end{tabular}

${ }^{1}$ Data are from raw nuts. SFA, saturated fatty acid; MUFA, monounsaturated fatty acid; PUFA, polyunsaturated fatty acid; $\mathrm{Ca}$, calcium; Mg, magnesium; K, potassium; $\mathrm{NR}$, not reported. 
The nutrients found in pistachios that are likely to have the greatest impact on improving lipid status are unsaturated fatty acids, phytosterols, dietary fiber, protein, and magnesium (Dreher, 2012). Studies have shown that the pistachio's high unsaturated fat percentage relative to saturated fat content is the most influential factor affecting lipid status (Berglund et al., 2007). One hundred grams of pistachios contains $45.39 \mathrm{~g}$ of total fat including $5.56 \mathrm{~g}$ of SFA, $13.74 \mathrm{~g}$ of PUFA, and $23.82 \mathrm{~g}$ of MUFA (USDA, 2015). The phytosterol content of pistachios (which is $214 \mathrm{mg}$ per $100 \mathrm{~g}$ and the highest among all tree nuts) is also beneficial to the lipid profile (Phillips et al., 2005). The structure of phytosterols resembles that of cholesterol, which can impede cholesterol absorption (Ostlund, 2007). The insoluble fiber found in pistachios (which accounts for $80 \%$ of the fiber in pistachios) has also been shown to cause both cholesterol and bile to be less efficiently absorbed by increasing fecal bulk and decreasing intestinal transit time (SalasSalvadó, Bulló, Pérez-Heras, \& Ros, 2006). Low-density lipoprotein cholesterol levels, in particular, may be improved with the consumption of plant-based protein when consumed in place of carbohydrates (pistachios contain $20.27 \mathrm{~g}$ of plant-based protein per 100g) (USDA, 2015; Wolfe \& Giovannetti, 1991). Pistachios also contain magnesium, which has been linked to improvements in hyperlipidemia (Kishimoto et al., 2010).

Pistachios have been listed among the top fifty foods highest in antioxidants (Halvorsen et al., 2006) and contain an abundance of both water- and fat-soluble antioxidants including carotenoids, gamma-tocopherol, and phenolic compounds. Reduced antioxidant values can lead to oxidative stress which impacts CHD progression (Kay et al., 2010), and oxidized LDL-C has been implicated in the initiation and progression of atherosclerotic plaques, which may lead to CVD (Toshima et al., 2000). 
Conversely, the consumption of antioxidants, like those found in pistachios, has been linked to protection against early atherosclerosis, decreases in oxidized LDL-C, and an inverse association with CHD (Dreher, 2012).

Pistachios have also been associated with improvements in fasting blood glucose and insulin levels (Sari et al., 2010), and hemodynamics (Sauder, McCrea, Ulbrecht, Kris-Etherton, \& West, 2014). Improved fasting blood glucose and insulin levels may help reduce the risk of T2DM (a risk factor for CVD) (Kendall, Josse, Esfahani, \& Jenkins, 2011), and the beneficial effects of pistachios on multiple hemodynamic measures such as stroke volume, cardiac output, and total peripheral resistance may be associated with a reduced risk of CVD outcomes (Sauder et al., 2014).

\section{Effects on Measures of Adiposity}

Nine studies have investigated the effects of a pistachio-supplemented diet on body weight, WC, intra-abdominal adipose tissue (IAAT), subcutaneous abdominal tissue (SCAT), waist-to-hip ratio, and BMI (Aldemir et al., 2011; Edwards et al., 1999; Gebauer et al., 2008; Gulati et al., 2014; Li et al., 2010; Sari et al., 2010; Kocygit et al., 2006; Sheridan et al., 2007) (Table 7). 
Table 7. Published clinical trials on effects of pistachio consumption on measures of adiposity and blood lipids.

\begin{tabular}{|c|c|c|c|c|c|c|c|}
\hline Study & Characteristics of subjects & $\begin{array}{l}\text { Number and } \\
\text { age of } \\
\text { subjects }\end{array}$ & Study type & Intervention & Duration & $\begin{array}{l}\text { Outcome } \\
\text { measure }\end{array}$ & Study results \\
\hline $\begin{array}{l}\text { Sheridan, } \\
\text { Cooper, } \\
\text { Erario, \& } \\
\text { Cheifetz, } \\
2007\end{array}$ & $\begin{array}{l}\text { Primary, moderate } \\
\text { hypercholesterolemia } \\
\text { Mean TC } 246 \pm 6 \mathrm{mg} / \mathrm{dL} \\
\text { Mean BMI } 28 \pm 0.9 \mathrm{~kg} / \mathrm{m}^{2}\end{array}$ & $\begin{array}{l}15 ; 11 \text { men } \\
\text { and } 4 \text { women, } \\
\text { average age } \\
60 \pm 3 \text { years } \\
\text { (range } 36 \text { to } \\
75 \text { years) }\end{array}$ & $\begin{array}{l}\text { Randomized } \\
\text { crossover } \\
\text { trial w/ } \\
\text { dietary } \\
\text { counseling }\end{array}$ & $\begin{array}{l}15 \% \text { daily caloric } \\
\text { intake from } \\
\text { pistachios } \\
\text { substituted for fat } \\
\text { calories or high } \\
\text { fat snacks }\end{array}$ & 4 weeks & $\begin{array}{l}\text { Blood lipids } \\
\text { BMI }\end{array}$ & $\begin{array}{l}\text { Decreased TC/HDL-C }(p<0.001), \text { LDL- } \\
\mathrm{C} / \mathrm{HDL}-\mathrm{C}(\mathrm{p}=0.004) \text { between diets } \\
\text { Increased HDL-C }(\mathrm{p}=0.02) \text { between diets } \\
\text { Decrease in LDL-C }(\mathrm{p}=0.04) \text { and LDL- } \\
\mathrm{C} / \mathrm{HDL}-\mathrm{C}(\mathrm{p}=0.009) \text { from baseline } \\
\text { Nonsignificant reductions for TC, TAG, } \\
\text { LDL-C between diets } \\
\text { Nonsignificant changes in BMI between or } \\
\text { within diets }\end{array}$ \\
\hline $\begin{array}{l}\text { Kocygit, } \\
\text { Koylu, \& } \\
\text { Keles, } 2006\end{array}$ & $\begin{array}{l}\text { Healthy men and women } \\
\text { Mean TC } 159 \mathrm{mg} / \mathrm{dL} \\
\text { Mean body weight } 64 \mathrm{~kg} \\
\text { (range } 55-87 \mathrm{~kg} \text { ) }\end{array}$ & $\begin{array}{l}44 ; \text { control } \\
\text { group, } \mathrm{n}=22, \\
33 \pm 6.7 \\
\text { years; } \\
\text { pistachio } \\
\text { group, } \mathrm{n}=22, \\
33 \pm 7.2 \text { years }\end{array}$ & $\begin{array}{l}\text { Randomized } \\
\text { control trial } \\
\text { w/ dietary } \\
\text { counseling }\end{array}$ & $\begin{array}{l}20 \% \text { daily caloric } \\
\text { intake from } \\
\text { pistachios }(65-75 \\
\text { g/day) substituted } \\
\text { for fatty foods and } \\
\text { visible fats }\end{array}$ & 3 weeks & $\begin{array}{l}\text { Blood lipids } \\
\text { BMI }\end{array}$ & $\begin{array}{l}\text { Decreased TC }(p<0.05), T C / H D L-C \\
(p<0.001), \text { LDL-C/HDL-C }(p<0.005) \\
\text { Increased HDL-C }(p<0.001) \\
\text { Nonsignificant decreases in LDL-C and } \\
\text { TAG } \\
\text { Nonsignificant change in BMI }\end{array}$ \\
\hline $\begin{array}{l}\text { Edwards, } \\
\text { Kwaw, } \\
\text { Matud, \& } \\
\text { Kurtz, } 1999\end{array}$ & $\begin{array}{l}\text { Primary, moderate } \\
\text { hypercholesterolemia } \\
\text { Median TC } 243 \mathrm{mg} / \mathrm{dL} \\
\text { (range } 214-336 \mathrm{mg} / \mathrm{dL} \text { ) } \\
\text { Median weight } 64 \mathrm{~kg} \text { (range } \\
55-102 \mathrm{~kg} \text { ) }\end{array}$ & $\begin{array}{l}10 ; 4 \text { men } \\
\text { (range } 41 \text { to } \\
53 \text { years) and } \\
6 \text { women } \\
\text { (range } 28 \text { to } \\
64 \text { years) }\end{array}$ & $\begin{array}{l}\text { Randomized } \\
\text { crossover } \\
\text { trial w/ } \\
\text { dietary } \\
\text { counseling }\end{array}$ & $\begin{array}{l}20 \% \text { daily caloric } \\
\text { intake from } \\
\text { pistachios } \\
\text { substituted for fat } \\
\text { calories or high } \\
\text { fat snacks }\end{array}$ & 3 weeks & $\begin{array}{l}\text { Blood lipids } \\
\text { Body weight }\end{array}$ & $\begin{array}{l}\text { Decreased TC }(p<0.04), T C / H D L-C \\
(p<0.01), \text { LDL-C/HDL-C }(p<0.02) \\
\text { Increased HDL-C }(p<0.09) \\
\text { Nonsignificant decreases in TAG and LDL- } \\
\text { C } \\
\text { Nonsignificant change in body weight }\end{array}$ \\
\hline $\begin{array}{l}\text { Gebauer, } \\
\text { West, Kay, } \\
\text { Alaupovic, } \\
\text { Bagshaw, } \\
\text { \& Kris- } \\
\text { Etherton, } \\
2008\end{array}$ & $\begin{array}{l}\text { Elevated LDL-C } \\
\text { Mean LDL-C } 137 \mathrm{mg} / \mathrm{dL} \\
\text { (range } 90-191 \mathrm{mg} / \mathrm{dL} \text { ) } \\
\text { Mean BMI } 26.8 \pm 0.7 \mathrm{~kg} / \mathrm{m}^{2}\end{array}$ & $\begin{array}{l}28 ; 10 \text { men } \\
\text { and } 18 \\
\text { women, } \\
\text { average age } \\
48 \pm 1.5 \text { years }\end{array}$ & $\begin{array}{l}\text { Randomized } \\
\text { crossover } \\
\text { controlled } \\
\text { feeding trial }\end{array}$ & $\begin{array}{l}3 \text { isoenergetic } \\
\text { diets: } \\
\text { Control diet - } \\
\text { Step I diet with no } \\
\text { pistachios } \\
\text { Pistachios as } 10 \%\end{array}$ & 4 weeks & $\begin{array}{l}\text { Blood lipids } \\
\text { Body weight }\end{array}$ & $\begin{array}{l}\text { Decreased TC and LDL-C with both the } \\
10 \% \text { and } 20 \% \text { energy diets }(\mathrm{p}<0.001) \\
\text { Decreased TAG }(\mathrm{p}<0.01), \mathrm{TC} / \mathrm{HDL}-\mathrm{C} \\
(\mathrm{p}<0.001) \text {, and LDL-C/HDL-C }(\mathrm{p}<0.001) \\
\text { with } 20 \% \text { energy diets } \\
\text { Differences between } 10 \% \text { and } 20 \% \text { energy } \\
\text { diets for TC/HDL-C and LDL-C/HDL-C }\end{array}$ \\
\hline
\end{tabular}




\begin{tabular}{|c|c|c|c|c|c|c|c|}
\hline & & & & $\begin{array}{l}\text { of total energy } \\
\text { (range } 32 \text { to } 63 \\
\text { g/d) } \\
\text { Pistachios as } 20 \% \\
\text { of total energy } \\
\text { (range } 63 \text { to } 126 \\
\mathrm{~g} / \mathrm{d} \text { ) }\end{array}$ & & & $\begin{array}{l}(\mathrm{p}<0.05) \text { indicating a dose-dependent effect } \\
\text { Nonsignificant differences in HDL-C or } \\
\text { body weight }\end{array}$ \\
\hline $\begin{array}{l}\text { Sari et al., } \\
2010\end{array}$ & $\begin{array}{l}\text { Healthy young men } \\
\text { Mean TC } 200 \pm 41.8 \mathrm{mg} / \mathrm{dL} \\
\text { Mean body weight } 69.3 \pm \\
4.9 \mathrm{~kg}\end{array}$ & $\begin{array}{l}32 ; \text { average } \\
\text { age } 22 \text { years } \\
\text { (range } 21 \text { to } \\
24 \text { years) }\end{array}$ & $\begin{array}{l}\text { Randomized } \\
\text { control trial }\end{array}$ & $\begin{array}{l}\text { Mediterranean- } \\
\text { type diet for } 4 \\
\text { weeks, then } 20 \% \\
\text { daily caloric } \\
\text { intake ( } 60 \text { to } \\
100 \mathrm{~g} \text { ) from } \\
\text { pistachios added } \\
\text { to replace MUFA } \\
\text { content for } \\
\text { another } 4 \text { weeks }\end{array}$ & 4 weeks & $\begin{array}{l}\text { Blood lipids } \\
\text { Body weight }\end{array}$ & $\begin{array}{l}\text { Decreased LDL-C }(\mathrm{p}<0.001), \text { TC } \\
(\mathrm{p}<0.001), \text { TAG }(\mathrm{p}=0.008), \text { TC/HDL-C } \\
(\mathrm{p}<0.001), \text { and LDL-C } / \text { HDL-C }(\mathrm{p}<0.001) \\
\text { Nonsignificant change in HDL-C }(\mathrm{p}=0.069) \\
\text { Nonsignificant changes in body weight }\end{array}$ \\
\hline $\begin{array}{l}\text { Li et al., } \\
2010\end{array}$ & $\begin{array}{l}\text { Overweight or obese adults } \\
\text { Mean TC: } \\
\text { Pistachio }-197 \pm 5.6 \mathrm{mg} / \mathrm{dL} \\
\text { Pretzel }-205 \pm 8.4 \mathrm{mg} / \mathrm{dL} \\
\text { Mean BMI range } 27 \text { to } 35 \\
\mathrm{~kg} / \mathrm{m}^{2}\end{array}$ & $\begin{array}{l}52 ; \text { (range } 20 \\
\text { to } 65 \text { years) }\end{array}$ & $\begin{array}{l}\text { Randomized } \\
\text { control trial }\end{array}$ & $\begin{array}{l}\text { Meal plans of } \\
1200,1400, \text { or } \\
1600 \mathrm{kcal} \text { based } \\
\text { on } 500 \mathrm{kcal} \text { per } \\
\text { day less than } \\
\text { resting metabolic } \\
\text { rate with } \\
\text { isocaloric daily } \\
\text { snack of either } \\
53 \mathrm{~g} \text { pistachios or } \\
56 \mathrm{~g} \text { pretzels }\end{array}$ & 12 weeks & $\begin{array}{l}\text { Blood lipids } \\
\text { BMI } \\
\text { Body weight }\end{array}$ & $\begin{array}{l}\text { Decreased TAG }(\mathrm{p}<0.05) \text { at } 6 \text { and } 12 \text { weeks } \\
\text { Decreased body weight in both groups from } \\
\text { baseline }(\mathrm{p}<0.01) \\
\text { Decreased BMI in both groups from } \\
\text { baseline }(\mathrm{p}<0.05) \\
\text { Decreased BMI in pistachio versus pretzel } \\
\text { group every } 2 \text { weeks except for week } 10 \\
(\mathrm{p}=0.08) \\
\text { Nonsignificant changes in TC, LDL-C, and } \\
\text { HDL-C } \\
\text { Nonsignificant decrease in body weight in } \\
\text { pistachio versus pretzel group }(\mathrm{p}=0.09)\end{array}$ \\
\hline $\begin{array}{l}\text { Baer, } \\
\text { Gebauer, \& } \\
\text { Novotny, } \\
2012\end{array}$ & $\begin{array}{l}\text { Healthy adults } \\
\text { Mean LDL-C } 115 \mathrm{mg} / \mathrm{dL} \\
\text { (range } 80 \text { to } 183 \mathrm{mg} / \mathrm{dL} \text { ) } \\
\text { Mean BMI } 27.9 \mathrm{~kg} / \mathrm{m}^{2}\end{array}$ & $\begin{array}{l}16 ; 8 \text { men } \\
\text { and } 8 \text { women, } \\
\text { average age } \\
50 \text { years } \\
\text { (range } 29 \text { to } \\
64 \text { years) }\end{array}$ & $\begin{array}{l}\text { Randomized } \\
\text { crossover } \\
\text { controlled } \\
\text { feeding trial }\end{array}$ & $\begin{array}{l}3 \text { isocaloric diets: } \\
0 \mathrm{~g} / \text { day control } \\
\text { diet } \\
42 \mathrm{~g} / \text { day pistachio } \\
\text { diet } \\
84 \mathrm{~g} / \text { day pistachio }\end{array}$ & 3 weeks & Blood lipids & $\begin{array}{l}\text { Decreased LDL-C after } 42 \mathrm{~g} / \text { day diet } \\
(\mathrm{p}=0.04) \text {, no additional reduction after } 84 \\
\mathrm{~g} / \text { day diet } \\
\text { Nonsignificant changes in TC, HDL-C, and } \\
\text { TAG }\end{array}$ \\
\hline
\end{tabular}




\begin{tabular}{|c|c|c|c|c|c|c|c|}
\hline & $\left(\right.$ range 20.8 to $\left.34.5 \mathrm{~kg} / \mathrm{m}^{2}\right)$ & & & diet & & & \\
\hline $\begin{array}{l}\text { Aldemir, } \\
\text { Okulu, } \\
\text { Neselioglu, } \\
\text { Erel, \& } \\
\text { Kayigil, } \\
2011\end{array}$ & $\begin{array}{l}\text { Men with erectile } \\
\text { dysfunction } \\
\text { Mean TC } 179.5 \pm 53.2 \\
\mathrm{mg} / \mathrm{dL} \\
\mathrm{Mean} \text { BMI } 27.33 \pm 2.88 \\
\mathrm{~kg} / \mathrm{m}^{2}\end{array}$ & $\begin{array}{l}17 ; \text { average } \\
\text { age } 47.9 \pm \\
6.2 \text { years } \\
\text { (range } 38-59 \\
\text { years) }\end{array}$ & $\begin{array}{l}\text { Prospective } \\
\text { study }\end{array}$ & $\begin{array}{l}20 \% \text { daily caloric } \\
\text { intake from } \\
\text { pistachios }(100 \mathrm{~g} \\
\text { or } 570 \mathrm{kcal}) \text { every } \\
\text { day at lunch }\end{array}$ & 3 weeks & $\begin{array}{l}\text { Blood lipids } \\
\text { BMI }\end{array}$ & $\begin{array}{l}\text { Decreased TC }(p=0.008), \text { LDL-C } \\
(p=0.007), T C / H D L-C(p=0.001), \text { LDL- } \\
C / H D L-C(p=0.001) \text {, and TAG/HDL-C } \\
(p=0.013) \\
\text { Increased HDL-C }(p=0.001) \\
\text { Nonsignificant decrease in TAG }(p=0.288) \\
\text { Nonsignificant changes in BMI }\end{array}$ \\
\hline $\begin{array}{l}\text { Gulati, } \\
\text { Misra, } \\
\text { Randey, } \\
\text { Bhatt, \& } \\
\text { Saluja, } \\
2013\end{array}$ & $\begin{array}{l}\text { Asian Indians with MetS } \\
\text { Mean TC } 192.5 \pm 35.1 \\
\mathrm{mg} / \mathrm{dL} \\
\text { Mean body weight } 80.9 \pm \\
11.6 \mathrm{~kg} \\
\text { Mean BMI } 30.9 \pm 75 \mathrm{~kg} / \mathrm{m}^{2} \\
\text { Mean WC } 104.86 \pm 8.4 \mathrm{~cm}\end{array}$ & $\begin{array}{l}68 ; 37 \text { men } \\
\text { and } 31 \\
\text { women, } \\
\text { average age } \\
42.5 \pm 8.2 \\
\text { years }\end{array}$ & $\begin{array}{l}\text { Randomized } \\
\text { controlled } \\
\text { parallel } \\
\text { study }\end{array}$ & $\begin{array}{l}20 \% \text { daily caloric } \\
\text { intake from } \\
\text { pistachios } \\
\text { substituted for } \\
\text { visible fat, a } \\
\text { portion of } \\
\text { carbohydrates, } \\
\text { and dairy }\end{array}$ & 24 weeks & $\begin{array}{l}\text { Blood lipids } \\
\text { Body weight } \\
\text { WC } \\
\text { SCAT } \\
\text { IAAT }\end{array}$ & $\begin{array}{l}\text { Decreased WC }(p=0.02) \\
\text { Decreased TC }(p=0.02) \text { and LDL-C } \\
(p<0.006) \\
\text { Nonsignificant decrease in SCAT }(p=0.07) \\
\text { Nonsignificant decrease in IAAT }(p=0.7) \\
\text { Nonsignificant change in weight }(p=0.7) \\
\text { Nonsignificant increase in HDL-C }(p=0.9) \\
\text { Nonsignificant decrease in TAG }(p=0.5)\end{array}$ \\
\hline $\begin{array}{l}\text { Wang, Li, } \\
\text { Liu, Lv, \& } \\
\text { Yang, } 2012\end{array}$ & $\begin{array}{l}\text { Chinese subjects with MetS } \\
\text { Mean TC: } \\
\text { RSG }-204.6 \pm 39.1 \mathrm{mg} / \mathrm{dL} \\
\mathrm{HSG}-204.6 \pm 36.0 \mathrm{mg} / \mathrm{dL} \\
\mathrm{DCG}-193.7 \pm 38.3 \mathrm{mg} / \mathrm{dL} \\
\text { Mean BMI: } \\
\text { RSG }-28.12 \pm 3.22 \mathrm{~kg} / \mathrm{m}^{2} \\
\text { HSG }-28.01 \pm 4.51 \mathrm{~kg} / \mathrm{m}^{2} \\
\text { DCG }-28.03 \pm 4.35 \mathrm{~kg} / \mathrm{m}^{2}\end{array}$ & $\begin{array}{l}90 ; 41 \text { men } \\
\text { and } 49 \\
\text { women, } \\
\text { average age: } \\
\text { RSG }-51.89 \\
\pm 8.82 \text { years } \\
\text { HSG }-51.83 \\
\pm 9.37 \text { years } \\
\text { DCG }-50.66 \\
\pm 9.86 \text { years }\end{array}$ & $\begin{array}{l}\text { Randomized } \\
\text { control trial }\end{array}$ & $\begin{array}{l}\text { RSG - } 42 \text { g/day } \\
\text { pistachios } \\
\text { HSG - } 70 \mathrm{~g} / \text { day } \\
\text { pistachios } \\
\text { DCG - no } \\
\text { pistachios } \\
\text { All participants } \\
\text { counseled on } \\
\text { AHA Step } 1 \text { diet }\end{array}$ & 12 weeks & $\begin{array}{l}\text { Blood lipids } \\
\text { Body weight } \\
\text { BMI } \\
\text { Waist-to-hip } \\
\text { ratio }\end{array}$ & $\begin{array}{l}\text { Decreased TAG in } 42 \mathrm{~g} / \text { day group } \\
(\mathrm{p}=0.018) \\
\text { Increased LDL-C in } 70 \mathrm{~g} \text { /day group } \\
(\mathrm{p}=0.003 \text { ) and the control group ( } \mathrm{p}=0.037) \\
\text { Nonsignificant change in LDL-C in } 42 \\
\mathrm{~g} / \text { day group } \\
\text { Nonsignificant decrease in TAG in } 70 \mathrm{~g} \text { /day } \\
\text { group } \\
\text { Nonsignificant changes in TC in any diet } \\
\text { group } \\
\text { Nonsignificant changes in HDL-C in any } \\
\text { diet group } \\
\text { Nonsignificant changes in body weight } \\
\text { Nonsignificant changes in BMI } \\
\text { Nonsignificant changes in waist-to-hip ratio }\end{array}$ \\
\hline
\end{tabular}


The amount of pistachios consumed in these studies ranged from $42 \mathrm{~g}$ to $100 \mathrm{~g}$, or $10 \%$ to $20 \%$ of energy intake. Researchers found that none of the measures of adiposity increased significantly following a diet supplemented with pistachios, and two studies showed significant reductions among these variables (Gulati et al., 2014; Li et al., 2010).

The randomized control trial by Gulati et al. (2014) involved the longest intervention period of any previous experiment with pistachios. In a 24-week free-living randomized control trial, 60 Asian Indians with MetS were designated to consume either a control diet based on dietary guidelines for Asian Indians containing 60\% carbohydrates, $15 \%$ protein, and $25 \%$ fat or a diet supplemented with pistachios as $20 \%$ of total energy making the ratio of carbohydrates, protein, and fat $51 \%, 20 \%$, and $29 \%$, respectively. Both groups were advised to consume a diet rich in vegetables and fruits; whole-grain, high-fiber foods; choose white meats over red meats; choose low-fat or fatfree dairy products; and limit consumption of hydrogenated oils, soft drinks, food with added sugar, salty foods and alcohol. The pistachio group was educated on how to incorporate pistachios into their diet by replacing visible fat, some carbohydrates, and dairy. Physical activity was to remain stable throughout the study.

Results showed that there was no significant change in body weight or IAAT between groups at the end of the intervention. However, WC decreased significantly in the intervention group versus the control group and there was a trend toward reduction in SCAT (Gulati et al., 2014).

After the 24-week intervention, the average weight of the intervention group (adjusted for sex and baseline values) compared to the control group was $79.1 \pm 2.1 \mathrm{~kg}$ versus $78.9 \pm 2.1 \mathrm{~kg}$, respectively, and the average IAAT was $107.1 \pm 16.3 \mathrm{~cm}^{2}$ versus 
$114.3 \pm 114.3 \mathrm{~cm}^{2}$, respectively. The difference between intervention group and control group at a $95 \%$ confidence interval was $-0.21(-1.2$ to 0.82$)$ for weight in $\mathrm{kg}(\mathrm{p}=0.7)$ and $7.2(-32.9$ to 47.4$)$ for IAAT in $\mathrm{cm}^{2}(\mathrm{p}=0.7)$. Additionally, the mean $\mathrm{WC}$ of the intervention group was $100.9 \pm 2.6 \mathrm{~cm}$ versus $102.5 \pm 2.6 \mathrm{~cm}$ in the control group, a difference of $1.5(0.3$ to 2.8$) \mathrm{cm}(\mathrm{p}<0.03)$. The mean SCAT for the intervention group was $168.7 \pm 27.2 \mathrm{~cm}^{2}$ versus $180.4 \pm 27.2 \mathrm{~cm}^{2}$ in the control group, a difference of 11.8 (1.4 to 24.9$) \mathrm{cm}^{2}$ ( $\left.\mathrm{p}<0.07\right)$ (Gulati et al., 2014). This study showed that incorporating pistachios into a healthy diet was not associated with weight gain or increased central adiposity and may be associated with reduced WC and SCAT in Asian Indians with MetS.

A second randomized control trial by Li et al. (2010) also showed significant reductions in measures of adiposity. Fifty-nine overweight or obese free-living participants between the ages of 20 and 65 years with BMI between 27 and $35 \mathrm{~kg} / \mathrm{m}^{2}$ were randomly assigned to consume isocaloric weight reduction diets. The diets consisted of 1200,1400 , or $1600 \mathrm{kcal}$, which equated to $500 \mathrm{kcals}$ per day less than resting metabolic rate. Roughly half of the participants consumed $53 \mathrm{~g}(240 \mathrm{kcal})$ of salted pistachios for a snack each day while the other half consumed $56 \mathrm{~g}(220 \mathrm{kcal})$ of salted pretzels each day. Pistachios replaced carbohydrates in the pistachio group so the groups consumed diets that were isocaloric but had different macronutrient compositions (the pretzel group was approximately $20 \%$ fat, $15 \%$ protein, and $65 \%$ carbohydrate; and the pistachio group was approximately $30 \%$ fat, $15 \%$ protein, and $55 \%$ carbohydrate). Participants filled out food records and met with a dietitian every 2 weeks for compliance but made all of their own meals. 
Participants in both groups lost a significant amount of weight compared to baseline after the 12-week study (reduced from $86.0 \pm 1.4$ to $82.3 \pm 1.6 \mathrm{~kg}, \mathrm{p}<0.01$ in the pistachio group and from $85.5 \pm 2.2$ to $82.8 \pm 2.5 \mathrm{~kg}, \mathrm{p}<0.01$ in the pretzel group). There was a non-statistically significant trend for the pistachio group to lose more weight than the pretzel group $(\mathrm{p}=0.09)$. At the end of 12 weeks, while both groups experienced significant reductions in BMI $\left(30.1 \pm 0.4\right.$ at baseline to $28.8 \pm 0.4 \mathrm{~kg} / \mathrm{m}^{2}$ in the pistachio group, $\mathrm{p}<0.05$ versus $30.9 \pm 0.4$ to $30.3 \pm 0.5 \mathrm{~kg} / \mathrm{m}^{2}$ in the pretzel group, $\mathrm{p}<0.05$ ), the pistachio group had a significantly greater reduction in BMI (4.3\%) compared to the pretzel group ( $2 \%$ ) except during week 10 when $\mathrm{p}=0.08$ (Li et al., 2010). When compared to a refined carbohydrate snack, an isocaloric quantity of pistachios as part of a weight reduction diet helped lower BMI in overweight or obese participants.

A third randomized control trial by Wang et al. (2012) investigated the effects of pistachio consumption on measures of adiposity in Chinese participants with MetS. Participants, who ranged from 25 to 65 years old, were educated on how to follow the American Heart Association Step 1 diet (a diet low in fat and cholesterol designed to lower CVD risk) and told not to consume any tree nuts. Participants were randomly assigned to either a recommended serving pistachio group (RSG) that consumed $42 \mathrm{~g}$ of pistachios daily, a high serving pistachio group (HSG) that consumed $70 \mathrm{~g}$ of pistachios daily, or a diet control group (DCG) that did not consume any pistachios. Pistachios were to be consumed as an afternoon snack and participants were instructed to continue their usual activity patterns during the study period. Results showed no significant changes in body weight (no data were provided for starting or ending weights), BMI $\left(28.03 \pm 4.35,28.12 \pm 3.22\right.$, and $28.01 \pm 4.51 \mathrm{~kg} / \mathrm{m}^{2}$ at baseline for the DCG, RSG, and 
HSG groups, respectively; no data for ending values were provided) or waist-to-hip ratio (change of $0.01 \pm 0.02,0.01 \pm 0.04$, and $0.0 \pm 0.03$ for RSG, HSG, and DCG, respectively from baseline to week 12) over the course of a 12-week treatment period. In this study, pistachio supplementation was not associated with any changes in measures of adiposity in participants with MetS when incorporated into a healthy diet.

Four additional studies (two randomized crossover trials [Gebauer et al., 2008; Sheridan et al., 2007], one randomized control trial [Kocygit et al., 2006)], and one prospective study [Aldemir et al., 2011]) showed no significant changes in BMI following pistachio supplementation.

Sheridan et al. (2007) investigated the effects of substituting $15 \%$ daily caloric intake worth of pistachios in place of fat or high fat snacks in a population of 15 men and women with primary, moderate hypercholesterolemia. The intervention phase lasted 4 weeks, and participants received pre-measured bags of pistachios matching their individual energy needs. Because this was a crossover study, participants served as their own controls. While on the control diet, participants consumed their normal, regular diets. One-day food records each week were used to measure compliance. Results showed that the BMI of participants following the conclusion of the pistachio diet $(27.8 \pm$ $\left..81 \mathrm{~kg} / \mathrm{m}^{2}\right)$ and regular diet $\left(27.7 \pm 0.82 \mathrm{~kg} / \mathrm{m}^{2}\right)$ did not differ significantly from baseline $\left(27.7 \pm 0.90 \mathrm{~kg} / \mathrm{m}^{2}\right)$. The difference in BMI between the pistachio group and baseline was $0.18(-0.26$ to 0.62$) \mathrm{kg} / \mathrm{m}^{2}(\mathrm{p}=0.39)$. There was also no significant difference in BMI between the pistachio group and the regular group during the study ( 0.14 [-0.17 to 0.45$]$ $\mathrm{kg} / \mathrm{m}^{2}, \mathrm{p}=0.35$ ). Overall, pistachio consumption had no effects on BMI in men and women with primary, moderate hypercholesterolemia. 
The randomized control trial by Kocygit et al. (2006) utilized 60 doctors and nurses at the Research Hospital, University of Harran, Sanliurfa, Turkey. Participants were randomized into a pistachio treatment group (that consumed 20\% [65 to $75 \mathrm{~g} /$ day] of their daily caloric intake from pistachios substituted for fatty foods and visible fats), and a regular diet group. After a 1-week pre-experimental period (during which participants consumed their regular diet excluding any nuts, nut butters, or nut oils) the participants began a 3-week experimental period. Participants in the regular diet group were to continue to exclude any nut-based products and participants in the pistachio group were encouraged to eat their nuts after dinner each day. Physical activity was to remain constant throughout the study. Each participant was provided a digital scale and education from a Registered Dietitian on how to complete food records, which were reviewed weekly. Results showed that changes in BMI during the study were not significant. The pistachio group had an average BMI of $24.2 \pm 6.1 \mathrm{~kg} / \mathrm{m}^{2}$ at baseline and $24.3 \pm 5.8 \mathrm{~kg} / \mathrm{m}^{2}$ at the end of the study with a difference of $1.1 \pm 0.2 \mathrm{~kg} / \mathrm{m}^{2}(\mathrm{p}>0.05)$. The regular diet group had an initial average BMI of $24.6 \pm 5.6 \mathrm{~kg} / \mathrm{m}^{2}$ and $24.5 \pm 5.4$ $\mathrm{kg} / \mathrm{m}^{2}$ at the end of the study with a difference of $0.9 \pm 0.02 \mathrm{~kg} / \mathrm{m}^{2}(\mathrm{p}>0.05)$. Pistachio supplementation in this healthy population was not associated with any change in BMI.

Similarly, Aldemir et al. (2011) investigated the effects of pistachio consumption on BMI in 17 married men who had experienced erectile dysfunction for at least 12 months. This prospective study provided all participants with $20 \%$ (100 g, 570 kcals) of their daily caloric intake from pistachios for 3 weeks, which were to be consumed during lunchtime. Participants were instructed to maintain normal patterns of physical activity and maintain their normal diets throughout the study. The average baseline BMI of 
participants was $27.33 \pm 2.88 \mathrm{~kg} / \mathrm{m}^{2}$ and did not change significantly after the pistachio intervention (no data for ending values were provided). Pistachio supplementation in men with erectile dysfunction was not associated with any significant changes in BMI.

Gebauer et al. (2008) studied the effects of the consumption of two different quantities of pistachios on body weight in 28 men and women with elevated LDL-C. In this randomized crossover controlled feeding trial, subjects were randomly assigned to three treatment diets for 4 weeks each, which were separated by 2 -week intervals. Each feeding period had isocaloric diets at an average of $2500 \mathrm{kcal} /$ day to maintain the weight of the participants. The control diet followed the American Heart Association's Step I diet, which contained low-fat or nonfat versions of typical American foods as well as fruits, vegetables, lean meats, and whole grains. The pistachio diets contained either $10 \%$ (32 g to $63 \mathrm{~g} /$ day) or $20 \%$ (63 g to $126 \mathrm{~g} /$ day) kcals from pistachios based on daily energy needs. While the pistachio diets were higher in protein and unsaturated fats and lower in carbohydrate and sodium than the control diet, all diets contained equal amounts of SFA and cholesterol. All of the participants' meals and snacks were made for them at the Metabolic Diet Study Center at the Pennsylvania State University. Participants ate one meal per day at the Metabolic Diet Study Center Monday through Friday, and picked up the remainder of their pre-packaged meals for the rest of the week. Daily questionnaires were used to ensure compliance.

Results showed no significant difference in average body weight before versus after treatment $(76.6 \pm 2.5 \mathrm{~kg}$ and $76.1 \pm 2.5 \mathrm{~kg}$, respectively; $\mathrm{p}>0.05)$ or average BMI before versus after treatment $(26.7 \pm 0.7 \mathrm{~kg}$ and $26.6 \pm 0.7 \mathrm{~kg}$, respectively; $\mathrm{p}>0.05)$. There were also no significant differences in body weight or BMI when comparing the 
control diet and pistachio diets ( $\mathrm{p}>0.05$; no other data were provided). In this study pistachio supplementation was not associated with weight gain or changes in BMI among adults with elevated LDL-C.

While body weight is not an accurate indicator of body composition, two additional studies showed non-significant changes in body weight following pistachio supplementation (Edwards et al., 1999; Sari et al., 2010).

Edwards et al. (1999) studied the effects of a diet supplemented with $20 \%$ daily caloric intake from pistachios (substituted for fat calories or high fat snacks) on a population of 10 men and women with primary, moderate hypercholesterolemia. This randomized crossover trial included a 3-week treatment period with no lag time between the control and treatment periods. Throughout the study participants were encouraged to consume their normal diets, but to substitute pistachios for high fat foods when following the treatment diet. Each week subjects kept one-day food records to ensure compliance and met with a dietitian weekly for education on substitutions. Results showed that there were no significant changes in body weight during the study (no data were provided). Pistachio consumption was not associated with weight gain in participants with primary, moderate hypercholesterolemia.

Likewise, Sari et al. (2010) examined the effects of pistachio consumption on body weight in 32 healthy young men ages 21 to 24 at a vocational police education school in Turkey where students lived and ate in a controlled environment. This randomized control trial began with a 4-week phase where participants consumed a Mediterranean-type diet, which emphasized vegetables and fish and limited red meat, egg products, and products with high amounts of fat. Following this period, participants 
maintained the Mediterranean-type diet but replaced MUFA content with 20\% daily energy needs from pistachios. The two diets were isocaloric and equal in proportion of protein and carbohydrate but the pistachio diet contributed lower SFA and PUFA content plus higher MUFA and fiber content than the control diet. A Registered Dietitian oversaw meal periods to ensure compliance, and collected and weighed leftover food for review by the researchers.

Results showed that there were no significant differences in body weight throughout the study $(\mathrm{p}>0.1)$. Average body weight at baseline was $69.3 \pm 4.9 \mathrm{~kg}$. Following the Mediterranean diet the average body weight of the participants was $69.7 \pm$ $5.0 \mathrm{~kg}$ and following the pistachio diet was $69.5 \pm 5.1 \mathrm{~kg}$. When pistachios were added into a Mediterranean diet pattern no significant changes in body weight were observed.

While Gulati et al. (2014) found significant reductions in WC and SCAT and Li et al. (2010) found significant reduction in body weight and BMI following pistachio consumption, the majority the of studies reviewed above found no significant changes in measures of adiposity in response to dietary pistachio supplementation.

Of the nine studies that examined the effects of pistachio consumption on measures of adiposity, only two studies focused on healthy populations (Kocygit et al., 2006; Sari et al., 2010). Thus, there has been limited research to date that examines the effects of a pistachio-supplemented diet on measures of adiposity in healthy populations with normal body weights. The intervention periods of the two studies that tested healthy populations lasted only 3 and 4 weeks and included only 32 and 44 participants, respectively (Kocygit et al., 2006; Sari et al., 2010). Consequently, more studies with 
longer intervention periods and greater numbers of participants are needed to support these findings.

\section{Effects on Blood Lipids}

Research has shown that pistachio consumption has beneficial effects on the blood lipid profile (Table 7). Four randomized crossover trials (Baer et al., 2012; Edwards et al., 1999; Gebauer et al., 2008; Sheridan et al., 2007), five randomized controlled trials (Gulati et al., 2014; Kocygit et al., 2006; Li et al., 2010; Wang et al., 2012; Sari et al., 2010), and one prospective study (Aldemir et al., 2011), have all detected positive impacts of pistachio consumption on blood lipids. These studies have investigated both healthy and unhealthy populations including those with moderate hypercholesterolemia, elevated LDL-C, erectile dysfunction, MetS, and overweight or obesity. The amount of pistachios consumed during treatment periods has ranged from $42 \mathrm{~g}$ to $100 \mathrm{~g}$ and $10 \%$ to $20 \%$ of daily caloric intake. All ten studies evaluated four parameters of the lipid profile: LDL-C, HDL-C, TC, and TAG. Nine of these studies were reviewed in the previous section regarding their findings on measures of adiposity, therefore descriptions of their study methods can be found above.

Baer et al. (2012) conducted a randomized crossover controlled feeding trial to study the effects of pistachio consumption on blood lipids in healthy adult men and women. Participants were recruited from the Beltsville Human Nutrition Research Center in Maryland and were each fed two of three possible dose levels of pistachios for 18 days each. Each participant then repeated one of the two previously consumed dose levels for another 18 days based on random group assignments. Doses were either a 0 g/day control diet, a $42 \mathrm{~g} /$ day pistachio diet, or an $84 \mathrm{~g} /$ day pistachio diet. Participant diets were controlled, isocaloric, based on weight maintenance, and consisted of typical 
American foods in a 7-day cycle menu. Participants were required to eat only food provided to them by the Beltsville Human Nutrition Research Center, where they consumed breakfast and dinner with a dietitian present to ensure compliance. Lunch and weekend meals were provided for the participants to eat at home. The background diet consisted of a fat to fiber ratio similar to that of nuts so that it would be constant across treatment groups.

Results showed that pistachio supplementation had no significant effect on TC, HDL-C, or TAG (no data were provided); however, LDL-C levels were $6 \%$ lower after the $42 \mathrm{~g} /$ day $(123.9 \pm 2.2 \mathrm{mg} / \mathrm{dL})$ and $84 \mathrm{~g} /$ day $(123.4 \pm 2.1 \mathrm{mg} / \mathrm{dL})$ treatments compared to the control treatment $(131.3 \pm 2.2 \mathrm{mg} / \mathrm{dL})$, with no additional reduction between the 42 $\mathrm{g} /$ day and $84 \mathrm{~g} /$ day treatments (Baer et al., 2012). This study showed that pistachio consumption was associated with improved LDL-C levels in healthy participants but not in a dose-dependent manner.

The study by Edwards et al. (1999) found that after a 3-week intervention, a diet with $20 \%$ daily caloric intake from pistachios had positive impacts on blood lipids in participants with primary, moderate hypercholesterolemia. Following the pistachio intervention there were significant decreases in TC $(243 \mathrm{mg} / \mathrm{dL}$ at baseline versus 239 $\mathrm{mg} / \mathrm{dL}$ at the end of the study, $\mathrm{p}<0.04$ ), TC/HDL-C ( 4.8 at baseline versus 4.5 at the end of the study, $\mathrm{p}<0.01$ ), LDL-C/HDL-C (3.2 at baseline versus 3.1 at the end of the study, $\mathrm{p}<0.02)$; and a significant increase in HDL-C $(50 \mathrm{mg} / \mathrm{dL}$ at baseline versus $56 \mathrm{mg} / \mathrm{dL}$ at the end of the study, $\mathrm{p}<0.09$ ). Results also showed that LDL-C decreased from 180 $\mathrm{mg} / \mathrm{dL}$ at baseline to $158 \mathrm{mg} / \mathrm{dL}$ at the end of the study, and that TAG decreased from $113 \mathrm{mg} / \mathrm{dL}$ at baseline to $108 \mathrm{mg} / \mathrm{dL}$ at the end of the study; however, for both variables, 
there was too much variation to assign a significant p-value. While this study had a relatively short intervention period, significant changes in lipid values where still established among participants with primary, moderate hypercholesterolemia.

The randomized crossover controlled feeding trial by Gebauer et al. (2008) also investigated the effects of pistachio consumption on lipid values. Results showed that after 4 weeks, participants with elevated LDL-C on both treatment diets had significantly lower TC $(193.7 \pm 3.9 \mathrm{mg} / \mathrm{dL}$ for $10 \%$ the pistachio diet and $190.3 \pm 3.9 \mathrm{mg} / \mathrm{dL}$ for the $20 \%$ pistachio diet $)$ compared to the control diet $(209.6 \pm 3.9 \mathrm{mg} / \mathrm{dL})(\mathrm{p}<0.001)$ and significantly lower LDL-C $(119.1 \pm 3.9 \mathrm{mg} / \mathrm{dL}$ for the $10 \%$ pistachio diet and $115.2 \pm 3.9$ $\mathrm{mg} / \mathrm{dL}$ for the $20 \%$ pistachio diet $)$ compared to the control diet $(132.3 \pm 1.9 \mathrm{mg} / \mathrm{dL})$ $(\mathrm{p}<0.001)$. Additionally, TAG $(\mathrm{p}<0.01)$, TC/HDL-C $(\mathrm{p}<0.001)$, and LDL-C/HDL-C $(p<0.001)$ were significantly lower following the $20 \%$ pistachio diet $(106.3 \pm 8.9,3.5 \pm$ 0.19 , and $2.15 \pm 0.2 \mathrm{mg} / \mathrm{dL}$, respectively) compared to the control diet $(124.0 \pm 8.9,3.98$ \pm 0.19 , and $2.55 \pm 0.2 \mathrm{mg} / \mathrm{dL}$, respectively).

Total cholesterol/HDL-C and LDL-C/HDL-C were also significantly lower following the $20 \%$ pistachio diet $(3.5 \pm 0.19$ and $2.15 \pm 0.2 \mathrm{mg} / \mathrm{dL}$, respectively $)$ compared to the $10 \%$ pistachio diet $(3.78 \pm 0.19$ and $2.38 \pm 0.2 \mathrm{mg} / \mathrm{dL})(\mathrm{p}<0.5)$, indicating a dose-dependent effect. There were no significant differences in HDL-C between either of the two treatment diets $(1.43 \pm 0.1 \mathrm{mg} / \mathrm{dL}$ for the $10 \%$ pistachio diet and $1.48 \pm 0.1$ $\mathrm{mg} / \mathrm{dL}$ for the $20 \%$ pistachio diet $)$ compared to the control diet $(1.43 \pm 0.3 \mathrm{mg} / \mathrm{dL})$ $(\mathrm{p}>0.05)$. Pistachio consumption beneficially impacted lipid status in those with elevated LDL-C and had a dose-dependent effect on TC/HDL-C and LDL-C/HDL-C. 
In the randomized crossover trial by Sheridan et al. (2007) participants with primary, moderate hypercholesterolemia showed significant reductions in TC/HDL-C ( $4.4 \pm 0.26$ versus $4.8 \pm 0.31 \mathrm{mg} / \mathrm{dL}$; mean difference -0.38 [-0.57 to -0.19$] \mathrm{mg} / \mathrm{dL}$; $\mathrm{p}<0.001)$ and LDL-C/HDL-C $(2.8 \pm 0.25$ versus $3.2 \pm 0.26 \mathrm{mg} / \mathrm{dL}$; mean difference -0.40 [-0.66 to -0.15$] \mathrm{mg} / \mathrm{dL} ; \mathrm{p}=0.004)$ and a significant increase in HDL-C $(57 \pm 3.5 \mathrm{mg} / \mathrm{dL}$ versus $54 \pm 3.4 \mathrm{mg} / \mathrm{dL}$; mean difference $2.3[0.48$ to 4.0$] \mathrm{mg} / \mathrm{dL} ; \mathrm{p}=0.02$ ) following treatment with $15 \%$ daily caloric intake from pistachios compared to the control diet.

Results also showed nonsignificant reductions in TC ( $237 \pm 8.0$ versus $246 \pm 8.7$ $\mathrm{mg} / \mathrm{dL}$; mean difference -9.2 [-21 to 2.4$] \mathrm{mg} / \mathrm{dL} ; \mathrm{p}=0.11)$, TAG (131 \pm 11 versus $130 \pm$ $14 \mathrm{mg} / \mathrm{dL}$; mean difference 0.67 [-25 to 26$] \mathrm{mg} / \mathrm{dL} ; \mathrm{p}=0.96)$, and LDL-C (148 \pm 9.9 versus $163 \pm 9.3 \mathrm{mg} / \mathrm{dL}$; mean difference -15 [-31 to 0.94$] \mathrm{mg} / \mathrm{dL} ; \mathrm{p}=0.06$ ) following the pistachio treatment compared to the control diet. In only 4 weeks pistachio consumption improved TC/HDL-C, LDL-C/HDL-C, and HDL-C in patients with primary, moderate hypercholesterolemia despite nonsignificant changes in TC, TAG, and LDL-C.

The randomized control trial by Gulati et al. (2014) found that among adults with MetS, a 24 -week treatment consisting of $20 \%$ daily caloric intake from pistachios was associated with significant decreases in TC $(174.5 \pm 19$ versus $185.5 \pm 18.9 \mathrm{mg} / \mathrm{dL}$; mean difference 10.5 [1.3 to 19.7$] \mathrm{mg} / \mathrm{dL} ; \mathrm{p}=0.02)$ and LDL-C ( $98.8 \pm 13.2$ versus $107.7 \pm 13.2$ $\mathrm{mg} / \mathrm{dL}$; mean difference 8.9 [2.5 to 15.3$] \mathrm{mg} / \mathrm{dL} ; \mathrm{p}<0.006$ ), a nonsignificant increase in HDL-C ( $38.1 \pm 5.4$ versus $37.9 \pm 5.4 \mathrm{mg} / \mathrm{dL}$; mean difference $-0.15[2.8$ to 2.5$] \mathrm{mg} / \mathrm{dL}$; $\mathrm{p}=0.9)$, and a nonsignificant decrease in TAG $(153.5 \pm 36.5$ versus $159.7 \pm 36.5 \mathrm{mg} / \mathrm{dL}$; mean difference $6.1[-11.6$ to 23.8$] \mathrm{mg} / \mathrm{dL} ; \mathrm{p}=0.5$ ) in the intervention group compared to 
the control group. This relatively long intervention period yielded significant reductions in TC and LDL-C in patients with MetS.

The randomized control trial by Wang et al. (2012) found significant decreases in TAG in participants with MetS from baseline to 12 weeks in the $42 \mathrm{~g}$ /day pistachio group $(218.8 \pm 113.4$ versus $189.5 \pm 91.2 \mathrm{mg} / \mathrm{dL}$, respectively; mean difference $-33.7 \pm 70.0$ $\mathrm{mg} / \mathrm{dL} ; \mathrm{p}=0.018$ ), although the $70 \mathrm{~g} /$ day pistachio group did not show any significant changes in TAG from baseline to 12 weeks $(194.0 \pm 67.3$ versus $181.6 \pm 70.9 \mathrm{mg} / \mathrm{dL}$; mean difference $15.9 \pm 77.1 \mathrm{mg} / \mathrm{dL}$ ). Additionally, there were no significant differences from baseline to 12 weeks in TC within the $42 \mathrm{~g}$ /day diet group (204.6 \pm 39.1 versus $201.1 \pm 36.3 \mathrm{mg} / \mathrm{dL})$, the $70 \mathrm{~g} /$ day diet $(204.6 \pm 36.0$ versus $209.2 \pm 41.0 \mathrm{mg} / \mathrm{dL})$, or the control diet $(193.7 \pm 38.2$ versus $199.1 \pm 40.2 \mathrm{mg} / \mathrm{dL})$. Likewise, there were no significant changes in HDL-C with the $42 \mathrm{~g}$ /day diet, the $70 \mathrm{~g} /$ day diet, or control diet (data not shown); however, there was a significant increase in LDL-C from baseline to 12 weeks with both the $70 \mathrm{~g} /$ day diet $(116.0 \pm 27.1$ versus $127.6 \pm 30.2 \mathrm{mg} / \mathrm{dL}$; mean difference $12.0 \pm 19.7 \mathrm{mg} / \mathrm{dL} ; \mathrm{p}=0.003)$ and the control diet $(104.4 \pm 34.8$ versus $115.6 \pm$ $33.3 \mathrm{mg} / \mathrm{dL}$; mean difference $11.2 \pm 28.6 \mathrm{mg} / \mathrm{dL} ; \mathrm{p}=0.037)$, but not with the $42 \mathrm{~g} /$ day diet $(119.1 \pm 27.1$ versus $119.9 \pm 26.7 \mathrm{mg} / \mathrm{dL})$. Despite increased LDL-C in the $70 \mathrm{~g} /$ day diet group, TAG values decreased significantly in participants with MetS following pistachio consumption.

The randomized control trial by Kocygit et al. (2006) found that among healthy men and women, $20 \%$ daily caloric intake from pistachios was associated with significant decreases in TC $(139.6 \pm 23.2$ versus $157.8 \pm 26.7 \mathrm{mg} / \mathrm{dL}$; mean difference $-18.2 \pm 3.5$ $\mathrm{mg} / \mathrm{dL} ; \mathrm{p}<0.05), \mathrm{TC} / \mathrm{HDL}-\mathrm{C}(3.17 \pm 1.04$ versus $3.98 \pm 1.41 ;$ mean difference $-0.81 \pm$ 
$0.37 ; \mathrm{p}<0.001), \mathrm{LDL}-\mathrm{C} / \mathrm{HDL}-\mathrm{C}(1.58 \pm 0.47$ versus $1.82 \pm 0.51$; mean difference $-0.24 \pm$ $0.04 ; \mathrm{p}<0.005)$, and a significant increase in HDL-C $(49.5 \pm 10.4$ versus $39.1 \pm 10.8$ $\mathrm{mg} / \mathrm{dL}$; mean difference $10.4 \pm 0.39 \mathrm{mg} / \mathrm{dL} ; \mathrm{p}<0.005)$ from baseline to end of the pistachio treatment group. There were also nonsignificant decreases in LDL-C (73.1 \pm 16.6 versus $75.0 \pm 16.6 \mathrm{mg} / \mathrm{dL}$; mean difference $-1.9 \pm 0.39 \mathrm{mg} / \mathrm{dL})$ and $\mathrm{TAG}(94.8 \pm$ 41.6 versus $104.5 \pm 52.3 \mathrm{mg} / \mathrm{dL}$; mean difference $-9.74 \pm 1.8 \mathrm{mg} / \mathrm{dL}$ ) from baseline to end of the pistachio treatment period.

Significant differences were also found between the pistachio diet and the regular diet following the 3 -week diet periods for TC $(-10.4[-0.77$ to -19.7$] \mathrm{mg} / \mathrm{dL} ; \mathrm{p}<0.05)$, HDL-C (7.34 [10.4 to 4.25] mg/dL; $\mathrm{p}<0.001)$, TC/HDL-C (-1.07 [0.58 to -1.56$]$; $\mathrm{p}<0.001)$, and LDL-C/HDL-C (-0.29 [0.12 to -0.47$] ; \mathrm{p}<0.005)$. Nonsignificant differences between diets were found for LDL-C $(0.77[-5.41$ to -7.35$] \mathrm{mg} / \mathrm{dL})$ and TAG $(-24.8[0.89$ to -59.3$] \mathrm{mg} / \mathrm{dL})$. These results indicate that even in a healthy population, pistachio consumption may have the potential to improve the blood lipid profile.

Sari et al. (2010) also found positive impacts on blood lipids in healthy young men. Results showed significant decreases in LDL-C $(124.5 \pm 24.5$ versus $95.0 \pm 23.2$ $\mathrm{mg} / \mathrm{dL}$, respectively; $\mathrm{p}<0.001), \mathrm{TC}(190.7 \pm 30.1$ versus $149.4 \pm 26.5 \mathrm{mg} / \mathrm{dL}$, respectively; $\mathrm{p}<0.001)$, TAG $(112.1 \pm 45.5$ versus $91.1 \pm 38.1 \mathrm{mg} / \mathrm{dL}$, respectively; $\mathrm{p}=0.008), \mathrm{TC} / \mathrm{HDL}-\mathrm{C}(4.40 \pm 0.8$ versus $3.78 \pm 0.7 \mathrm{mg} / \mathrm{dL}$, respectively; $\mathrm{p}<0.001)$, and LDL-C/HDL-C ( $2.88 \pm 0.7$ versus $2.3 \pm 0.6 \mathrm{mg} / \mathrm{dL}$, respectively; $\mathrm{p}<0.001)$ with the Mediterranean diet compared to the pistachio diet; but no significant change in HDL-C $(43.5 \pm 9.2$ versus $41.7 \pm 7.38 \mathrm{mg} / \mathrm{dL}$, respectively; $\mathrm{p}=0.069)$. This study supports 
evidence that pistachio consumption may have beneficial impacts on lipid status in healthy adults.

The randomized control trial by Li et al. (2010) measured the difference in lipid values at weeks 0,6 , and 12 in a sample of overweight and obese adults following a weight loss diet. The pistachio snack group compared to the pretzel snack group showed significant decreases in TAG at weeks 6 and 12. Triacylglycerol values at week 6 were $88.0 \pm 9.8 \mathrm{mg} / \mathrm{dL}$ for the pistachio group and $144.6 \pm 18.9 \mathrm{mg} / \mathrm{dL}$ for the pretzel group $(\mathrm{p}<0.05)$. At 12 weeks, $T A G$ values were $88.1 \pm 6.8 \mathrm{mg} / \mathrm{dL}$ for the pistachio group versus $132.1 \pm 16.8 \mathrm{mg} / \mathrm{dL}$ for the pretzel group $(\mathrm{p}<0.05)$. Total cholesterol values were not significantly different between the pistachio group and pretzel group at week 12 $(191.6 \pm 7.5$ versus $183.2 \pm 8.2 \mathrm{mg} / \mathrm{dL}$, respectively), nor were values of LDL-C (79.9 \pm 11.0 versus $72.9 \pm 10.7 \mathrm{mg} / \mathrm{dL}$, respectively) or HDL-C (42.9 \pm 2.5 versus $39.5 \pm 2.5$ $\mathrm{mg} / \mathrm{dL}$, respectively). This evidence suggests that when compared to a refined carbohydrate snack, pistachio consumption may have beneficial effects on TAG in obese adults.

Among adult men with erectile dysfunction, Aldemir et al. (2011) found that $20 \%$ daily caloric intake from pistachios had positive effects on blood lipids. After 3 weeks, compared to baseline, there were significant decreases in TC (148.3 \pm 38.9 versus $179.5 \pm 53.2 \mathrm{mg} / \mathrm{dL}, \mathrm{p}=0.008)$, LDL-C $(84.8 \pm 10.1$ versus $106.1 \pm 30 \mathrm{mg} / \mathrm{dL}, \mathrm{p}=0.007)$, TC/HDL-C ( $2.4 \pm 0.6$ versus $4.3 \pm 1.4, \mathrm{p}=0.001)$, LDL-C/HDL-C $(1.4 \pm 0.2$ versus $2.6 \pm$ $0.8, \mathrm{p}=0.001), \mathrm{TAG} / \mathrm{HDL}-\mathrm{C}(2.1 \pm 0.9$ versus $4 \pm 2.9, \mathrm{p}=0.013)$, a significant increase in HDL-C (62.1 \pm 7.9 versus $42 \pm 6.4 \mathrm{mg} / \mathrm{dL}, \mathrm{p}=0.001)$, and a nonsignificant decrease in TAG $(133.9 \pm 71.1$ versus $160.8 \pm 99 \mathrm{mg} / \mathrm{dL}$, respectively; $\mathrm{p}=0.288)$. Even a relatively 
short intervention of 3 weeks was shown to significantly improve nearly all aspects of the lipid profile.

Significant reductions in LDL-C were found in six out of ten studies and were present in populations with moderate hypercholesterolemia (Sheridan et al., 2007), elevated LDL-C (Gebauer et al., 2008), MetS (Gulati et al., 2014), erectile dysfunction (Aldemir et al., 2011), and in normolipidemic populations (Baer et al., 2012; Sari et al., 2010) in interventions lasting 3 to 4 weeks. Likewise, six out of ten studies showed significant reductions in TC in similar populations (Aldemir et al., 2011; Edwards et al., 1999; Gebauer et al., 2008; Gulati et al., 2014; Sari et al., 2010; Kocygit et al., 2006) over the course of 3 to 4 weeks, as well as one intervention that lasted 24 weeks (Gulati et al., 2014).

Of the ten studies reporting improvements in the lipids profile, four showed significant increases in HDL-C in one population with moderate hypercholesterolemia (Edwards et al., 1999), one with elevated LDL-C (Gebauer et al., 2008), one with erectile dysfunction (Aldemir et al., 2011), and in one healthy population (Kocygit et al., 2006).

Significant reductions in TAG were reported in four out of the ten studies including populations with elevated LDL-C (Gebauer et al., 2008), overweight or obesity (Li et al., 2010), MetS (Wang et al., 2012), and in a healthy population (Sari et al., 2010) with interventions ranging from 4 to 12 weeks. The literature indicates that pistachios are not only beneficial to healthy populations but may be utilized as part of nutrition therapy for unhealthy populations as well. Beneficial changes to the lipid profile occurred in as little as 3 weeks (Aldemir et al., 2011; Baer et al., 2012; Edwards et al., 1999; Kocygit et 
al., 2006), indicating that it does not take a long-term intervention to see positive results from healthy lifestyle changes.

Also shown in the studies above were significant reductions in the ratios of LDLC/HDL-C and TC/HDL-C following pistachio supplemented diets. Of the six studies that evaluated the impact of pistachios on these ratios all of them found significant reductions in both LDL-C/HDL-C and TC/HDL-C (Aldemir et al., 2011; Edwards et al., 1999;

Gebauer et al., 2008; Sari et al., 2010; Kocygit et al., 2006; Sheridan et al., 2007).

Previous studies indicate that the ratios of LDL-C/HDL-C and TC/HDL-C are even better predictors of CVD than LDL-C alone (Edwards et al., 1999).

With two exceptions, the intervention lengths of these ten studies were relatively short. While one randomized controlled trial had a 24-week intervention period (Gulati et al., 2014) and two others utilized 12-week interventions (Li et al., 2010; Wang et al., 2012), the duration of the interventions for the other seven studies were either 3 or 4 weeks long (Aldemir et al., 2011; Baer et al., 2012; Edwards et al., 1999; Gebauer et al., 2008; Sari et al., 2010; Kocygit et al., 2006; Sheridan et al., 2007). Additionally, the sample sizes utilized in these studies were relatively small. In all ten studies, sample sizes were composed of 90 participants or fewer with four studies containing samples sizes of fewer than 20 participants (Aldemir et al., 2011; Baer et al., 2012; Edwards et al., 1999; Gebauer et al., 2008; Gulati et al., 2014; Li et al., 2010; Sari et al., 2010; Kocygit et al., 2006; Sheridan et al., 2007). Because the existing literature is composed of studies with small sample sizes and short duration, larger controlled feeding studies are needed to ensure the accuracy of the results (London, Pawlak, Colby, Wall-Bassett, \& Sira, 2013). 


\section{Rationale}

Pistachio consumption has been shown to have beneficial impacts on a variety of health indicators including oxidative status, inflammatory markers, glucose control, diabetes, hemodynamics, lipid status, and measures of adiposity. As such, pistachio consumption may be a simple way to reduce risk for CVD through dietary modification. Previous studies have found that pistachio consumption increases HDL-C and decreases TC, LDL-C, TC/HDL-C, LDL-C/HDL-C, and TAG; however, research evaluating pistachios' effects on lipid status has largely focused on unhealthy populations.

Of the studies that have investigated the effects of pistachio consumption on measures of adiposity, none of these studies have assessed the impact of pistachio consumption on total body fat percentage or have used DXA for such measures. Therefore, research examining the effects of pistachio consumption on lipid status and measures of adiposity in healthy populations is lacking, and this study aims to address some of the current gaps in the literature.

\section{Objectives}

The objective of this research was to determine the impact of pistachio consumption on lipid status and measures of adiposity in a healthy population using a crossover design with two 10 -week treatment periods: a pistachio diet ( $20 \%$ of kcals) and a no-pistachio control diet. It is hypothesized that daily pistachio consumption will help improve lipid status and have little or no effect on measures of adiposity. 


\section{CHAPTER 3: MATERIALS AND METHODS}

\section{Recruitment and Participants}

Female students from both California Polytechnic State University, San Luis Obispo (CP-SLO) and California State Polytechnic University, Pomona (CP-P) were recruited via email, flyers, and word of mouth. Interested students were given a screening questionnaire (Appendix A) to determine if they were qualified to participate. Inclusion criteria were biological female, age 18 to 40 years old, and BMI 18.5 to 25

$\mathrm{kg} / \mathrm{m}^{2}$. Exclusion criteria included non-Cal Poly students, males, BMI below $18.5 \mathrm{~kg} / \mathrm{m}^{2}$ or above $25 \mathrm{~kg} / \mathrm{m}^{2}$, not liking pistachios, allergy to nuts, chronic disease of any kind, medications that affected fat malabsorption, laxative use, excessive alcohol consumption (more than 1 ounce of ethyl alcohol per day), pregnancy or plans for pregnancy, presence of pacemaker or metal pins/plates in the body, or elite athletes.

Study participants were limited to the first 30 qualified female students enrolled at CP-SLO and the first 30 qualified female students enrolled at CP-P.

\section{Study Design}

This study utilized a crossover design with two 10 -week treatment periods $(20 \%$ of kcals from pistachios and a no-pistachio control diet) separated by a 15 -week washout period. The first treatment period occurred during fall quarter 2012 (September 2012 to December 2012) and the second treatment period occurred during spring quarter 2013 (April 2013 to June 2013). Half of the participants at each campus were randomized to the pistachio diet ( $20 \%$ of kcals to be included daily as snacks or with meals) and the other half were assigned to the control diet (maintained usual diets excluding nuts). During the washout period participants were asked to resume their usual diets. During 
the second treatment period, those who were following the pistachio diet during the first treatment transitioned to the control diet and those who were following the control diet during the first treatment transitioned to the pistachio diet. Participants were provided with roasted, unsalted, shelled pistachios supplied by the American Pistachio Growers.

\section{Study Visits}

The participants met researchers on their respective campuses once a week for 10 weeks during the first treatment period and once a week for 10 weeks during the second treatment period. During these visits, participants on the pistachio diet picked up bags of pre-measured pistachios for the week and all participants submitted completed food records (Appendix B). Additionally, at the beginning and end of each treatment period, participants had their height, body weight, WC, and total body composition measured; and had their blood drawn at the Student Health Center on each respective campus. At CP-SLO total body composition was measured using DXA (Lunar, GE Healthcare).

At the first study visit, all participants from both groups were educated on the U.S. Department of Agriculture's MyPlate guidelines and how pistachios fit in a healthy diet. They were also provided with recipe ideas of how to incorporate pistachios into their meals each day (Appendix C). To determine the amount of pistachios each participant was to consume (20\% of daily caloric need) researchers used the HarrisBenedict Equation to determine the energy needs of each participant based on age, height, and body weight. Physical activity questionnaires were also used to determine physical activity levels, which were considered when determining energy needs.

Participants completed the 2002 International Physical Activity Questionnaire short form (Appendix D), which assessed physical activity level during the preceding 7 days, and 
were counseled to maintain a constant level of physical activity throughout the study. Based on this information, pistachios were pre-measured weekly for each participant into individual bags, one for each day of the week.

\section{Food/Satiety Records}

Participants were asked to keep three sets of 3-day food records ( 9 records total) during each treatment period, for a total of 18 records per participant. No food records were collected during the washout period. Each set of food records began on a randomly assigned day throughout the quarter. Participants were trained to accurately record different food components. The participants' diets were analyzed using the Nutrition Data System for Research (NDSR) version 2012, developed by the Nutrition Coordinating Center (NCC), University of Minnesota (Minneapolis, MN). On each food record, participants filled out a numerical Hunger/Satiety rating (Appendix E) corresponding to their hunger level before, during, and after each meal. Additionally, a validated Visual Analog Scale (VAS) (Appendix F) was used to measure the participants' hunger and satiety ratings before and after consuming their meal or snack containing pistachios (for those on the pistachio diet) or a randomly chosen snack or meal (for those on the control diet).

\section{Compliance}

Participants received an Unusual Diet Diary (Appendix G), on which they were instructed to record any accidental pistachio consumption, medications that were taken, or perceived side effects of nut consumption. At each weekly meeting, participants returned all empty pistachio bags from the previous week to ensure adherence to the diet. 
Both of these methods were utilized to assess compliance. Additionally, prior to study visits participants received reminders via email regarding their appointment time and protocols for each visit.

\section{Anthropometric Measurements}

Total body fat percentage was measured at weeks one and 10 of each treatment period at the CP-SLO campus only using full-body DXA scans. The scans were completed on-campus in the Nutrition DXA Lab. Prior to the scan, participants were asked to fast for 4 hours; remove any metal objects, jewelry, and shoes; and to take a pregnancy test to eliminate the possibility of pregnancy. Even though the radiation level of the DXA scan is low, all efforts were made to protect the safety of a potential fetus. Any participant with a positive test would have been disqualified.

Body weight was recorded to the nearest $0.1 \mathrm{~kg}$ on a calibrated scale and height was recorded to the nearest $0.1 \mathrm{~cm}$. Because there were no differences in height for any of the participants, the first height measurement was used as a constant. Body mass index was calculated as body weight $(\mathrm{kg})$ divided by height $(\mathrm{m})$ squared. Trained researchers measured WC based on NHANES III standardized procedures using a flexible measuring tape to the nearest $0.1 \mathrm{~cm}$.

\section{Biochemical Analysis}

Prior to blood draws participants were told to fast for 12 hours and consume 1.5 cups of water the morning of the visit to prevent dehydration. Blood samples were collected on each campus' Student Health Center by trained phlebotomists at weeks one 
and 10 of each treatment period. A lipid panel including TC, LDL-C, HDL-C, and TAG, was processed for each sample at an off-campus laboratory site.

\section{Staff}

Researchers at CP-SLO recruited 15 undergraduate research assistants from the Food Science and Nutrition Department to assist with pistachio delivery and bag pick-up as well as food record review and collection. A Registered Dietitian trained all research assistants to evaluate the completeness of the food records and gave final approval on all food record completeness.

\section{Statistical Analyses}

For statistical analysis JMP Pro 11 (Cary, NC) was used. Separate mixed effects models were used to determine significant differences for each response variable (TC, TAG, LDL-C, HDL-C, TC/HDL, body weight, BMI, WC, and total body fat percentage) with the following predictors: campus (fixed effect; 2 levels - CP-SLO or CP-P), subject ID (random effect; 30 levels nested within each campus), diet (fixed effect; 2 levels pistachio or habitual), visit (fixed effect; 2 levels - baseline and end of diet), diet*visit (interaction of diet and visit to determine if change in outcome from baseline to end depends on which type of diet), and diet*campus (interaction of diet and campus to determine if the diet had different effects for the two campuses, with regard to outcome

of interest). The only exception was the variable total body fat percentage which was not evaluated with regard to campus or diet*campus since data on total body fat percentage was only collected at CP-SLO. A sample of 30 participants on each campus was expected to provide statistical power of $80 \%$. 


\section{Compensation}

Participants received a $\$ 10$ university gift card following completion of the first treatment period and a second $\$ 10$ university gift card following completion of the second treatment period.

\section{Ethical Approval}

All procedures involving human participants were approved by the Institutional Review Boards at both CP-SLO and CP-P. Participants gave their signed informed consent prior to start of the study (Appendix $\mathbf{H}$ ).

\section{Funding}

This research was funded by the Agricultural Research Initiative (Grant \#59654) and by the American Pistachio Growers (Grant \#47031). 


\section{CHAPTER 4: RESULTS}

\section{Participants}

At CP-SLO, 56 potential participants were screened, 33 of whom qualified for the study based on the screening questionnaire. Before the start of the study, three participants dropped out (one cited family reasons and the two others underestimated their workload for the quarter and could not meet the time requirement). At CP-P, 55 potential participants were screened, 31 of whom qualified for the study. Of those who qualified, one participant dropped out before the study began due to an adverse reaction to the initial blood draw. Of the 60 total participants who were recruited from both campuses, 48 completed the study: 23 from CP-P and 25 from CP-SLO. Reasons for dropout during the study included being put on medication, not answering emails, personal reasons, and stomach discomfort (Figure 6). 

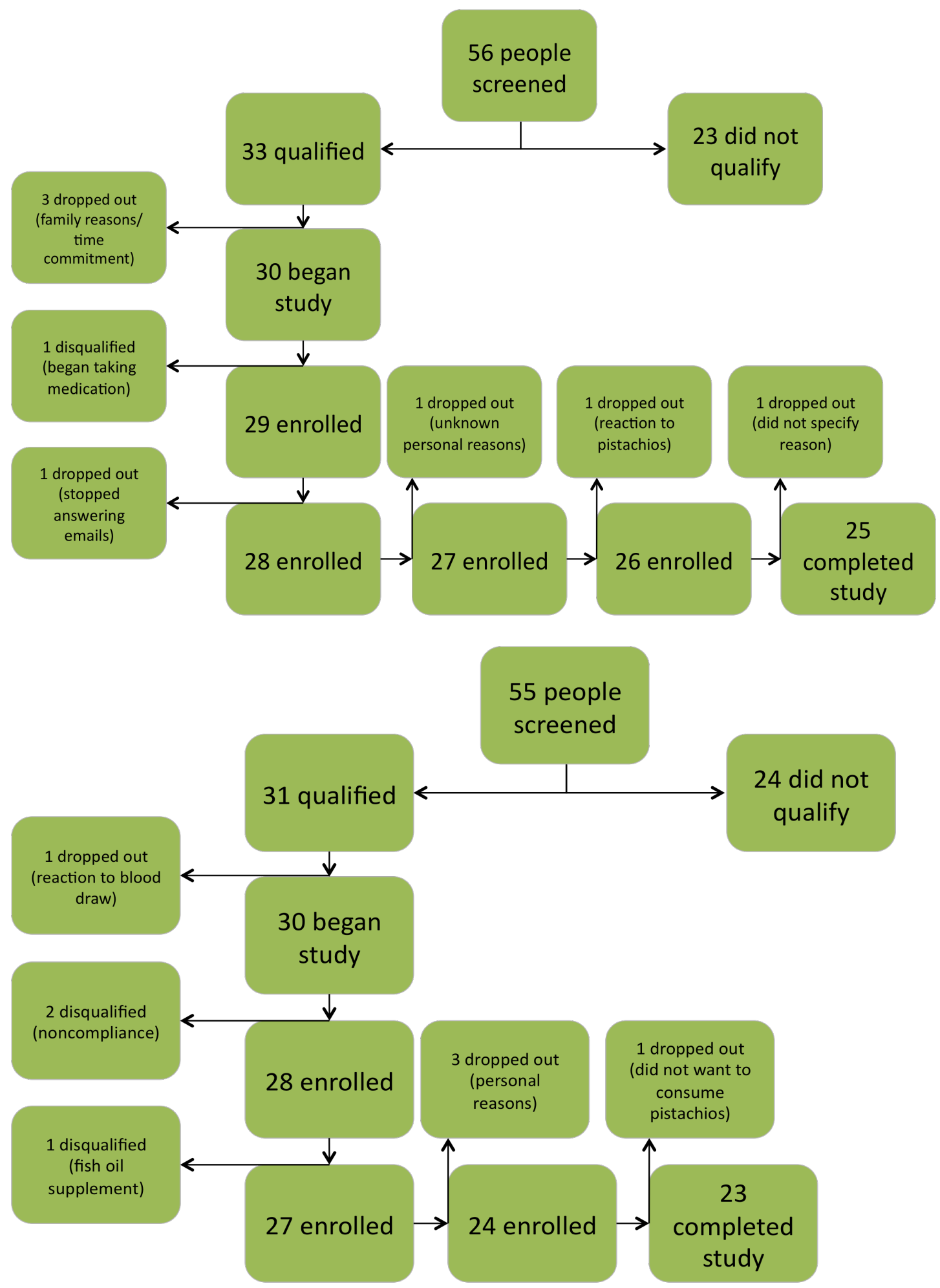

Figure 6. Participant flow-charts from CP-SLO (top) and CP-P (bottom). 
Baseline characteristics are shown in Table 8. None of the characteristics listed were significantly different between participants at CP-P compared to participants at CPSLO.

Table 8. Participant baseline characteristics, mean \pm SD.

\begin{tabular}{|l|c|c|c|c|}
\hline \multicolumn{1}{|c|}{ Characteristic } & $\begin{array}{c}\text { Cal Poly } \\
\text { Pomona } \\
(\mathrm{n}=23)\end{array}$ & $\begin{array}{c}\text { Cal Poly SLO } \\
(\mathrm{n}=25)\end{array}$ & $\begin{array}{c}\text { Mean } \\
(\mathrm{n}=48)\end{array}$ & P-value \\
\hline Age, years & $22.8 \pm 4.45$ & $20.0 \pm 1.47$ & $21.0 \pm 0.51$ & ----- \\
\hline Body weight, $\mathrm{kg}$ & $60.2 \pm 8.05$ & $57.8 \pm 7.30$ & $58.9 \pm 7.66$ & 0.26 \\
\hline BMI, kg/m ${ }^{2}$ & $22.0 \pm 2.22$ & $21.6 \pm 2.21$ & $21.9 \pm 2.32$ & 0.18 \\
\hline WC, $\mathrm{cm}$ & $186 \pm 12.8$ & $184 \pm 18.8$ & $185 \pm 16.3$ & 0.32 \\
\hline TAG, $\mathrm{mg} / \mathrm{dL}$ & $79.0 \pm 34.6$ & $76.6 \pm 38.5$ & $77.7 \pm 36.3$ & 0.30 \\
\hline TC, $\mathrm{mg} / \mathrm{dL}$ & $151 \pm 30.8$ & $159 \pm 24.7$ & $155 \pm 27.7$ & 0.06 \\
\hline LDL-C, $\mathrm{mg} / \mathrm{dL}$ & $76.2 \pm 23.1$ & $79.0 \pm 24.5$ & $77.7 \pm 23.6$ & 0.24 \\
\hline HDL-C, $\mathrm{mg} / \mathrm{dL}$ & $59.1 \pm 13.4$ & $64.3 \pm 10.4$ & $61.8 \pm 12.1$ & 0.22 \\
\hline TC/HDL-C & $2.64 \pm 0.58$ & $2.54 \pm 0.62$ & $2.59 \pm 0.56$ & 0.68 \\
\hline Total body fat $\%{ }^{\mathrm{a}}$ & ----- & $30.4 \pm 4.29$ & ----- & ----- \\
\hline
\end{tabular}

${ }^{\mathrm{a}}$ Region \% Fat from DXA

\section{Measures of Adiposity}

Results for BMI, body weight, and WC among all 48 participants and results for total body fat percentage among the 25 CP-SLO participants are shown in Table 9. There were no significant differences in any of the measures of adiposity between diet groups. 
Table 9. Measures of adiposity at baseline and end of diet treatments, $(n=48)$.

\begin{tabular}{|l|l|l|l|l|l|}
\hline $\begin{array}{l}\text { Measure of } \\
\text { Adiposity }^{\mathrm{a}}\end{array}$ & $\begin{array}{l}\text { Pistachio } \\
\text { Baseline }^{\mathrm{b}}\end{array}$ & $\begin{array}{l}\text { Pistachio } \\
\text { End }^{\mathrm{b}}\end{array}$ & $\begin{array}{l}\text { Control } \\
\text { Baseline }^{\mathrm{b}}\end{array}$ & $\begin{array}{l}\text { Control } \\
\text { End }^{\mathrm{b}}\end{array}$ & P-value \\
\hline BMI, kg/m & $21.9(0.06)$ & $21.9(0.07)$ & $21.9(0.07)$ & $21.9(0.07)$ & 0.9 \\
\hline Body weight, $\mathrm{kg}$ & $59.6(0.26)$ & $59.4(0.26)$ & $59.1(0.26)$ & $59.0(0.26)$ & 0.8 \\
\hline WC, $\mathrm{cm}$ & $71.9(0.36)$ & $72.1(0.36)$ & $72.4(0.36)$ & $72.1(0.36)$ & 0.4 \\
\hline $\begin{array}{l}\text { Total body fat } \\
\%\end{array}$ & $30.2(0.28)$ & $30.2(0.29)$ & $30.0(0.29)$ & $30.0(0.30)$ & 0.9 \\
\hline
\end{tabular}

${ }^{\mathrm{a}}$ Mixed effects model

${ }^{\mathrm{b}}$ Least squares mean (standard error of the mean)

${ }^{\mathrm{c}}$ Mixed effects model; Least squares mean and (standard error of the mean)

${ }^{\mathrm{d}}$ Only tested at Cal Poly SLO $(\mathrm{n}=25)$

${ }^{\mathrm{e}}$ Region Fat \% from DXA

There were no significant differences in BMI between diet treatments (pistachio diet and control diet $)(p=0.9)$. Average BMI at baseline of the pistachio treatment was $21.9(0.06) \mathrm{kg} / \mathrm{m}^{2}$ and at the end of the pistachio treatment was $21.9(0.07) \mathrm{kg} / \mathrm{m}^{2}$.

Average BMI at baseline of the control treatment was $21.0(0.07) \mathrm{kg} / \mathrm{m}^{2}$ and at the end of the control treatment was $21.9(0.07) \mathrm{kg} / \mathrm{m}^{2}$.

Similarly, there were no significant differences in body weight between diet treatments (pistachio diet and control diet) $(\mathrm{p}=0.8)$. Average body weight at baseline of the pistachio treatment was $59.6(0.26) \mathrm{kg}$ and at the end of the pistachio treatment was $59.4(0.26) \mathrm{kg}$. Average body weight at baseline of the control treatment was $59.1(0.26)$ $\mathrm{kg}$ and at the end of the control treatment was $59.0(0.26) \mathrm{kg}$.

No significant differences in WC were found between diet treatments (pistachio diet and control diet $)(p=0.4)$. Average WC at baseline of the pistachio treatment was $71.9(0.36) \mathrm{cm}$ and at the end of the pistachio treatment was $72.1(0.36) \mathrm{cm}$. Average WC at baseline of the control treatment was $72.4(0.36) \mathrm{cm}$ and at the end of the control treatment was $72.1(0.36) \mathrm{cm}$. 
Additionally, there were no significant differences in total body fat percentage between diet treatments (pistachio diet and control diet) $(p=0.9)$. Average total body fat percentage at baseline of the pistachio treatment was $30.2(0.28) \%$ and at the end of the pistachio treatment was $30.2(0.29) \%$. Average total body fat percentage at baseline of the control treatment was $30.0(0.30) \%$ and at the end of the control treatment was 30.0 $(0.30) \%$.

No significant differences were found in any measures of adiposity between baseline and end of the pistachio diet or between baseline and end of the control diet

\section{(Figure 7).}

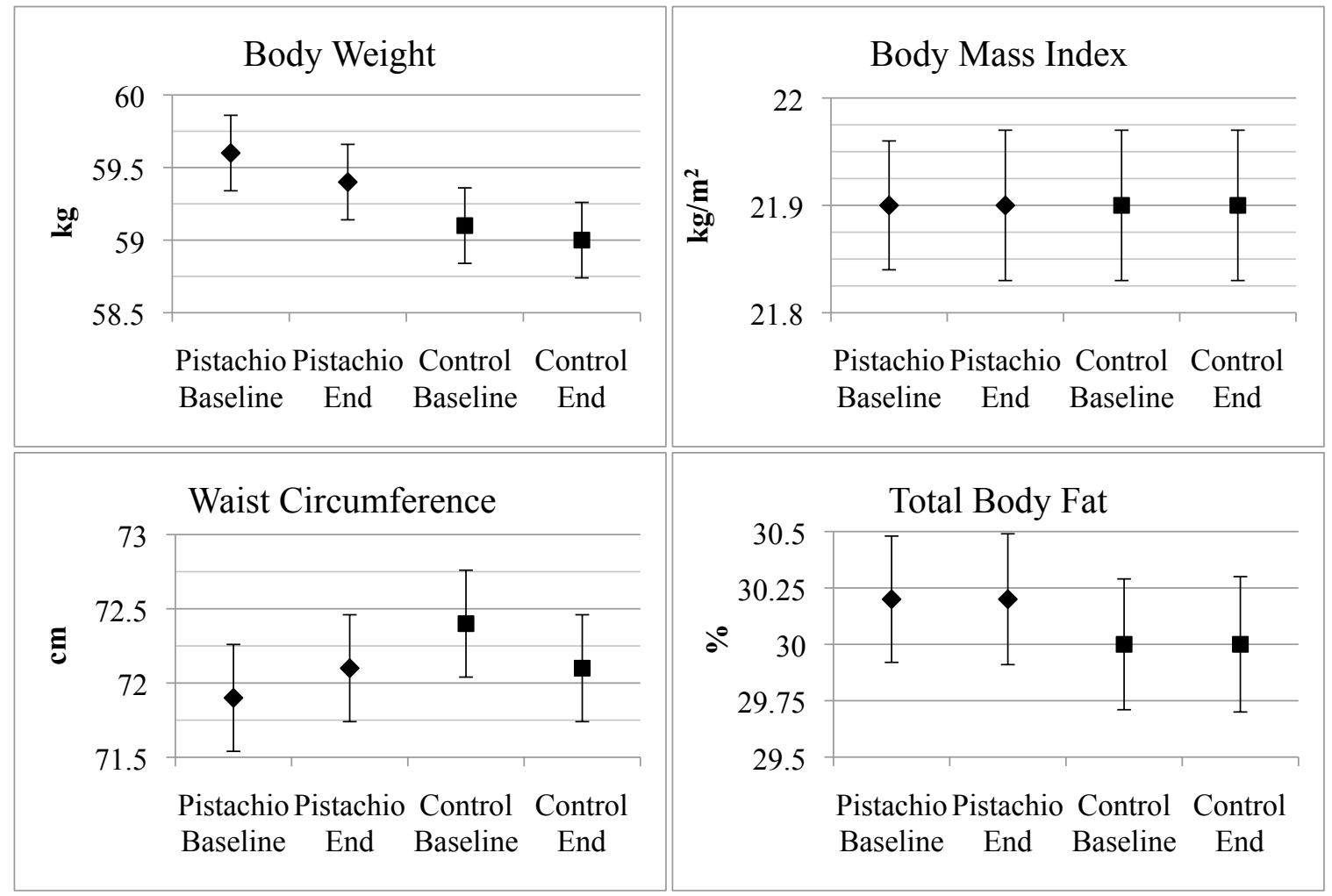

Least squares mean (standard error of the mean); pistachio diet

Least squares mean (standard error of the mean); control diet

Figure 7. Measures of adiposity at baseline and end of diet treatments. 


\section{Blood Lipids}

Results for TAG, TC, LDL-C, HDL-C, and TC/HDL-C among all 48 participants are shown in Table 10. There were no significant differences in any of the blood lipid variables between diet groups.

Table 10. Blood lipids at baseline and end of diet treatments, $(n=48)$.

\begin{tabular}{|l|l|l|l|l|l|}
\hline $\begin{array}{l}\text { Blood Lipid } \\
\text { Variables }^{\mathrm{a}}\end{array}$ & $\begin{array}{l}\text { Pistachio } \\
\text { Baseline }^{\mathrm{b}}\end{array}$ & $\begin{array}{l}\text { Pistachio } \\
\text { End }^{\mathrm{b}}\end{array}$ & $\begin{array}{l}\text { Control } \\
\text { Baseline }^{\mathrm{b}}\end{array}$ & $\begin{array}{l}\text { Control } \\
\text { End }^{\mathrm{b}}\end{array}$ & P-value \\
\hline TAG, $\mathrm{mg} / \mathrm{dL}$ & $80.8(3.43)$ & $80.8(3.57)$ & $82.0(3.38)$ & $86.0(3.46)$ & 0.6 \\
\hline TC, mg/dL & $158(1.90)$ & $161(1.88)$ & $161(1.88)$ & $162(1.90)$ & 0.5 \\
\hline LDL-C, mg/dL & $79.4(1.64)$ & $82.1(1.73)$ & $81.5(1.64)$ & $81.5(1.66)$ & 0.4 \\
\hline HDL-C, mg/dL & $62.8(0.90)$ & $63.3(0.95)$ & $63.6(0.90)$ & $63.8(0.91)$ & 0.9 \\
\hline TC/HDL-C & $2.59(0.04)$ & $2.62(0.04)$ & $2.61(0.04)$ & $2.61(0.04)$ & 0.7 \\
\hline
\end{tabular}

${ }^{\mathrm{a}}$ Mixed effects model

${ }^{\mathrm{b}}$ Least squares mean and (standard error of the mean)

There were no significant differences in TAG between the pistachio and control diets $(\mathrm{p}=0.6)$. The average TAG value at baseline of the pistachio diet was $80.8(3.43)$ $\mathrm{mg} / \mathrm{dL}$ and after the pistachio diet was $80.8(3.57) \mathrm{mg} / \mathrm{dL}$. At baseline of the control diet average TAG value was $82.0(3.38) \mathrm{mg} / \mathrm{dL}$ and after the control diet was $86.0(3.46)$ $\mathrm{mg} / \mathrm{dL}$.

Additionally, there were no significant differences in TC between the pistachio and control diets $(\mathrm{p}=0.5)$. The average $\mathrm{TC}$ value at baseline of the pistachio diet was 158 (1.90) $\mathrm{mg} / \mathrm{dL}$ and after the pistachio diet was $161(1.88) \mathrm{mg} / \mathrm{dL}$. At baseline of the control diet average TC value was $161(1.88) \mathrm{mg} / \mathrm{dL}$ and after the control diet was 162 (1.90) $\mathrm{mg} / \mathrm{dL}$.

No significant differences in LDL-C were found between the pistachio and control diets $(\mathrm{p}=0.4)$. The average LDL-C value at baseline of the pistachio diet was 79.4 (1.64) $\mathrm{mg} / \mathrm{dL}$ and after the pistachio diet was 82.1 (1.73) $\mathrm{mg} / \mathrm{dL}$. At baseline of the 
control diet average LDL-C value was $81.5(1.64) \mathrm{mg} / \mathrm{dL}$ and after the control diet was $81.5(1.66) \mathrm{mg} / \mathrm{dL}$.

Likewise, there were no significant differences in HDL-C between the pistachio and control diets $(\mathrm{p}=0.9)$. The average HDL-C value at baseline of the pistachio diet was $62.8(0.90) \mathrm{mg} / \mathrm{dL}$ and after the pistachio diet was $63.3(0.95) \mathrm{mg} / \mathrm{dL}$. At baseline of the control diet average HDL-C value was $63.6(0.90) \mathrm{mg} / \mathrm{dL}$ and after the control diet was $63.8(0.91) \mathrm{mg} / \mathrm{dL}$.

There were no significant differences in TC/HDL-C between the pistachio and control diets $(\mathrm{p}=0.7)$. The average TC/HDL-C value at baseline of the pistachio diet was $2.59(0.04)$ and after the pistachio diet was $2.62(0.04)$. At baseline of the control diet average TC/HDL-C value was $2.61(0.04)$ and after the control diet was $2.61(0.04)$.

No significant differences were found from baseline to the end of the control treatment or from baseline to the end of the pistachio treatment among any of the blood lipid variables (Figure 8). 


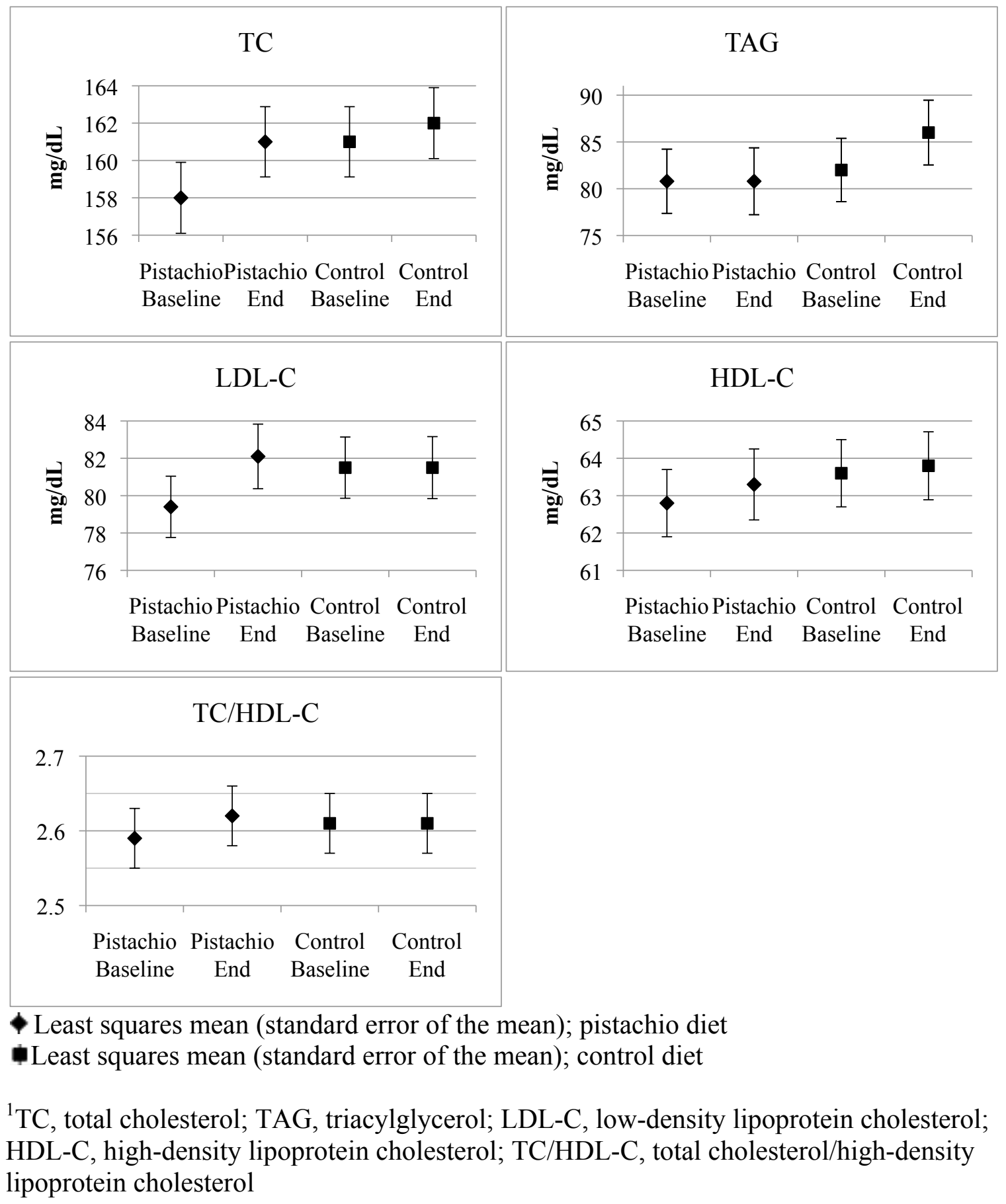

Figure 8. Blood lipids at baseline and end of diet treatments ${ }^{1}$. 


\section{CHAPTER 5: DISCUSSION}

This study examined the effects of pistachio consumption on measures of adiposity and blood lipids in a 10 -week crossover trial with two treatment groups (a 20\% kcal per day pistachio diet and a control diet). Pistachio consumption was not associated with significant changes in lipid profile (TC, TAG, LDL-C, HDL-C, or TC/HDL) or measures of adiposity (body weight, BMI, WC, or total body fat percentage). Similarly, no changes were observed in the control group or between the two diets for any variable.

This study is unique compared to previous research for a number of reasons. First, the sample of participants in this study was composed of healthy, young female college students. To date only two previous studies have investigated the effects of pistachio consumption in healthy populations with a normal BMI, and of those, one study tested only male subjects (Sari et al., 2010) and the other tested both male and female subjects (Kocygit et al., 2006). Therefore, this is the first study to evaluate the effects of pistachio consumption on healthy young (average of less than 25 years of age) females with an average healthy BMI.

Additionally, while three previous pistachio consumption studies incorporated treatment periods of 12 weeks or longer (Gulati et al., 2014; Li et al., 2010; Wang et al., 2012), the 10-week treatment period of this study was substantially longer than the majority of previous studies, which have consisted of treatment periods of 3 to 4 weeks (Aldemir et al., 2011; Baer et al., 2012; Edwards et al., 1999; Gebauer et al., 2008; Kocygit et al., 2006; Sari et al., 2010; Sheridan et al., 2007). The longer treatment period provided more opportunity for the potential impacts of pistachio consumption to become apparent. This study also utilized a sample size of 48 , the fourth highest to date among pistachio feeding studies that evaluated blood lipids or measures of adiposity. The 
relatively larger sample size of this study increased its power to detect individual changes.

This study is also distinctive in that only two previous studies have examined the effects of pistachio consumption on measures of adiposity other than body weight or BMI, and neither have done so in healthy populations (Gulati et al., 2014; Wang et al., 2012). This is the first study to evaluate the effects of pistachio consumption on total body fat percentage in any population. While Gulati et al. (2014) evaluated WC, SCAT, and IAAT, and Wang et al. (2012) evaluated waist-to-hip ratio, no previous pistachio feeding studies have assessed total body fat percentage nor utilized DXA to do so. This is only the second study to evaluate $\mathrm{WC}$ and the first to do so in a healthy population.

\section{Measures of Adiposity}

Participants did not show any significant differences in any measure of adiposity (body weight, BMI, WC, or total body fat percentage) during the pistachio treatment or the control treatment. These findings are fairly consistent with the findings of previous pistachio intervention trials. All but one (Li et al., 2010) of the nine previous studies evaluating the effects of pistachio consumption on body weight and/or BMI found no significant changes in either variable (Aldemir et al., 2011; Edwards et al., 1999; Gebauer et al., 2008; Gulati et al., 2014; Kocygit et al., 2006; Sari et al., 2010; Sheridan et al., 2007; Wang et al., 2012). While Li et al. (2010) did find significant changes in body weight and BMI from baseline to the end of each diet treatment (pistachio or pretzel), participants in each diet group were also on weight reduction diets, and no significant changes in body weight were found between treatment groups. Participants on the 
pistachio diet did, however, showed significantly lower BMI compared to the pretzel group at all but one two-week checkpoint.

Only the randomized control trial by Gulati et al. (2014) evaluated the effects of pistachio consumption on WC and found a significant decrease in WC in the intervention group compared to the control group. However, the study sample included participants with MetS and an average BMI in the obese category, compared to the sample of the current study with no indicators of MetS and an average BMI in the normal range. With less or no weight to lose, changes in WC may not have been as likely to occur in this sample. Additionally, the significant changes in WC previously found occurred following an intervention of 24 weeks compared to the current intervention of only 10 weeks; therefore, it is possible that significant changes in WC may take longer than 10 weeks to occur.

Though no previous research has evaluated the effects of pistachio consumption on total body fat percentage, Gulati et al. (2014) found no significant changes in SCAT or IAAT in the pistachio group versus the control group, similar to the lack of significant changes in total body fat percentage found in this study.

Large epidemiological studies have also found limited effects of nut consumption on measures of adiposity. In a review study, Natoli and McCoy (2007) showed that of the five major epidemiological studies that have evaluated the effects of nut consumption on body weight or BMI, only the California Seventh Day Adventist Health Study showed a statistically significant negative association between nut consumption and BMI (Fraser et al. 1992). The Iowa Women's Health Study (Ellsworth, Kushi, \& Folsom, 2001) and Nurses' Health Studies (Hu et al., 1998; Jiang, Manson, Stampfer, Liu, Willett, \& Hu, 
2002) found non-statistically significant trends with higher nut consumption and lower BMI, and the Physicians' Health Study found no association between nut consumption and BMI (Albert, Gaziano, Willett, \& Manson, 2002). These findings suggest that frequent nut consumers ( 5 servings/week or more) do not have statistically significant differences in body weight or BMI compared to infrequent nut consumers (less than one serving/week) (Natoli \& McCoy, 2007), similar to the findings from the current study.

To date three principal mechanisms have been proposed describing the impact of nuts on weight gain despite their high-fat, energy-dense composition, including their satiety properties, lack of bioaccessibility, and potential to increase energy expenditure. First, in terms of the satiety properties of nuts, Mattes, Kris-Etherton, \& Foster (2008) determined that $55-75 \%$ of the energy from nuts is offset by a reduction in subsequent energy intake. Not only are nuts energy-rich and contain a variety of nutrients including protein, fiber, and unsaturated fats, they also require significant mastication, which helps to signal satiation through various sensory pathways (Mattes \& Dreher, 2010). While not the primary focus of this thesis, the effect of pistachios on satiety was illustrated by other data from the current study which found that participants felt more full, were not as hungry, and had fewer cravings while on the pistachio diet compared to the control diet (Burns-Whitmore, Hall, Towne, Bushnell, \& Roy, 2014). Interestingly, the current study also found that overall energy intake was significantly higher on the pistachio diet compared to the control diet $(\mathrm{p}=0.0012$, data not shown). This suggests that participants may have added, rather than substituted pistachios into their diets, yet participants still showed no significant change in total body fat percentage, body weight, BMI, or WC between the two diet treatments. Despite other plausible explanations for this result such 
as increased physical activity while on the pistachio diet or inaccurate food record completion, this finding supports the hypothesis that the energy in pistachios may not be fully absorbed.

Secondly, it has been estimated that $10-15 \%$ of the energy in nuts is lost in the feces (Mattes et al., 2008). One study by Ellis et al. (2004) determined that the intracellular lipids found in almonds are not fully bioaccessible during human digestion. The lipids are excreted leading to lower energy absorption than expected based on the quantity of nut consumed. Additionally, by comparing energy excretion during pistachio diet treatments versus a control diet treatment, Baer et al. (2012) found that the energy density of pistachios was 5\% less than the generally accepted value based on the Atwater principle that assumes a constant $10 \%$ of food remains undigested after passing through the gut (Mattes \& Dreher, 2010).

Thirdly, while the literature remains inconclusive, nut consumption may increase metabolic energy expenditure, which could offset energy contribution by as much as $10 \%$ (Mattes \& Dreher, 2010). Therefore, issues associated with bioaccessibility, satiety properties, and energy expenditure may have contributed to the observed null measures of adiposity following increased energy consumption on the pistachio diet compared to the control diet in the current study.

These properties, coupled with the nutrient-rich composition of nuts suggest that nuts may yield nutritional benefits while not having observable impacts on body weight or body composition. 


\section{Blood Lipids}

Over the course of the 10-week treatment periods in the current study, participants did not show any significant differences in any blood lipid variables (TC, TAG, LDL-C, HDL-C, or TC/HDL) during the pistachio treatment compared to the control treatment. These results contrast the literature, which overwhelmingly shows the effects of pistachio consumption on blood lipids to be favorable. Notably, all six studies that have evaluated the effects of pistachio consumption on TC/HDL-C have found significant reductions following the pistachio treatment period (Aldemir et al., 2011; Edwards et al., 1999; Gebauer et al., 2008; Sari et al., 2010; Kocygit et al., 2006; Sheridan et al., 2007). The majority of studies have also found significant improvements in TC (Aldemir et al., 2011; Edwards et al., 1999; Gebauer et al., 2008; Gulati et al., 2014; Kocygit et al., 2006; Sari et al., 2010) and LDL-C (Aldemir et al., 2011; Baer et al., 2012; Gebauer et al., 2008; Gulati et al., 2014; Sari et al., 2010; Sheridan et al., 2007) following the pistachio treatments, while improvements in HDL-C (Aldemir et al., 2011; Edwards et al., 1999; Kocygit et al., 2006; Sheridan et al., 2007) and TAG (Gebauer et al., 2008; Sari et al., 2010; Li et al., 2010; Wang et al., 2012) have occurred but less frequently.

In addition to the positive effects of pistachio intervention trials on TC and LDL$\mathrm{C}$, clinical trials involving the consumption of other types of nuts have supported these findings. A review of 23 human intervention trials found significant reductions in TC (between 2 and 16\%) and LDL-C (between 2 and 19\%) following interventions with various types of nuts including almonds, peanuts, pecans, and walnuts, but found that the effects of nut consumption on HDL-C and TAG were less consistent (MukuddemPetersen, Oosthuizen, \& Jerling, 2005). Similarly, Griel and Kris-Etherton (2006) reviewed the effects of 15 clinical trials involving tree nuts (including walnuts, almonds, 
pecans, macadamia nuts, pistachios, and hazelnuts) and found that the greatest improvements in the lipid profile were in LDL-C. This review established that tree nutcontaining diets yielded a $13 \mathrm{mg} / \mathrm{dL}$ reduction in LDL-C in comparison to a usual diet and a $9 \mathrm{mg} / \mathrm{dL}$ reduction in comparison to a Step I Diet (Griel \& Kris-Etherton, 2006).

While long-term prospective epidemiological studies have not specifically evaluated the effects of nut consumption on lipid profile, the beneficial association between nut consumption and CVD is well established. A review of five large epidemiological studies revealed that after accounting for all possible confounding factors, the risk of CHD, nonfatal MI, fatal CHD, and sudden cardiac death decreased in a dose-dependent manner with frequency of nut consumption (from $<1$ time/week to $\geq 5$ times /week). This equated to an $18-51 \%$ reduced risk of CHD in those who consumed nuts more than 5 times/week (Kris-Etherton, Zhao, Binkoski, Coval, \& Etherton, 2001). While the literature is consistent in showing the beneficial effects of nut consumption on the lipid profile and CVD risk, the current study could not replicate these findings.

\section{Explanation of Findings}

While the findings of the current study relating to measures of adiposity reflect those found in both short-term clinical and long-term epidemiological studies, the lack of significant findings related to blood lipids differs from the current state of research involving both pistachios and other types of nuts. Despite utilizing a longer intervention period with a greater number of participants with a similar intervention ( $20 \%$ daily intake worth of pistachios) compared to previous studies that have found significant changes in blood lipids between diet groups (Aldemir et al., 2011; Baer et al., 2012; Edwards et al., 1999; Gebauer et al., 2008; Gulati et al., 2014; Kocygit et al., 2006; Li et al., 2010; Sari et 
al., 2010; Sheridan et al., 2007; Wang et al., 2012), this study revealed no significant changes in blood lipids.

The demographics of the sample of participants in this study may be a contributing factor to the lack of significant changes. The sample population of the current study had a mean age of $21 \pm 0.51$ years, average BMI of $21.9 \pm 2.32 \mathrm{~kg} / \mathrm{m}^{2}$ (normal), average TC of $155.0 \pm 27.7 \mathrm{mg} / \mathrm{dL}$ (desirable), and average LDL-C of $77.7 \pm$ $23.6 \mathrm{mg} / \mathrm{dL}$ (optimal), making this an extremely healthy population. Additionally, the sample consisted of all females and all participants were students at either CP-SLO or CP-P. Based on the demographics listed above, a number of potential factors exist that may have reduced the likelihood of observable changes to the lipid profile in this sample.

Firstly, many previous studies have focused on populations with unhealthy lipid values, whereas the sample from the current study had healthy lipid values at the beginning of the study, leaving less opportunity for changes to be observed during the intervention period. Of the ten previous pistachio consumption studies that have examined blood lipids, two have examined populations with primary, moderate hypercholesterolemia (Edwards et al., 1999; Sheridan et al., 2007), one has examined a population with elevated LDL-C (Gebauer et al., 2008), two studied populations with MetS (Gulati et al., 2013; Wang et al., 2012), and even among the remaining studies citing no overarching dyslipidemia among their respective samples, many of the samples had baseline cholesterol or LDL-C values that are considered borderline high or above optimal. Previous intervention studies involving physical activity have found that participants with higher baseline TAG concentrations showed larger reductions in TAG levels following exercise training compared to subjects with low baseline TAG 
concentrations (Fletcher et al., 2005). If the same concept is applied to dietary interventions then the lack of significant changes in the lipid profile in this study may have been a result of the optimal starting values of the current sample.

A second explanation for the lack of significant changes may be that the participants already consumed a healthy diet, thereby diluting the beneficial effects of pistachio consumption. Previous studies have theorized that the beneficial effects of pistachio consumption are based heavily on the pistachio's nutritional components such as unsaturated fatty acids, fiber, phytochemicals, vitamins, and minerals (Dreher, 2012). Additionally, the positive effects many of these dietary components on the lipid profile have been well established (Appel et al., 2005), meaning that an optimal diet at baseline may have muted any potential effects of the pistachios.

The sample of the current study included all female college students and many of the participants were studying nutrition (based on a questionnaire provided at the beginning of the study). Based on previous research these criteria support the idea that this sample of participants consumed a diet higher in beneficial nutrients compared to the average population. It is well documented that females consume more fruits and vegetables compared to men, which contain vitamins, minerals, phytochemicals, and fiber. As of 2005, 20.3\% of men consumed fruits and/or vegetables five or more times a day compared to $29.6 \%$ of women (Blanck, Gillespie, Kimmons, Seymour, \& Serdula, 2008), and in 2009-2010, among men aged 20 to $39,33.2 \%$ consumed nuts compared to $36.8 \%$ of women in the same age group (Nielsen, Kit, \& Ogden, 2014). While the current study was composed entirely of women, previous pistachio intervention trials have either included or have been composed entirely of men (Aldemir et al., 2011; Baer 
et al., 2012; Edwards et al., 1999; Gebauer et al., 2008; Gulati et al., 2013; Kocygit et al., 2006; Li et al., 2010; Sari et al., 2010; Sheridan et al., 2007; Wang et al., 2012). The gender composition of such samples may have contributed to a lower overall diet quality, leaving greater opportunity for beneficial changes in the diet from pistachio supplementation to improve the lipid profile.

Additionally, people who are more educated tend to consume a better quality diet. Darmon \& Drewnowski (2008) found that measures of socioeconomic status including education showed a consistent positive association with multiple measures of diet quality including intake of fiber and other nutrients as well as certain plasma biomarkers. This finding held true in multiple countries including the United States, Canada, and Australia. While data on the education level of participants in previous studies was not provided, in the United States between 2009 and 2013 only $28.8 \%$ of adults aged 25 years and older achieved a bachelor's degree or higher (U.S. Census Bureau, 2015), whereas the participants in the current sample were all in the process of completing their bachelor's degree. Therefore, due to their education level, the participants in the current study may have a better overall diet quality compared to participants from similar studies.

Furthermore, many previous pistachio consumption studies have included samples that were suffering from a medical issue like overweight or obesity (Li et al., 2010), MetS (Gulati et al., 2013; Wang et al., 2012), or hypercholesterolemia (Edwards et al., 1999; Sheridan et al., 2007), making it reasonable to assume that the diet quality of these participants prior to the beginning of the studies was not ideal. Conversely, all of the participants chosen for this sample were in good health and many were studying nutrition at either CP-SLO or CP-P, which may have increased their nutrition knowledge 
compared to previously studied populations, leading them to consume a more nutrient rich diet. Therefore, the beneficial components of pistachios may have yielded a greater impact on those individuals with poorer diet quality compared to the current sample that likely maintained a healthier diet.

Another possible explanation for the lack of significant changes in the current study is that this sample was relatively homogenous compared to previous pistachio feeding studies. Most notably, the age range of previous pistachio interventions have spanned over 30 years (Baer et al., 2012; Edwards et al., 1999; Li et al., 2010; Sheridan et al., 2007), and with the exception of one study composed of all males (Sari et al., 2010), these studies have all been mixed gender (Aldemir et al., 2011; Baer et al., 2012; Edwards et al., 1999; Gebauer et al., 2008; Gulati et al., 2013; Kocygit et al., 2006; Li et al., 2010; Sheridan et al., 2007; Wang et al., 2012). Similarly, the range of baseline lipid values in many previous studies has been broad. For example, the baseline TC values in one pistachio treatment study of adults with hypercholesterolemia ranged from 214 to $336 \mathrm{mg} / \mathrm{dL}$ (Edwards et al., 1999), which spans the "borderline high" and "high" risk categories. Another pistachio treatment study among "healthy adults" cited LDL-C values at baseline from 80 to $183 \mathrm{mg} / \mathrm{dL}$ (Baer et al., 2012), which spans categories of "desirable," "near optimal/above optimal," "borderline high," and "high risk." Conversely, in the current study, all participants had baseline TC values in the "desirable" range except for 4 participants in the "borderline high" range. Similarly, all participants in the current study had baseline LDL-C values in the "desirable" or "near optimal" categories, with 40 out of 48 participants having LDL-C values in the "desirable" category. Previous pistachio feeding studies have utilized samples with 
greater variation in baseline lab values and anthropometric characteristics compared to the relatively homogenous sample utilized in this study. A more heterogeneous sample may have provided more opportunity for changes to occur during the intervention periods.

\section{Strengths and Limitations}

This study followed a crossover design, which allowed each participant to serve as their own control thereby decreasing variability between participants in each treatment group. Another strength of the study was that participants in the pistachio group were given individually labeled, pre-measured bags of pistachios for each day of the week. This helped participants keep track of their intake and made sure that participants consumed the proper quantity of pistachios each day. All empty pistachio bags were collected at the end of each week to help ensure compliance. Additionally, the use of DXA provided a high level of precision in determining total body fat percentage (Rothney et al., 2012).

One limitation of this study is the relatively small sample size. While the sample size of this study was larger than that of most previous pistachio feeding studies, a larger sample size may have yielded more power to detect significant results. Initially, a power of $80 \%$ to predict individual changes was based on a sample size of 30 participants per study site; however, due to loss of follow-up, CP-SLO and CP-P only retained 25 and 23 participants, respectively, thereby decreasing the power of the study.

Additionally, while previous studies have shown significant changes in blood lipids in as little as 3 weeks (Aldemir et al., 2011; Baer et al., 2012; Edwards et al., 2009; Kocygit et al., 2006), a longer intervention period may have provided more time for 
changes to occur in this specific sample. The only pistachio feeding studies that have shown significant changes in measures of adiposity utilized intervention periods spanning 12 weeks or more.

Because this was a free-living study design researchers expected that participants consumed all of the pistachios they were given. Despite measures to account for empty bags there was no way to guarantee that participants actually consumed all required servings of pistachios.

\section{Future Research}

While historically there has been concern for the relatively high fat content of nuts and subsequent impacts on blood lipids, body weight, and CVD risk (Hu, 2003), this study is part of the large body of literature that has helped to dispel that notion. This study showed that consuming $20 \%$ of energy per day worth of pistachios did not negatively impact the lipid profile and was not associated with changes in measures of adiposity. While previous research is fairly consistent in highlighting the beneficial effects of nut consumption on the lipid profile and thus on CVD risk, this study cannot confirm these findings.

Therefore, future research may benefit from utilizing a greater number of participants, more diversity and heterogeneity in study participants, and longer treatment periods. Including a greater number of participants will help increase statistical power, and longer treatment periods will help determine the longer-term effects of pistachio consumption in conjunction with other dietary variables, and help determine the limits of improvements in the lipid profile based on pistachio consumption. Implementing a controlled feeding design is also beneficial to more effectively monitor energy intake, 
account for variations in the background diet, and to ensure that participants adhere to their assigned dietary interventions. Future nut intervention studies should attempt to have participants complete food records and conduct nutrient analyses to help determine any significant changes in diet quality due to nuts. This will help confirm and/or provide new information on particular dietary components found in pistachios that are responsible for beneficial changes in health.

Due to the increased risk of CVD with age (Odden et al., 2011) future pistachio intervention trials may find it useful to focus on the effects of pistachio consumption on blood lipids in elderly populations both with and without dyslipidemia. Additionally, because results have been mixed among previous studies targeting young, healthy populations, follow-up studies should continue to evaluate this demographic to determine if pistachio consumption provides any significant health benefits in already healthy populations.

While previous research has focused heavily on the ability of nuts to prevent CVD and other diseases, far less research has studied the potential of nuts to treat CVD. In certain cases plant-based diets have been shown to be as effective at reducing LDL-C as lipid lowering medication, with lower costs and fewer side effects (Rosenthal, 2000). Therefore, future intervention trials should be conducted in patients who have already suffered a cardiovascular event to determine the potential of nuts to protect against a second incident. If such research yields positive results then pistachio consumption may be a relatively inexpensive and noninvasive way to help manage the lipid profile and reduce the risk of subsequent cardiovascular events without relying exclusively on medications. 
While many large epidemiological studies have made the association between nut consumption and CVD risk (Mukuddem-Petersen et al., 2005), associations between nut consumption and the lipid profile have not been established in long-term prospective cohort studies, despite being widely studied in short-term clinical trials. Longer-term evaluations of the effects of pistachios on the lipid profile may be an area for future research. Additionally, large epidemiological studies often are not specific to the type of nut consumed, which may be a helpful addition to future research. Lastly, because childhood obesity has become so prevalent (Must \& Strauss, 1999) prospective cohort studies in children would be beneficial in determining if nut consumption at a young age is preventative against overweight or obesity as a teenager or young adult.

Because there is still some uncertainty as to the mechanisms behind the effects of pistachio consumption (and nut consumption in general) on blood lipids and measures of adiposity, future research should continue to focus on this area. Studies suggest that TC and LDL-C levels following nut consumption are $25 \%$ lower than would be predicted if the effect were due to the fatty acid composition of the nuts alone (Griel \& Kris-Etherton, 2006). The extent to which various nutritional components of pistachios play a role in lipid lowering is unknown, therefore more mechanistic research is needed to determine which nutrients found in pistachios are most important for improving health.

The potential of nuts to increase energy expenditure has also been controversial and more research is needed to determine the validity of past results. Similarly, more research is needed on the satiety properties of nuts and how this information may be used to promote health. Research comparing the satiety properties of nuts to other snack foods may help provide useful dietary advice to help maintain a healthy weight. 


\section{WORKS CITED}

Albert, C. M., Gaziano, J. M., Willett, W. C., \& Manson J. E. (2002). Nut consumption and decreased risk of sudden cardiac death in the Physicians' Health Study. Archives of Internal Medicine, 162, 1382-1387.

Aldemir, M., Okulu, E., Neşelioğlu, S., Erel, O., \& Kayıgil, O. (2011). Pistachio diet improves erectile function parameters and serum lipid profiles in patients with erectile dysfunction. International Journal of Impotence Research, 23(1), 32-38. doi:10.1038/ijir.2010.33

Alexiadou, K., \& Katsilambros, N. (2011). Nuts: anti-atherogenic food? European Journal of Internal Medicine, 22(2), 141-146. doi:10.1016/j.ejim.2010.11.008

Ambring, A., Friberg, P., Axelsen, M., Laffrenzen, M., Taskinen, M., Basu, S., \& Johansson, M. (2004). Effects of a Mediterranean-inspired diet on blood lipids, vascular function and oxidative stress in healthy subjects, Clinical Science, 104, $519-525$.

American Heart Association (2010). Levels of cholesterol. Retrieved from http://www.heart.org/HEARTORG/GettingHealthy/FatsAndOils/Fats101/Levelsof-Cholesterol_UCM_305051_Article.jsp

Appel, L. J., Sacks, F. M., Carey, V. J., Obarzanek, E., Swain, J. F., Miller, E. R., ... Bishop, L. M. (2005). Effects of protein, monounsaturated fat, and carbohydrate intake on blood pressure and serum lipids. The Journal of the American Medical Association, 294(19), 2455-2464.

Baer, D. J., Gebauer, S. K., \& Novotny, J. A. (2012). Measured energy value of pistachios in the human diet. The British Journal of Nutrition, 107(1), 120-125. doi:10.1017/S0007114511002649

Berglund, L., Lefevre, M., Ginsberg, H. N., Kris-Etherton, P. M., Elmer, P. J., Stewart, P. W., ... Reed, R. (2007). Comparison of monounsaturated fat with carbohydrates as a replacement for saturated fat in subjects with a high metabolic risk profile: Studies in the fasting and postprandial states. American Journal of Clinical Nutrition, 86, 1611-1620.

Berry, S. E. E., Tydeman, E. A., Lewis, H. B., Phalora, R., Rosborough, J., Picout, D. R., \& Ellis, P. R. (2008). Manipulation of lipid bioaccessibility of almond seeds influences postprandial lipemia in healthy human subjects. American Journal of Clinical Nutrition, 88, 922-929.

Bes-Rastrollo, M., Sabaté, J., Gomez-Gracis, E., Alonso, A., Martinez, J. A., \& MartinezGonzalez, M. A. (2007). Nut consumption and weight gain in a Mediterranean cohort: The SUN Study. Obesity, 15, 107-116. 
Blanck, H. M., Gillespie, C., Kimmons, J. E., Seymour, J. D., \& Serdula, M. K. (2008). Trends in fruit and vegetable consumption among U.S. men and women, 19942005. Preventing Chronic Disease, 5(2), 1-10.

Blomhoff, R., Carlsen, M. H., Andersen, L.F., \& Jacobs, D. R. (2006). Health benefits of nuts: Potential role of antioxidants. British Journal of Nutrition, 96, 52S-60S.

Bray, G. A. (2004). Medical consequences of obesity. The Journal of Clinical Endocrinology \& Metabolism, 89(6), 2583-2589.

Brotman, D. J., Golden, S. H., \& Wittstein, I. S. (2007). The cardiovascular toll of stress. Lancet, 370, 1089-1100.

Brown, M. A., Munford, A. M., \& Munford, P. R. (1993). Behavior therapy of psychological distress in patients after myocardial infarction or coronary bypass. Journal of Cardiopulmonary Rehabilitation and Prevention, 13, 201-210.

Burns-Whitmore, B., Hall, L. M., Towne, A. H., Bushnell, A. H., \& Roy, S. (2014). Pistachio consumption at $20 \%$ of energy does not significantly change body composition or blood lipids, but significantly decreases hunger, and increases satiety in free-living, healthy college-aged women. Manuscript submitted for publication.

Casas-Agustench, P., López-Uriarte, P., Bulló, M., Ros, E., Cabré-Vila, J. J., \& SalasSalvadó, J. (2009). Effects of one serving of mixed nuts on serum lipids, insulin resistance and inflammatory markers in patients with the metabolic syndrome. Nutrition, Metabolism \& Cardiovascular Diseases, 21(2), 126-135.

Chaput, J. P., Klingenberg, L., Astrup, A., \& Sjodin, A. M. (2011). Modern sedentary activities promote overconsumption of food in our current obesogenic environment. Etiology and Pathophysiology, 12, e12-e20.

Centers for Disease Control and Prevention. (2003). Public health and aging: Trends in aging - United States and worldwide. Morbidity and Mortality Weekly Report, 52(6), 101-106. Retrieved from http://www.cdc.gov/mmwr/preview/mmwrhtml/mm5206a2.htm

Centers for Disease Control and Prevention (2010). Heart disease and stroke prevention. Retrieved from http://www.cdc.gov/chronicdisease/resources/publications/aag/dhdsp.htm

Centers for Disease Control and Prevention (2013). Preventable deaths from heart disease and strokes. Retrieved from http://www.cdc.gov/VitalSigns/HeartDiseaseStroke/ 
Centers for Disease Control and Prevention. (2014). Heart disease facts.

Retrieved from: http://www.cdc.gov/heartdisease/facts.htm

Chen, C. O., \& Blumberg, J. B. (2008). Phytochemical composition of nuts. Asian Pacific Journal of Clinical Nutrition, 17, 329-332.

Darmon, N., \& Drewnowski, A. (2008). Does social class predict quality? American Journal of Clinical Nutrition, 87, 1107-1017.

Denova-Gutierrez, E., Castanon, S., Talavera, J. O., Flores, M., Macias, N., RodriquezRamirez, S., ... Salmeron, J. (2011). Dietary patterns are associated with different indexes of adiposity and obesity in an urban Mexican population. The Journal of Nutrition, 141, 921-927. doi:10.3945/jn.110.132332.

DeVol, R., \& Bedroussian, A. (2007). An unhealthy America: The economic burden of chronic disease, charting a new course to save lives and increase productivity and economic growth. Retrieved from Milken Institute website:

http://assets1b.milkeninstitute.org/assets/Publication/ResearchReport/PDF/chroni c_disease_report.pdf

Dreher, M. L. (2012). Pistachio nuts: Composition and potential health benefits. Nutrition Reviews, 70(4), 234-240. doi:10.1111/j.1753-4887.2011.00467.x

Edwards, K., Kwaw, I., Matud, J., \& Kurtz, I. (1999). Effect of pistachio nuts on serum lipid levels in patients with moderate hypercholesterolemia. Journal of the American College of Nutrition, 18(3), 229-232. Retrieved from http://www.ncbi.nlm.nih.gov/pubmed/10376778

Ellis, P. R., Kendall, C. W. C., Ren, Y., Parker, C., Pacy, J. F., Waldron, K. W., \& Jenkins, D. J. A. (2004). Role of cell walls in the bioaccessibility of lipids in almond seeds. The American Journal of Clinical Nutrition, 80, 604-613.

Ellsworth, J. L., Kushi, L. H., \& Folsom, A. R. (2001). Frequent nut intake and risk of death from coronary heart disease and all causes in postmenopausal women: The Iowa Women's Health Study. Nutrition, Metabolism, and Cardiovascular Diseases, 11, 372-377.

Estruch, R., Ros, E., Salas-Salvadó, J., Covas, M. I., Corella, D., Arós, F., ... MartínezGonzález, M. A. (2013). Primary prevention of cardiovascular disease with a Mediterranean diet. The New England Journal of Medicine, 368(14), 1279-1290. doi:10.1056/NEJMoa1200303

Ferdowsian, H. R., \& Barnard, N. D. (2009). Effects of plant-based diets on plasma lipids. American Journal of Cardiology, 104, 947-956. 
Flegal, K. M., Williamson, D. F., Pamuk, E. R., \& Rosenberg, H. M. (2004). Estimating deaths attributable to obesity in the United States. The American Journal of Public Health, 94(9), 1486-1489.

Fletcher, B., Berra, K., Ades, P., Braun, L. T., Burke, L. E., Durstine, J L., ... Winston, M. (2005). Managing abnormal blood lipids. Circulation, 112, 3184-3209.

Flores-Mateo, G., Rojas-Rueda, D., Basora, J., Ros, E., \& Salas-Salvadó, J. (2013). Nut intake and adiposity: Meta-analysis of clinical trials. The American Journal of Clinical Nutrition, 97(6), 1346-1355. doi:10.3945/ajcn.111.031484

Fowke, J. H., \& Matthews, C. E. (2010). PSA and body composition by dual x-ray absorptiometry (DXA) in NHANES. Prostate, 70(2), 120-125.

Fraser, G. E., Sabaté, J., Beeson, W. L., Strahan, T. M. (1992). A possible protective effect of nut consumption on risk of coronary heart disease. The Adventist Health Study. Archives of Internal Medicine, 152, 1416-1424.

Fryar, C. D., Hirsch, R., Eberhardt, M. S., Yoon, S. S., \& Wright, J. D. (2010). Hypertension, high serum total cholesterol, and diabetes: Racial and ethnic prevalence differences in U.S. adults, 1999-2006 (NCHS Data Brief No. 36). Retrieved from U.S. Department of Health and Human Services, Centers for Disease Control and Prevention website: http://www.cdc.gov/nchs/data/databriefs/db36.htm

Fung, T. T., Rexrode, K. M., Mantzoros, C. S., Manson, J. E., Willett, W. C., \& Hu, F. B. (2009). Mediterranean diet and incidence of and mortality from coronary heart disease and stroke in women. Circulation, 119(8), 1093-1100. doi:10.1161/CIRCULATIONAHA.108.816736

Gebauer, S. K., West, S. G., Kay, C. D., Alaupovic, P., Bagshaw, D., \& Kris-Etherton, P. M. (2008). Effects of pistachios on cardiovascular disease risk factors and potential mechanisms of action: a dose-response study. The American Journal of Clinical Nutrition, 88(3), 651-659. Retrieved from http://www.ncbi.nlm.nih.gov/pubmed/18779280

Go, A. S., Mozaffarian, D., Roger, V. L., Benjamin, E. J., Berry, J. D., Blaha, M. J., ... Turner, M. B. (2014). Heart disease and stroke statistics--2014 update: A report from the American Heart Association. Circulation, 129, e28-e292. doi:10.1161/01.cir.0000441139.02102.80

Gordon, D. J., Probstfield, J. L., Garrison, R. J., Neaton, J. D., Castelli, W. P., Knoke, J., ... Tyroler, H. A. (1989). High-density lipoprotein cholesterol and cardiovascular disease: Four prospective American studies. Circulation, 79, 8-15.

Griel, A. E., \& Kris-Etherton, P. M. (2006). Tree nuts and the lipid profile: A review 
of clinical studies. British Journal of Nutrition, 96(2), S68-S78.

Gropper, S. S., Smith, J. L., \& Groff, J. L. (2009). Advanced nutrition and human metabolism. Belmont, CA: Wadsworth, Cengage Learning.

Grundy, S. M. (1998). Hypertriglyceridemia, atherogenic dyslipidemia, and the metabolic syndrome. American Journal of Cardiology, 81, 18B-25B.

Grundy, S. M., Cleeman J. I., Daniels S. R., Donato K. A., Eckel R. H., Franklin B. A., ... Costa, F. (2005). Diagnosis and management of the metabolic syndrome: An American Heart Association/National Heart, Lung, and Blood Institute scientific statement. Circulation, 112, 2735-2752.

Gulati, S., Misra, A., Pandey, R. M., Bhatt, S. P., \& Saluja, S. (2014). Effects of pistachio nuts on body composition, metabolic, inflammatory and oxidative stress parameters in Asian Indians with metabolic syndrome: A 24-wk, randomized control trial. Nutrition, 30(2), 192-197. doi:10.1016/j.nut.2013.08.005

Halvorsen, B. L., Carlsen, M. H., Phillips, K. M., Bøhn, S. K., Holte, K., Jacobs, D. R. Jr., \& Blomhoff, R. (2006). Content of redox-active compounds (i.e. antioxidants) in foods consumed in the United States. The American Journal of Clinical Nutrition, 84, 95-135.

Heidemann, C., Schulze, M. B., Franco, O. H., van Dam, R. M., Mantzoros, C. S., \& Hu, F. B. (2008). Dietary patterns and risk of mortality from cardiovascular disease, cancer, and all causes in a prospective cohort of women. Circulation, 118(3), 230-237. doi:10.1161/CIRCULATIONAHA.108.771881

Heidenreich, P. A, Trogdon, J. G., Khavjou, O. A., Butler, J., Dracup, K., Ezekowitz, M. D., ... Woo, Y. J. (2011). Forecasting the future of cardiovascular disease in the United States: A policy statement from the American Heart Association. Circulation, 123(8), 933-944. doi:10.1161/CIR.0b013e31820a55f5

Herber, D., \& Bowerman, S. (2008). The pistachio: A surprising and colorful nut. Nutrition Today, 43(1), 36-40.

Hill, J. O., Wyatt, H. R., Reed, G. W., \& Peters, J. C. (2003). Obesity and the environment: Where do we go from here? Science, 299, 853-855.

Hsu, S., Ton, V. K., Dominique Ashen, M., Martin, S. S., Gluckman, T. J., Kohli, P., ... Blaha, M. J. (2013). A clinician's guide to the ABCs of cardiovascular disease prevention: The Johns Hopkins Ciccarone Center for the Prevention of Heart Disease and American College of Cardiology Cardiosource Approach to the Million Hearts Initiative. Clinical Cardiology, 36(7), 383-393. doi:10.1002/clc.22137 
$\mathrm{Hu}, \mathrm{F}$. B. (2003). Plant-based foods and prevention of cardiovascular disease: An overview. The American Journal of Clinical Nutrition, 78, 544-551.

Hu, F. B., Rimm, E. B., Stampfer, M. J., Ascherio, A., Spiegelman, D., \& Willett, W. C. (2000). Prospective study of major dietary patterns and risk of coronary heart disease in men. The American Journal of Clinical Nutrition, 72, 912-921.

Hu F. B. Stampfer, M. J., Manson J. E., Rimm E. B., Colditz, G. A., Rosner, B. A., ... Willett, W. C. (1998). Frequent nut consumption and risk of coronary heart disease in women: Prospective cohort study. British Medical Journal, 317, 13411345 .

Hyre, A. D., Muntner, P., Menke, A,. Raggi, P., \& He, J. (2007). Trends in ATP-IIIdefined high blood cholesterol prevalence, awareness, treatment and control among U.S. adults. Annals of Epidemiology, 17, 548-555.

Iqbal, R., Anand, S., Ounpuu, S., Islam, S., Zhang, X., Rangarajan, S., ... Yusuf, S. (2008). Dietary patterns and the risk of acute myocardial infarction in 52 countries: Results of the INTERHEART study. Circulation, 118(19), 1929-1937. doi:10.1161/CIRCULATIONAHA.107.738716

Jenkins, D. J., Hu, F. B., Tapsell, L. C., Josse, A. R., \& Kendall, C. W. (2008). Possible benefit of nuts in type 2 diabetes. Journal of Nutrition, 138, 1752-1756.

Jiang, R., Manson J. E., Stampfer, M. J. Liu, S., Willet, W. C., \& Hu, F. B. (2002). Nut and peanut butter consumption and risk of type 2 diabetes in women. The Journal of the American Medical Association, 288, 2554-2560.

Josse, A. R., Kendall, C. W., Augustin, L. S., Ellis, P. R, \& Jenkins, D. J. (2007). Almonds and postprandial glycemia - a dose-response study. Metabolism, 56, 400-404.

Jude, E., \& Gibbons, J. (2005). Identifying and treating intermittent claudication in people with diabetes. The Diabetic Foot, 8, 84-92.

Kay, C. D., Gebauer, S. K., West, S. G., \& Kris-Etherton, P. M. (2010). Pistachios increase serum antioxidants and lower serum oxidized-LDL in hypercholesterolemia adults. The Journal of Nutrition, 140, 1093-1098. doi:10.3945/jn.109.117366.1093

Kelly Jr. J. H., \& Sabaté, J. (2006). Nuts and coronary heart disease: An epidemiological perspective. British Journal of Nutrition, 96(2), S61-S67.

Kendall, C. W. C., Josse, A. R., Esfahani, A. \& Jenkins, D. J. (2011). The impact of pistachio intake alone or in combination with high-carbohydrate foods on postprandial glycemia. European Journal of Clinical Nutrition, 65(6), 696-702. doi:10.1038/ejen.2011.12 
Kishimoto, Y., Tani, M., Uto-Kondo, H., Saita, E., Iizuka, M., Sone, H., ... Kondo, K. (2010). Effects of magnesium on postprandial serum lipid responses in healthy human subjects. The British Journal of Nutrition, 103(4), 469-472. doi:10.1017/S0007114509992716

Kochanek, K. D., Xu, J. Q., Murphy, S. L., Miniño, A. M., \& Kung, H. C. (2009). Deaths: final data for 2009 (National Vital Statistics Reports). Retrieved from U.S. Department of Health and Human Services, Centers for Disease Control and Prevention, National Center for Health Statistics website: http://www.cdc.gov/nchs/data/nvsr/nvsr60/nvsr60_03.pdf

Kocyigit, A., Koylu, A. A., \& Keles, H. (2006). Effects of pistachio nuts consumption on plasma lipid profile and oxidative status in healthy volunteers. Nutrition, Metabolism, and Cardiovascular Diseases, 16(3), 202-209. doi:10.1016/j.numecd.2005.08.004

Krebs-Smith, S. M., Guenther, P. M., Subar, A. F., Kirkpatrick, S. I., \& Dodd, K. W. (2010). Americans do not meet federal dietary recommendations. The Journal of Nutrition, 140(10), 1832-1838. doi:10.3945/jn.110.124826

Kris-Etherton P.M., Hu, F.B., Ros E., \& Sabaté J. (2008). The role of tree nuts and peanuts in the prevention of coronary heart disease: Multiple potential mechanisms. Journal of Nutrition, 138, S1746-S1751.

Kris-Etherton, P. M., Zhao, G., Binkoski, A. E., Coval, S. M., \& Etherton, T. D. (2001). The effects of nuts on coronary heart disease risk. Nutrition Reviews, 59(4), 10311. Retrieved from http://www.ncbi.nlm.nih.gov/pubmed/11368503

Li, D. (2013). Effect of the vegetarian diet on non-communicable diseases. Journal of the Science of Food and Agriculture, 94(2), 169-73. doi:10.1002/jsfa.6362

Li, Z., Song, R., Nguyen, C., Zerlin, A., Karp, H., Naowamondhol, K., ... Heber, D. (2010). Pistachio nuts reduce triglycerides and body weight by comparison to refined carbohydrate snack in obese subjects on a 12-week weight loss program. Journal of the American College of Nutrition, 29(3), 198-203. doi:10.1080/07315724.2010.10719834

Lloyd-Jones, D., Adams, R., Carnethon, M., De Simone, G., Ferguson, T. B., Flegal, K., ... Hong, Y. (2009). Heart disease and stroke statistics--2009 update: A report from the American Heart Association Statistics Committee and Stroke Statistics Subcommittee. Circulation, 119(3), e21-181, 480-486.

Lloyd-Jones, D. M., Larson, M. G., Beiser, A., \& Levy, D. (1999). Lifetime risk of developing coronary heart disease. Lancet, 353, 89-92. 
London, H. A., Pawlak, R., Colby, S. E., Wall-Bassett, E., \& Sira, N. (2013). The impact of pistachio consumption on blood lipid profile: A literature review. American Journal of Lifestyle Medicine, 7(4), 274-277. doi:10.1177/1559827613479910

Lutsey, P. L., Steffen, L. M., \& Stevens, J. (2008). Dietary intake and the development of the metabolic syndrome: The Atherosclerosis Risk in Communities study. Circulation, 117(6), 754-761. doi:10.1161/CIRCULATIONAHA.107.716159

Marieb, E. N., \& Hoehn, K. (2013). Human anatomy and physiology. Glenview, IL: Pearson.

Mattes, R., \& Dreher, M. L. (2010). Nuts and healthy body weight maintenance mechanisms. Asian Pacific Journal of Clinical Nutrition, 19(1), 137-141.

Mattes, R. D., Kris-Etherton, P. M., \& Foster, G. D. (2008). Impact of peanuts and tree nuts on body weight and healthy weight loss in adults. Journal of Nutrition, 138, 1741-1745.

McEvoy, C. T., Temple, N., \& Woodside, J. V. (2012). Vegetarian diets, low-meat diets and health: A review. Public Health Nutrition, 15(12), 2287-2294. doi:10.1017/S1368980012000936

Mendez, M. A., Popkin, B. M., Jakszyn, P., Berenguer, A., Chirlaque, D., Barricarte, A., ... Gonza, C. A. (2006). Adherence to a Mediterranean diet is associated with reduced 3-Year incidence of obesity. The Journal of Nutrition, 136, 2934-2938.

Miller, M., Stone, N. J., Ballantyne, C., Bittner, V., Criqui, M. H., Ginsberg, H. N., ... Pennathur, S. (2011). Triglycerides and cardiovascular disease: A scientific statement from the American Heart Association. Circulation, 123(20), 22922333. doi:10.1161/CIR.0b013e3182160726

Mukuddem-Petersen, J., Oosthuizen, W., \& Jerling, W. (2005). A systematic review of the effects of nuts on blood lipid profiles in humans. Journal of Nutrition, 135, 2082-2089.

Must, A., \& Strauss, R. S. (1999). Risks and consequences of childhood and adolescent obesity. International Journal of Obesity, 23(2), S2-S11.

Nash, S. D., \& Nash, D. T. (2008). Nuts as part of a healthy cardiovascular diet. Current Atherosclerosis Reports, 10, 529-535.

Natoli, S., \& McCoy, P. (2007). A review of the evidence: Nuts and body weight. Asian Pacific Journal of Clinical Nutrition, 16(4), 588-597.

Nelms, M., Sucher, K. P., Lacey, K., \& Roth, S. L. (2011). Nutrition therapy and pathophysiology. Belmont, CA: Brooks/Cole. 
Nicholson, A., Kuper, H., \& Hemingway, H. (2006) Depression as an aetiologic and prognostic factor in coronary heart disease: A meta-analysis of 6362 events among 146538 participants in 54 observational studies. European Heart Journal, 27, 2763-2774. doi: 10.1093/eurheartj/ehl338

Nielsen, S. J., Kit, B. K., \& Ogden, C. L. (2014). Nut consumption among U.S. adults, 2009-2010 (NCHS data brief, No. 176). Retrieved from U.S. Department of Health and Human Services, Centers for Disease Control and Prevention, National Center for Health Statistics website: http://www.cdc.gov/nchs/data/databriefs/db176.pdf

Nielsen, S. J., \& Popkin, B. M. (2003). Patterns and trends in food portion sizes, 19771998. The Journal of the American Medical Association, 298, 450-453.

Nutrition Data System for Research (version 2012) [Computer software]. Minneapolis, $\mathrm{MN}$ : Nutrition Coordinating Center (NCC), University of Minnesota.

Odden, M. C., Coxson, P. G., Moran, A., Lightwood, J. M., Goldman, L., \& BibbinsDomingo, K. (2011). The impact of the aging population on coronary heart disease in the U.S. American Journal of Medicine, 124(9), 827-833. doi:10.1016/j.amjmed.2011.04.010.

Ogden, C. L., Carroll, M. D., Kit, B. K., \& Flegal, K. M. (2014). Prevalence of childhood and adult obesity in the United States, 2011-2012. The Journal of the American Medical Association, 311(8), 806-814. doi:10.1001/jama.2014.732

O’Neil, C. E., Keast, D. R., Fulgoni, V. L., \& Nicklas, T. A. (2010). Tree nut consumption improves nutrient intake and diet quality in US adults: An analysis of National Health and Nutrition Examination Survey (NHANES) 1999-2004. Asia Pacific Journal of Clinical Nutrition, 19(1), 142-150. Retrieved from http:/www.ncbi.nlm.nih.gov/pubmed/20200000

Ornish, D., Brown, S. E., Scherwitz, L. W., Billings, J. H., Armstrong, W. T., Ports, T. A., ... Gould, K. L. (1990). Can lifestyle changes reverse coronary heart disease? The Lifestyle Heart Trial. Lancet, 336(8708), 129-133. doi: http://dx.doi.org/10.1016/0140-6736(90)91656-U

Ornish, D., Scherwitz, L. W., Billings, J. H., Gould, K. L., Merritt, T. A., Sparler, S., ... Brand, R. J. (1998). Intensive lifestyle changes for reversal of coronary heart disease. The Journal of the American Medical Association, 280(23), 2001-2007. doi: http://dx.doi.org/10.1001/jama.280.23.2001

Ostlund, R. E. (2007). Phytosterols, cholesterol absorption and healthy diets. Lipids, 42(1), 41-45. doi:10.1007/s11745-006-3001-9 
Phillips, K.M., Ruggio, D.M., \& Ashraf-Khorassani, M. (2005). Phytosterol composition of nuts and seeds commonly consumed in the United States. Journal of Agriculture and Food Chemistry, 53, 9436-9466.

Pilis, W., Stec, K., Zych, M., \& Pilis, A. (2014). Health benefits and risk associated with adopting a vegetarian diet. Roczniki Państwowego Zakładu Higieny, 65(1), 9-14.

Prosser, L. A., Stinnett, A. A., Goldman, P.A., Williams, L. W., Hunink, M. G. M., Goldman, L., \& Weinstein, M. C. (2000). Cost effectiveness of cholesterollowering therapies according to selected patient characteristics. Annals of Internal Medicine, 132, 769-79.

Reid, J., Ski, C. F., \& Thompson, D. R. (2013). Psychological interventions for patients with coronary heart disease and their partners: a systematic review. Public Library of Science One, 8(9), e73459. doi:10.1371/journal.pone.0073459

Roest, A. M., Martens, E. J., Denollet, J., \& De Jonge, P. (2010) Prognostic association of anxiety post myocardial infarction with mortality and new cardiac events: A meta-analysis. Psychosomatic Medicine, 72, 563-569. doi:10.1097/psy.0b013e3181dbff97

Roger, V. L., Go, A. S., Lloyd-Jones, D. M., Benjamin, E. J., Berry, J. D., Borden, W. B., ... Turner, M. B. (2012). Heart disease and stroke statistics--2012 update: A report from the American Heart Association. Circulation, 125(1), e2-e220. doi:10.1161/CIR.0b013e31823ac046

Ros, E. (2010). Health benefits of nut consumption. Nutrients, 2(7), 652-82. doi:10.3390/nu2070652

Ros. E., Núñez, I., Pérez-Heras, A., Serra, M., Gilabert, R., Casals, E., \& Deulofeu, R. (2004). A walnut diet improves endothelial function in hypercholesterolemic subjects: A randomized crossover trial. Circulation, 109, 1609-1614.

Rosenthal, R. L. (2000). Effectiveness of altering serum cholesterol levels without drugs. Baylor University Medical Center Proceedings, 13, 351-355.

Rothney, M. P., Martin, F.P., Xia, Y., Beaumont, M., Davis, C., Ergun, D., ... Rezzi, S. (2012). Precision of GE Lunar iDXA for the measurement of total and regional body composition in nonobese adults. Journal of Clinical Densitometry, 15(4), 399-404. http://doi.org/10.1016/j.jocd.2012.02.009

Sabaté, J. (1993). Does nut consumption protect against ischaemic heart disease? European Journal of Clinical Nutrition, 47, S71-S75.

Sabaté, J. (2003). Nut consumption and body weight, American Journal of Clinical Nutrition, 78(11), 647-650. 
Sabaté, J., \& Ang, Y. (2009). Nuts and health outcomes: New epidemiologic evidence. American Journal of Clinical Nutrition, 89, 1643-1648. doi:10.3945/ajen.2009.26736Q.Am

Sabaté, J., Oda, K., \& Ros, E. (2010). Nut consumption and blood lipids: A pooled analysis of 25 intervention trials. Archives of Internal Medicine. 170, 821-827.

Sabaté, J., \& Wien, M. (2010). Nuts, blood lipids and cardiovascular disease. Asia Pacific Journal of Clinical Nutrition, 19(1), 131-136. Retrieved from http://www.ncbi.nlm.nih.gov/pubmed/20199998

Salas-Salvadó, J., Bulló, M., Pérez-Heras, A., \& Ros, E. (2006). Dietary fibre, nuts and cardiovascular diseases. British Journal of Nutrition, 96(S2), S45-S51. doi:10.1017/BJN20061863

Salas-Salvadó J., Casas-Agustench, P., \& Salas-Huetos, A. (2011). Cultural and historical aspects of Mediterranean nuts with emphasis on their attributed healthy and nutritional properties. Nutrition, Metabolism \& Cardiovascular Disease, 21(S1), S1-S6.

Sari, I., Baltaci, Y., Bagci, C., Davutoglu, V., Erel, O., Celik, H., ... Aksoy, M. (2010). Effect of pistachio diet on lipid parameters, endothelial function, inflammation, and oxidative status: A prospective study. Nutrition, 26(4), 399-404. doi:10.1016/j.nut.2009.05.023

Sauder, K.A, McCrea, C. E., Ulbrecht, J. S., Kris-Etherton, P. M., \& West, S. G. (2014). Pistachio nut consumption modifies systemic hemodynamics, increases heart rate variability, and reduces ambulatory blood pressure in well-controlled type 2 diabetes: A randomized trial. Journal of the American Heart Association, 3(4), e000873. doi:10.1161/JAHA.114.000873

Schroder, H., Marrugat, J., Vila, J., Covas, M. I., \& Elosua, R. (2004). Adherence to the traditional Mediterranean diet is inversely associated with body mass index and obesity in a Spanish population. The Journal of Nutrition, 134, 3355-3361.

Schulze B. M., Fung, T. T., Manson, J. E., Willett, W. C., \& Hu, F. B. (2006). Dietary patterns and changes in body weight in women. Obesity, 14(8), 1444-1453.

Sheridan, M. J., Cooper, J. N., Erario, M., \& Cheifetz, C. E. (2007). Pistachio nut consumption and serum lipid levels. Journal of the American College of Nutrition, 26(2), 141-148. doi:10.1080/07315724.2007.10719595

Simmonds, R. L., Tylee, A., Walters, P., \& Rose, D. (2013). Patients' perceptions of depression and coronary heart disease: A qualitative UPBEAT-UK study. BioMed Central Family Practice, 14, 38-46. doi:10.1186/1471-2296-14-38 
Stamler, J., Daviglus, M. L., Garside, D. B., Dyer, A. R., Greenland, P., \& Neaton, J. D. (2000). Relationship of baseline serum cholesterol levels in 3 large cohorts of younger men to long-term coronary, cardiovascular, and all-cause mortality and to longevity. The Journal of the American Medical Association, 284, 311-318.

Stapelberg, N. J. C., Neumann, D. L., Shum, D. H. K., McConnell, H., \& HamiltonCraig, I. (2011). A topographical map of the causal network of mechanisms underlying the relationship between major depressive disorder and coronary heart disease. The Australian and New Zealand Journal of Psychiatry, 45(5), 351-369. doi:10.3109/00048674.2011.570427

Toshima, S., Hasegawa, A., Kurabayashi, M., Itabe, H., Takano, T., Sugano, J., ... Nagai, R. (2000). Circulating oxidized low density lipoprotein levels: A biochemical risk marker for coronary heart disease. Arteriosclerosis, Thrombosis, and Vascular Biology, 20(10), 2243-2247. doi:10.1161/01.ATV.20.10.2243

Traoret, C. J., Lokko, P., Cruz, A. C. R. F., Oliveira, C. G., Costa, N. M. B., Bressan, J., ... Mattes, R. D. (2008). Peanut digestion and energy balance. International Journal of Obesity, 32(2), 322-328. doi:10.1038/sj.ijo.0803735

Tuso, P. J., Ismail, M. H., Ha, B. P., \& Bartolotto, C. (2013). Nutritional update for physicians: Plant-based diets, The Permanente Journal, 17(2), 61-66.

Uberoi, N., \& Cohen, J. (2012). Expenditures for heart disease among adults age 18 and older: Estimates for the U.S. civilian noninstitutionalized population, 2009 (Statistical Brief No. 393). Retrieved from U.S. Department of Health and Human Services, Agency for Healthcare Research and Quality website: http://meps.ahrq.gov/mepsweb/data_files/publications/st393/stat393.shtml

U.S. Census Bureau. (2015). State \& county QuickFacts: USA. Retrieved from http://quickfacts.census.gov/qfd/states/00000.html

U.S. Department of Agriculture, Agricultural Research Service. (2015) National nutrient database for standard reference release 27. Available from http://ndb.nal.usda.gov/ndb/search/list

U.S. Department of Agriculture and U.S. Department of Health and Human Services. (2010). Dietary guidelines for Americans $\left(7^{\text {th }}\right.$ ed.). Available from http://www.health.gov/dietaryguidelines/2010.asp

U.S. Department of Health and Human Services, Administration on Aging and Administration for Community Living. (2012). A profile of older Americans: 2012. Retrieved from http://www.aoa.gov/Aging_Statistics/Profile/2012/docs/2012profile.pdf 
U.S. Department of Health and Human Services, National Institute of Health, National Heart, Lung and Blood Institute. (2002). Third report of the National Cholesterol Education Program expert panel on detection, evaluation, and treatment of high blood cholesterol in adults (Adult Treatment Panel III) final report. Retrieved from http://www.nhlbi.nih.gov/files/docs/resources/heart/atp3full.pdf

U.S. Department of Health and Human Services, National Institute of Health, National Heart, Lung and Blood Institute. (2011). What are the signs and symptoms of coronary heart disease? Retrieved from http://www.nhlbi.nih.gov/health/healthtopics/topics/cad/signs

Vader, J. M., \& Drazner, M. H., (2009). Clinical assessment of heart failure: Utility of symptoms, signs, and daily weights. Heart Failure Clinics, 5(2), 149-160.

Vadivel, V., Kunyanga, C. N., \& Biesalski, H. K. (2012). Health benefits of nut consumption with special reference to body weight control. Nutrition, 28(11-12), 1089-1097. doi:10.1016/j.nut.2012.01.004

Vincent-Baudry, S., Defoort, C., Gerber, M., Bernard, M., Verger, P., \& Helal, O. (2005). The Medi-RIVAGE study: Reduction of cardiovascular disease risk factors after a 3-mo intervention with a Mediterranean-type diet or a low-fat diet. The American Journal of Clinical Nutrition, 82, 964-971.

Wang, X., Li, Z., Liu, Y., Lv, X., \& Yang, W. (2012). Effects of pistachios on body weight in Chinese subjects with metabolic syndrome. Nutrition Journal, 11(20), 4-6. doi:10.1186/1475-2891-11-20

Wolfe, B. M., \& Giovannetti, P. M. (1991). Short term effects of substituting protein for carbohydrate in the diets of moderately hypercholesterolemic human subjects. Metabolism, 40, 338-343.

World Health Organization. (2000). Obesity: Preventing and managing the global epidemic (WHO Technical Report Series No. 894). Retrieved from http://www.who.int/nutrition/publications/obesity/WHO_TRS_894/en/

World Health Organization, Division of Mental Health and Prevention of Substance Abuse. (1997). Measuring quality of life. Retrieved from http://www.who.int/mental_health/media/68.pdf 


\section{A. Screening Questionnaire}

\section{PISTACHIO STUDY INITIAL SCREENING QUESTIONNAIRE}

California State Polytechnic University, San Luis Obispo and California State Polytechnic University, Pomona

Date:

Major:

Thank you for taking the time to fill out this questionnaire. Please be sure to read each question carefully, and then check the appropriate box. All information you provide on this form will be kept confidential. After filling out the form, please save a copy on your computer, then attach it to an e-mail and return it to Alison at abushnel@calpoly.edu Alison will email you back and let you know if you qualify. Thank you again!

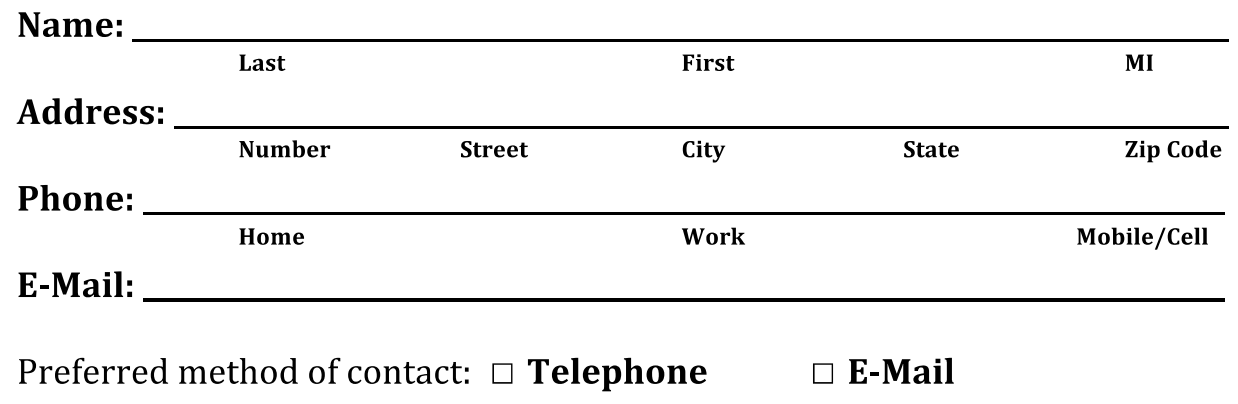

1. What is your age? __ years.

2. What is your biological gender?
$\square$ Male
$\square$ Female

3. What is your weight? __ pounds or __ kilograms.

4. Have you experienced any weight changes in the last year?

$\square$ No

$\square$ Yes: pounds gained or pounds lost over a period of months.

5. Do you currently have an exercise plan or are involved in sports? If you answer "No", please skip to question 7.

$\square$ No

$\square$ Yes, I exercise every __ day(s) using the following activities:

6. How long have you been following this exercise plan?

_ Days Months Y_ Years

7. What is your height? inches or centimeters. 
8. Do you have any current medical problems (ex. diabetes, high blood pressure)? $\square$ No

$\square$ Yes, I have the following:

9. Do you have any gastrointestinal problems (ex. IBS, ulcerative colitis)?

$\square$ No

$\square$ Yes, I have the following:

10. Are you currently taking any medications (prescription or over the counter)? $\square$ No

$\square$ Yes, I am taking:

11. How often do you take the following medications?

\begin{tabular}{|l|c|c|c|c|c|}
\hline Types of Medication & Never & Daily & Weekly & Monthly & Yearly \\
\hline Aspirin & $\square$ & $\square$ & $\square$ & $\square$ & $\square$ \\
\hline Tylenol (Acetominophen) & $\square$ & $\square$ & $\square$ & $\square$ & $\square$ \\
\hline Advil (Ibuprofen) & $\square$ & $\square$ & $\square$ & $\square$ & $\square$ \\
\hline Naprosin/Naproxin/Aleve & $\square$ & $\square$ & $\square$ & $\square$ & $\square$ \\
\hline Steroids/Steroidal drugs & $\square$ & $\square$ & $\square$ & $\square$ & $\square$ \\
\hline Hormone supplements & $\square$ & $\square$ & $\square$ & $\square$ & $\square$ \\
\hline Statins & $\square$ & $\square$ & $\square$ & $\square$ & $\square$ \\
\hline
\end{tabular}

12. Are you currently taking any supplements (ex. vitamins, plant sterols, fish oil)? $\square$ No

$\square$ Yes, I am taking:

13. Do you have high cholesterol?

$\square$ No

$\square$ Yes, my total blood cholesterol is $\mathrm{mg} / \mathrm{dL}$.

$\square$ I'm not sure, but I think so.

$\square$ I don't know.

14. Are you a(n):

$\square$ Omnivore

$\square$ Vegetarian

$\square$ Vegan/Strict Vegetarian

15. How long have you followed that diet? Days Months Years

16. Do you have any food allergies (ex. peanuts, shellfish, dairy)?

$\square$ No

$\square$ Yes, I have the following allergies: 
17. Are you allergic to nuts?
$\square$ No
$\square$ Yes

18. How often do you eat pistachios?
$\square$ Never
$\square$ Daily
$\square$ Weekly
$\square$ Monthly
$\square$ Yearly

19. Do you like pistachios?
$\square$ Yes
$\square$ No
$\square$ I am indifferent

20. How often do you eat any kinds of nuts?
$\square$ Never
$\square$ Daily
$\square$ Weekly
$\square$ Monthly
$\square$ Yearly

21. Are you willing to come to campus once a week to pick up your pistachios?
$\square$ Yes
$\square$ No

22. Would you be willing not to eat any other nuts during this study?
$\square$ Yes
$\square$ No

23. Do you have any pins or metal objects in your body (other than piercings that can be removed)?
$\square$ Yes
$\square$ No

24. Where did you find out about this study?

$\square$ E-Mail

$\square$ Flyer

$\square$ Friend or coworker 


\section{B. Food Records}

\section{Diet Record Instructions}

Directions: Record what you eat and drink on the sheets provided. As you record each food, make careful note of the amount and how it was prepared (fried, baked etc.). Estimate the amount to the nearest weight or fluid ounce, quarter cup, tablespoon, or other common measure. It is suggested to bring a measuring cup with you to meals.

In guessing at the sizes of meat portions, it helps to know that a piece of meat the size of the palm of your hand weighs about 3 or 4 ounces. It also helps to know that a slice of cheese (such as sliced American cheese) or a 1 1/2-inch cube of cheese weighs about 1 ounce. If you are unable to estimate serving sizes, measure out servings the size of a cup, tablespoon, and teaspoon onto a plate or into a bowl to see how they look. You will have to break down mixed dishes to their ingredients (for example: burrito $=10$ inch whole wheat tortilla, $1 / 4$ cup black beans drained, $1 / 4$ cup Spanish rice, 1oz. Monterey jack cheese, 2 tbs. chopped tomatoes, 1 tbs. chopped onion, 1/8 medium avocado sliced).

The closer your approximations, the closer your actual intake will be reflected. Some common errors include using weight ounces instead of fluid ounces. Record the liquids as fluid ounces and the solids as weight oz. It is also very helpful to read the labels of the foods you consume. If you eat name brand foods, please also include the name brand of the food or the restaurant chain name if applicable. Be sure to list the actual amounts of foods eaten (ie. don't include milk left in your bowl after eating cereal. Only count what you're consumed).

Please record any nutrient supplements you take.

Some Common Portion Sizes :

http://www.win.niddk.nih.gov/publications/just_enough.htm

Serving Sizes

1 cup of cereal $=\mathbf{a}$ fist

$1 / 2$ cup of cooked rice, pasta, or potato $=1 / 2$ baseball

1 baked potato $=$ a fist
Everyday Objects
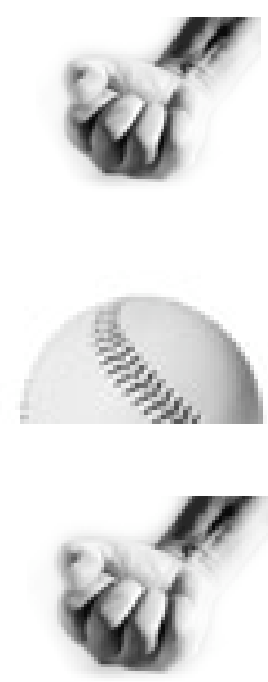
1 medium fruit $=\mathbf{a}$ baseball

$1 / 2$ cup of fresh fruit $=1 / 2$ baseball

$11 / 2$ ounces of low-fat or fat-free cheese $=4$ stacked dice
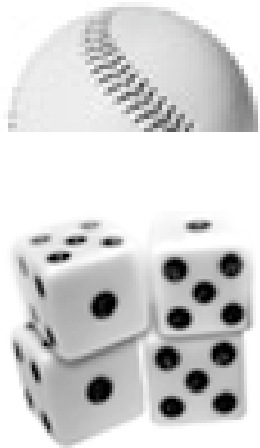

$1 / 2$ cup of ice cream $=1 / 2$ baseball

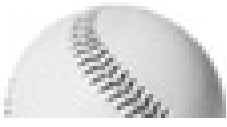

2 tablespoons of peanut butter $=$ a ping-pong ball 
Food Record \#

\begin{tabular}{|c|c|c|c|c|}
\hline $\begin{array}{l}\text { Hunger/Satiety } \\
\text { Rating* }^{*}\end{array}$ & $\begin{array}{l}\text { Meal }(B, L, D) \\
\text { or snack (S) }\end{array}$ & Food/Beverage (Brand) & Cooking Method & Amount \\
\hline & & & & \\
\hline & & & & \\
\hline & & & & \\
\hline & & & & \\
\hline & & & & \\
\hline & & & & \\
\hline & & & & \\
\hline & & & & \\
\hline & & & & \\
\hline & & & & \\
\hline & & & & \\
\hline & & & & \\
\hline & & & & \\
\hline & & & & \\
\hline & & & & \\
\hline & & & & \\
\hline & & & & \\
\hline & & & & \\
\hline & & & & \\
\hline & & & & \\
\hline & & & & \\
\hline & & & & \\
\hline & & & & \\
\hline & & & & \\
\hline & & & & \\
\hline
\end{tabular}

* See Hunger/Satiety Scale directions and list 3 numbers by each meal/snack for your rating (1-10) before, during and after each meal/snack (ie. 1, 5, 10 for Breakfast)

\begin{tabular}{|l|l|l|}
\hline $\begin{array}{l}\text { Supplements Taken } \\
\text { Today }\end{array}$ & Brand & $\begin{array}{l}\text { Amount } \\
\text { Taken }\end{array}$ \\
\hline & & \\
\hline & & \\
\hline & & \\
\hline
\end{tabular}

Page 3 of 3 


\section{Pistachio Recipe Ideas}

\section{How to Incorporate Pistachios Into Your Everyday Diet!}

\section{For breakfast:}

Sprinkle them on top of your favorite...

Cereal

Yogurt

Oatmeal

Blend them into your favorite...

Smoothie (You won't even know they are there!)

\section{For lunch or dinner:}

Chop them up and make a delicious crust for...

Tofu

Chicken

Fish

Mix them into your favorite...

Salad

Fruit salad

Sautéed vegetables or greens

Stir-fry

Rice dish

Pasta dish

\section{For a snack:}

Mix with dry fruit for a delicious...

Trail mix (But be sure not to add any other nuts!)

Grind them up to make your own...

Pistachio butter (You know, like peanut butter.)

Or...

Eat them just as they are! 


\section{Physical Activity Questionnaire \\ INTERNATIONAL PHYSICAL ACTIVITY QUESTIONNAIRE}

We are interested in finding out about the kinds of physical activities that people do as part of their everyday lives. The questions will ask you about the time you spent being physically active in the last 7 days. Please answer each question even if you do not consider yourself to be an active person. Please think about the activities you do at work, as part of your house and yard work, to get from place to place, and in your spare time for recreation, exercise or sport.

Think about all the vigorous activities that you did in the last 7 days. Vigorous physical activities refer to activities that take hard physical effort and make you breathe much harder than normal. Think only about those physical activities that you did for at least 10 minutes at a time.

1. During the last $\mathbf{7}$ days, on how many days did you do vigorous physical activities like heavy lifting, digging, aerobics, or fast bicycling? days per week

$\square$ No vigorous physical activities $\rightarrow$ Skip to question 3

2. How much time did you usually spend doing vigorous physical activities on one of those days?

hours per day minutes per day

Don't know/Not sure

Think about all the moderate activities that you did in the last 7 days. Moderate activities refer to activities that take moderate physical effort and make you breathe somewhat harder than normal. Think only about those physical activities that you did for at least 10 minutes at a time.

3. During the last $\mathbf{7}$ days, on how many days did you do moderate physical activities like carrying light loads, bicycling at a regular pace, or doubles tennis? Do not include walking. days per week

No moderate physical activities $\rightarrow$ Skip to question 5 
4. How much time did you usually spend doing moderate physical activities on one of those days?

hours per day minutes per day

Don't know/Not sure

Think about the time you spent walking in the last 7 days. This includes at work and at home, walking to travel from place to place, and any other walking that you might do solely for recreation, sport, exercise, or leisure.

5. During the last $\mathbf{7}$ days, on how many days did you walk for at least 10 minutes at a time? days per week

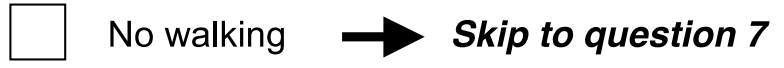

6. How much time did you usually spend walking on one of those days?

hours per day

minutes per day

$\square$ Don't know/Not sure

The last question is about the time you spent sitting on weekdays during the last 7 days. Include time spent at work, at home, while doing course work and during leisure time. This may include time spent sitting at a desk, visiting friends, reading, or sitting or lying down to watch television.

7. During the last $\mathbf{7}$ days, how much time did you spend sitting on a week day?

hours per day

minutes per day

Don't know/Not sure

This is the end of the questionnaire, thank you for participating. 


\section{E. Hunger/Satiety Scale}

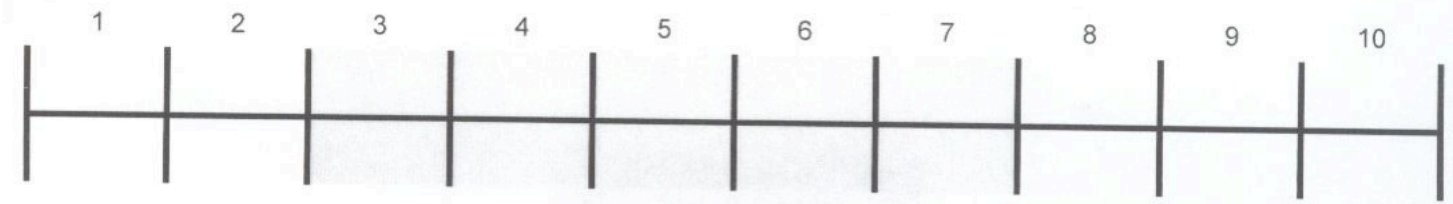

$1=$ Famished, starving

2 = Headache, weak, cranky, low energy

$3=$ Want to eat now, stomach growls and feels empty

4 = Hungry - but could wait to eat, starting to feel empty but not there yet

$5=$ Not hungry, not full

$6=$ Feeling satisfied, stomach feels full and comfortable

7 = Feeling full, definitely don't need more food

$8=$ Uncomfortably full

$9=$ Stuffed, very uncomfortable

$10=$ Bursting, painfully full

Rate how your stomach feels before, during and after each meal or snack. Be sure to put a number to your hunger and fullness each time you eat to help you develop an understanding of eating based on your internal physical cues.

Developed by Lisa Burgoon MS, RD, LD, Sports Nutritionist, SportWell Center

University of Illinois at Urbana - Champaign, 1998 


\section{F. Visual Analog Scale}

\section{Instructions for $\vee A S$}

Before and after the meal, you are going to be asked a series of questions asking you how you feel. The questions will ask you to rate how strongly you feel specific sensations. The following is an example of the type of question that you will be asked to answer:

How happy are you?

Not at all Extremely

To answer each question, place a single vertical mark on the line to indieate how strongly you are feeling. A mark on the far left of the line indicates you do not feel that sensation at all. A mark on the far right indicates that you feel the sensation intensely.

Please carefully consider your answers. Please only make a straight line, not an ' $x$ '. 


\section{Food Record 1: Before meal/snack'(with pistachios Visual Analog Scale (VAS)}

How hungry are you right now?

Not at all Extremely

How satisfied do you feel right now?

Not at all

How full do you feel right now?
Not at all How much do you crave something sweet right now?

Not at all

How much do you think you can eat right now?

Nothing Extremely

How much nausea or stomach discomfort do you feel right now?

Not at all Extremely 
Food Recard 1: after

Visual Analog Scale (VAS)

How hungry are you right now?

Not at all

Extremely

How satisfied do you feel right now?

Not at all

Extremely

How full do you feel right now?

Not at all

Extremely

How much do you crave something sweet right now?

Not at all Extremely

How much do you think you can eat right now?

Nothing

A lot

How much nausea or stomach discomfort do you feel right now?

Not at all

Extremely 


\section{G. Unusual Diet Diary}

There will be some days that you will accidentally eat a food that is restricted during the treatments. Please use the form to document those accidents.

Also there will be days when you are not eating normally or you have had to take certain medications. Please list those in the next table.

\section{Example:}

Diet: Pistachio Treatment

\begin{tabular}{|l|l|l|l|l|l|l|}
\hline \multicolumn{2}{|c|}{ Food } & \multicolumn{5}{|l|}{} \\
\hline How much? & $\begin{array}{l}\text { What kind } \\
\text { of food? }\end{array}$ & Date & Time & Where & Activity & $\begin{array}{l}\text { How did it } \\
\text { happen? }\end{array}$ \\
\hline $\begin{array}{l}1 \text { cookie and } \\
\text { about 1/2 } \\
\text { teaspoon of } \\
\text { pistachios }\end{array}$ & $\begin{array}{l}\text { Chocolate } \\
\text { chip } \\
\text { cookies } \\
\text { with } \\
\text { pistachios }\end{array}$ & $\begin{array}{l}10-31- \\
2003\end{array}$ & $\begin{array}{l}3: 25 \\
\text { p.m. }\end{array}$ & Office & $\begin{array}{l}\text { Working } \\
\text { on report }\end{array}$ & $\begin{array}{l}\text { Co-worker } \\
\text { gave to me, } \\
\text { then I found } \\
\text { out it had } \\
\text { pistachios in it }\end{array}$ \\
\hline
\end{tabular}

\section{Example:}

Diet: No Pistachio Treatment

\begin{tabular}{|l|l|l|l|l|}
\hline \multicolumn{1}{|c|}{ Medication } & \multicolumn{1}{|c|}{ Illness } & \multicolumn{1}{c|}{ Date } & \multicolumn{1}{c|}{ Time } & $\begin{array}{l}\text { Describe diet or } \\
\text { appetite } \\
\text { changes? }\end{array}$ \\
\hline $\begin{array}{l}\text { Amoxicillin } \\
\text { (Antibiotic) }\end{array}$ & $\begin{array}{l}\text { Respiratory } \\
\text { infection }\end{array}$ & $12-20-2012$ & $\begin{array}{l}8 \text { a.m., } \\
\text { noon, } \\
6 p m\end{array}$ & $\begin{array}{l}\text { Stomach upset. } \\
\text { Ate soup all day }\end{array}$ \\
\hline Aspirin & Headache & $12-21-2012$ & $10 \mathrm{am}$ & $\begin{array}{l}\text { Slept all day- } \\
\text { didn't eat }\end{array}$ \\
\hline $\begin{array}{l}\text { Amoxicillin } \\
\text { (Antibiotic) }\end{array}$ & $\begin{array}{l}\text { Respiratory } \\
\text { infection }\end{array}$ & $\begin{array}{l}12-20-2012 \\
\text { to 12-30- } \\
2012 \\
(10 \text { days) }\end{array}$ & $\begin{array}{l}\text { 8 a.m., } \\
\text { noon, } \\
6 p m\end{array}$ & $\begin{array}{l}\text { No diet changes } \\
\text { after 12-21-2012 }\end{array}$ \\
\hline
\end{tabular}


Diet Check:

Pistachio Treatment

NO Pistachio Treatment

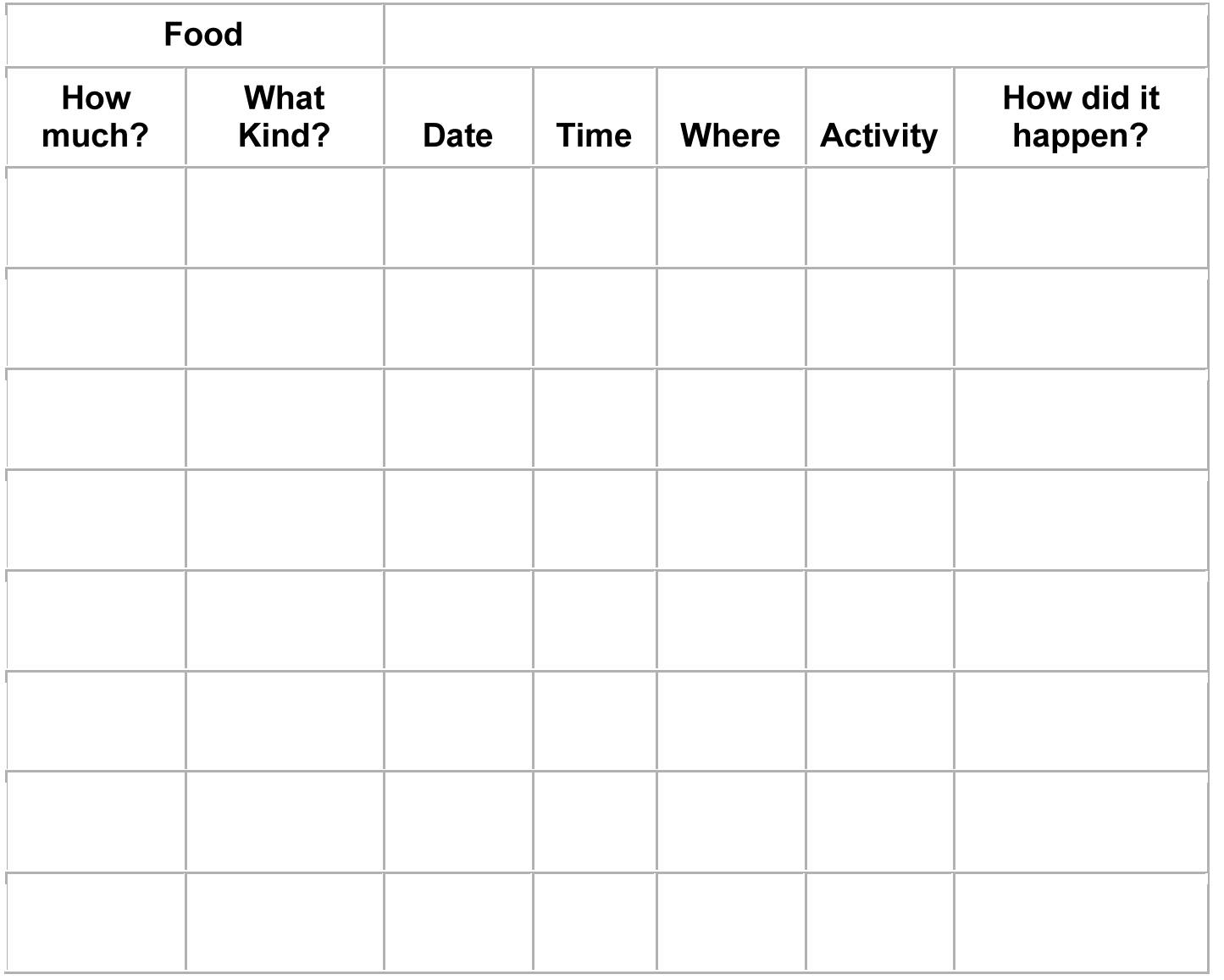

Diet Check:

Pistachio Treatment

NO Pistachio Treatment

\begin{tabular}{|l|l|l|l|l|}
\hline & & & & $\begin{array}{c}\text { Describe diet } \\
\text { or appetite } \\
\text { changes? }\end{array}$ \\
\hline & Illness & Date & Time & \\
\hline & & & & \\
\hline & & & & \\
\hline & & & & \\
\hline & & & & \\
\hline & & & & \\
\hline
\end{tabular}




\title{
H. Informed Consent Form
}

\section{INFORMED CONSENT TO PARTICIPATE IN A RESEARCH PROJECT ON:}

\author{
"Effects of Pistachio Consumption on Body Composition, Blood Lipids, Bone Density, \\ Satiety, Inflammatory Markers, and Erythrocyte Membrane Incorporation of Fatty Acids"
}

Researchers: A research project on pistachio consumption and health is being conducted by Dr. Laura Hall in the Department of Food Science and Nutrition at Cal Poly, San Luis Obispo and by Dr. Bonny Burns-Whitmore in the Department of Human Nutrition and Food Science at Cal Poly, Pomona. You are being asked to participate in this study because you are a student at $\mathrm{Cal}$ Poly (San Luis Obispo or Pomona).

Purpose of Study: We hope to show the health benefits of pistachios as part of an overall healthy lifestyle. Specifically, we will examine the effects of pistachio consumption on body composition, bone density, markers of bone turnover, erythrocyte membrane incorporation of fatty acids, lipid status, inflammatory markers, dietary quality/micronutrient quality and satiety (how full you feel). The study will involve two 12-week treatment periods (pistachio added to your diet and a no-pistachio control diet), separated by a 15-week "washout" period. We will recruit 30 female students from Cal Poly, San Luis Obispo (CP-SLO) and 30 female students from Cal Poly, Pomona (CP-P).

Explanations of Procedures: You fit our inclusion criteria, per our screening questionnaire. Therefore, you are being asked to take part in this study by attending an initial training meeting and 2 study visits with measurements and 2 blood-draw visits during Fall quarter 2012 (week 1 and week 12) and 2 study visits with measurements and 2 blood-draw visits during Spring quarter 2013 (week 1 and week 12) for a total of 4 study visits with measurements and 4 blooddraw visits. You will also meet the researcher for a weekly meeting to receive your pistachios (when you are on the pistachio diet) and to check your food records for completeness (everyone). Thus, there will be a total of 24 weekly visits throughout the study. For each visit at week 1 and week 12, you will be asked to fill out a dietary intake/physical activity questionnaire, and have your height, weight, waist circumference, hip circumference, body composition/bone density measured at the Nutrition Assessment Lab and have your blood drawn at the Student Health Center.

At the initial study/measurement visit, half of you $(n=15)$ will be given pistachios to include in your diet as snacks or in meals (intervention group) while half $(\mathrm{n}=15)$ will continue your normal diets (control group). During Spring 2013, the other half of the of you will switch and consume the pistachios while the first half will not. When you are in the phase of the study when pistachios are included in your diet, they will contribute $20 \%$ of the calories your normally consume. Diet counseling will also be given at weekly visits and compliance to study protocols will be evaluated by counting the number of pistachio packages and looking at your "Unusual Diet Diary".

The initial training meeting will take one hour. You will be trained on how to keep food records and how to substitute pistachios into your diet using MyPlate as a guide. Total time to complete the 4 study measurements will be approximately one hour each at the Nutrition Assessment Lab. You are required to fast (not eat) for four hours prior to the testing, as well as refrain from smoking, drinking coffee and exercising. One and a half cups of water are okay. The 4 blood draws will take approximately 20-30 minutes each at the Student Health Center. You are required to fast for 12 hours before the blood draw. One and a half cups of water are

Hall \& Burns-Whitmore, 9-5-12 
okay and recommended the morning before the blood draw. The weekly counseling meetings will take approximately 30 minutes and will be scheduled at your convenience.

Study Design and Measurements:

This study is composed of two distinct experimental phases (12 weeks each) with a 15week "washout" diet inbetween the treatment diets: 1) the pistachio-free diet (ie. control/normal diet), in which you must maintain just the background diet; 2) the pistachio-added diet, in which you must consume $20 \%$ of your calories as pistachios per day, in addition to your background/normal diet. The order in which you complete these two trials will be randomly determined at the beginning of the study. The two experimental phases will be separated by a 15 -week period during Winter quarter 2013 in which only the background/normal diet is consumed (this includes the holiday break). We want you to continue to eat your regular diet during this time. The study will resume in Spring quarter and you will switch diets.

Calculation/Distribution of Pistachios and Weekly Study Visits:

The researchers will calculate how many pistachios you need based on your initial 3-day food record/Harris Benedict Equation (calculates calorie needs) during the lead-in period of the study. This amount will be $20 \%$ of your usual caloric need and the pistachios will be pre-measured into daily individually-wrapped servings. The researchers will meet with you weekly to give you a week's supply of your pre-measured packet of pistachios (one for each day). This could amount to anywhere from 1.5-3.5 oz. of pistachios a day. You will be asked to bring in your used wrappers to the weeklyj counseling meetings. At the weekly counseling meetings, you will be shown how to incorporate the pistachios into your diet (either as snacks or in recipes), to check if you had an "unusual diet diary" day and to check your food records for accuracy.

Data Collected during Fall 2012 (wk 1 and wk 12) \& Spring 2013 (wk 1 and wk 12) at the Nutrition Assessment Lab (Bld 24-104A): $\quad$ This visit will take 1 hour.

Anthropometric Measurements: Body weight will be measured using a calibrated scale and recorded to the nearest $0.1 \mathrm{~kg}$. Height will be measured using a stadiometer and recorded to the nearest $0.1 \mathrm{~cm}$. Body mass index (BMI) will be calculated as weight $(\mathrm{kg})$ divided by height $(\mathrm{m})$ squared. Waist circumference will be measured using a flexible measuring tape between the middle of the bottom rib and iliac crest (top of the hip bone) and recorded to the nearest $0.1 \mathrm{~cm}$. Hip circumference will be measured using a flexible measuring tape around the largest part of the hips (i.e. buttocks) and recorded to the nearest $0.1 \mathrm{~cm}$. These measurements will be taken twice. We will also calculate your waist-to-hip ratio.

Blood Pressure: You will be asked to sit down and have your blood pressure measured using a blood pressure cuff around your left arm. This measurement will be taken twice. This will take less than 1 minute each time.

Body Composition Measurement: Body composition will be assessed by bioelectrical impedance analysis (BIA) using the Tanita Body Composition Analyzer Scale. You are required to remove all metal, heavy objects from your clothing, or remove heavy clothing before using the Tanita. Your feet need to completely cover the dimples on the scale and must be dry and bare. You will need to stand still for less than one minute as the unnoticeable electrical current travels through your body. This measurement will be taken twice. This will take less than 10 minutes each time. Food Records/Unusual Diet Diary: Before you begin the first experimental phase, you will 
complete a one-week "run-in" period in which your background/normal diet will be consumed and we will ask you to complete 3 food/diet records. You will be trained on how to do this ahead of time which will take one hour. During the study if unusual quantities of foods, accidental pistachio consumption occurs, medical treatment is required, or pharmaceuticals are consumed you will record this on an "Unusual Diet Diary" form, provided ahead of time. You will also need to keep nine food records (randomly chosen dates) during each 12 week period (18 total). Satiety and Hunger ratings: You will rate your satiety(fullness)/hunger using a rating scale (110) before, during and after each snack or meal directly on your 9 required food records during each treatment (18 each). You will also use a validated visual analog scale (VAS) to rate your hunger after consuming your snack or meal with pistachios for the intervention group and randomly chosen snacks/meals for the control. You will be given a binder with the food record forms and VAS questionnaires in them with the randomly chosen dates and instructions listed. Completed forms will be checked for accuracy and collected at the weekly visits from the binders.

Physical Activity Questionnaire: You will be asked to recall you physical activity level over the preceding week (7 day recall) using the 2002 International Physical Activity Questionnaire (IPAQ) short form during week 1 and week 12. Please maintain your current levels of physical activity.

Body Composition/Bone Mineral Density (DXA): Full-body DXA (iDXA, GE Healthcare) will be used to determine body fat mass, body fat percentages, visceral fat (with additional software), lean body mass and bone mineral density. You must fast for $4 \mathrm{hrs}$ prior and not wear anything metallic (i.e. no underwire bras, no jeans, etc). First, you will be given a pregnancy test. Second, you must remove all jewelry and your shoes. Third, you will lie on your back for approximately 5-8 minutes as the machine scans over you.

Data Collected during Fall 2012 (wk 1 and wk 12) \& Spring 2013 (wk 1 and wk 12) at the Student Health Center: $\quad$ This visit will take $\sim 20-30$ minutes.

Blood Draw/Analyses: At the beginning and end of each distinct period (treatments), your blood will be drawn and assessed for total cholesterol, HDL, LDL cholesterol, inflammatory factors, bone turnover markers and a regular blood lab screening (glucose, calcium, potassium, iron, sodium, etc...) by a trained phlebotomist at the Cal Poly Student Health Center (via appointment). One additional tube will be taken and stored for future analyses that will include gene typing, red blood cell membrane analysis, and selected biological markers of inflammation. The blood draw will take approximately 20 minutes. You must fast (do not eat or drink anything besides water) for 12 hours before your scheduled appointment but we recommend drinking 1.5 cups of water the morning of your appointment.

Rights and Risks: Please be aware that you are not required to participate in this research, you may omit any items you prefer not to answer on questionnaires and you may discontinue your participation at any time. The possible risks associated with participation in this study are low. The possible risks associated with participation in this study come from having your blood drawn, such as bleeding/bruising and infection, but the chances of this occurring are low. There is no risk or pain involved from using the BIA or DXA or having your blood pressure measured. The DXA analyses are completely non-invasive and the radiation dose given is as low as or even insignificant in comparison with natural background radiation levels (each DXA is $1 / 10^{\text {th }}$ of a standard chest $\mathrm{x}$-ray and you will have $4 \mathrm{DXA}$ measurements within one year). However, a 
pregnancy test will be given to female participants before the test to ensure safety of the fetus. If positive, the participant will be asked to terminate her participation in the study. There is also the risk of weight gain if you do not substitute the pistachios in your diet (and eat less calories from your habitual diet to balance the $20 \%$ calorie consumption from pistachios).

It is possible that regularly consuming pistachios will result in mild gastrointestinal discomfort. Symptoms of an allergic reaction or intolerance to pistachios include scratchy throat, difficulty breathing and/or swallowing, skin rash, blurred vision, persistent diarrhea, vomiting, and excessive gastrointestinal discomfort. If you experience any of these symptoms stop eating pistachios immediately and seek medical attention. If you should experience any discomfort or distress, please be aware that you may contact Dr. Laura Hall at 805-756-2958 for assistance. Confidentiality: Your confidentiality will be protected. You will be assigned a study identification number that will identify you instead of your name. Personal identifiers, such as name, phone number and address, will be kept in a locked file cabinet in a separate, secure location from study data forms and from the main study database. No personal identifiers will be included on computer files. All computers will be secure with password and firewall protection. Only the study investigators will have access to this information. Results from the study may be presented or published but your identity will not be included. Personal information will be destroyed once the study is finished. The Cal Poly Human Subjects Committee has the authority to review your research records, if necessary to protect your safety.

Benefits: Potential benefits associated with the study include free pistachios for 12 weeks, $2 \$ 10$ bookstore gift cards and finding out personal health information (ie. blood lipids, bone density and body composition). This study will help us better understand how pistachio intake contributes to one's health. Specifically, you will receive a $\$ 10$ bookstore gift card for participating in Fall 2012 after completing all measurements and a second $\$ 10$ bookstore gift card for participating in Spring 2013 after completing all measurements.

Questions: If you have questions regarding this study or would like to be informed of the results when the study is completed, please feel free to contact Dr. Laura Hall at 805-756-2958. If you have concerns regarding the manner in which the study is conducted, you may contact Dr. Steve Davis, Chair of the Cal Poly Human Subjects Committee, at 805-756-2754, sdavis@calpoly.edu, or Dr. Susan Opava, Dean of Research and Graduate Programs, at 805-756-1508, sopava@calpolv.edu, Research Agreement: If you agree to voluntarily participate in this research project as described, please indicate your agreement by signing below. Please keep one copy of this form for your reference, and thank you for your participation in this research.

Signature of Volunteer

Signature of Researcher
Date

Date 